\title{
REVIEW OF AERONAUTICAL FATIGUE INVESTIGATIONS IN POLAND (2013-2014)
}

\author{
Antoni Niepokólczycki ${ }^{1}$ \\ Andrzej Leski ${ }^{2}$ \\ Krzysztof Dragan ${ }^{2}$ \\ ${ }^{1}$ Institute of Aviation, Al. Krakowska 110/114, Warsaw, Poland \\ ${ }^{2}$ Air Force Institute of Technology, ul. Księcia Bolesława 6, 01-494 Warsaw, Poland \\ antoni.niepokolczycki@ilot.edu.pl, andrzej.leski@itwl.pl, krzysztof.dragan@itwl.pl
}

\begin{abstract}
This review was presented on the 34 Conference of the International Committee on Aeronautical Fatigue and Structural Integrity, Helsinki, Finland, June 1-2, 2015. It contains description of main works and investigations in fatigue of aircraft structures performed in Poland during the years 2013 and 2014.
\end{abstract}

Keywords: fatigue of aircraft structures.

\section{INVESTIGATIONS IN CIVIL AVIATION}

\section{FULL-SCALE FATIGUE TESTS OF THE PZL M28 - SELECTED ASPECTS}

The computation of the service life of the PZL M28 was based on the results of the full-scale fatigue tests of the structure. As the PZL M28 is a commuter category airplane according to the 14 CFR Part 23 and CS-23 regulations, the test objects included: (1) the wing and wing load carry-through structure, (2) the empennage and attached fuselage structure. Additionally, fatigue tests were carried out for the landing gear and other selected elements including the control system elements. The aircraft's load carry-through structure is metallic and the cabin is unpressurized. The fatigue tests were conducted stage-by-stage. As the tests progressed, it was possible to extend the aircraft's target service life, applying a safe life philosophy with reference to the primary components of the load carry-through structure.

\section{Test Plan Preparation}

The first and very important step in determining an aircraft's service life is to establish its operation model. The goal is to establish the basic parameters of the airplane's operation affecting the airframe service life and to enable the proper selection of load cases for the purpose of conducting fatigue analyses and fatigue tests.

A typical flight profile, i.e. basic flight parameters, of the PZL M28 05 in one-hour flight is shown in Fig. 1. 


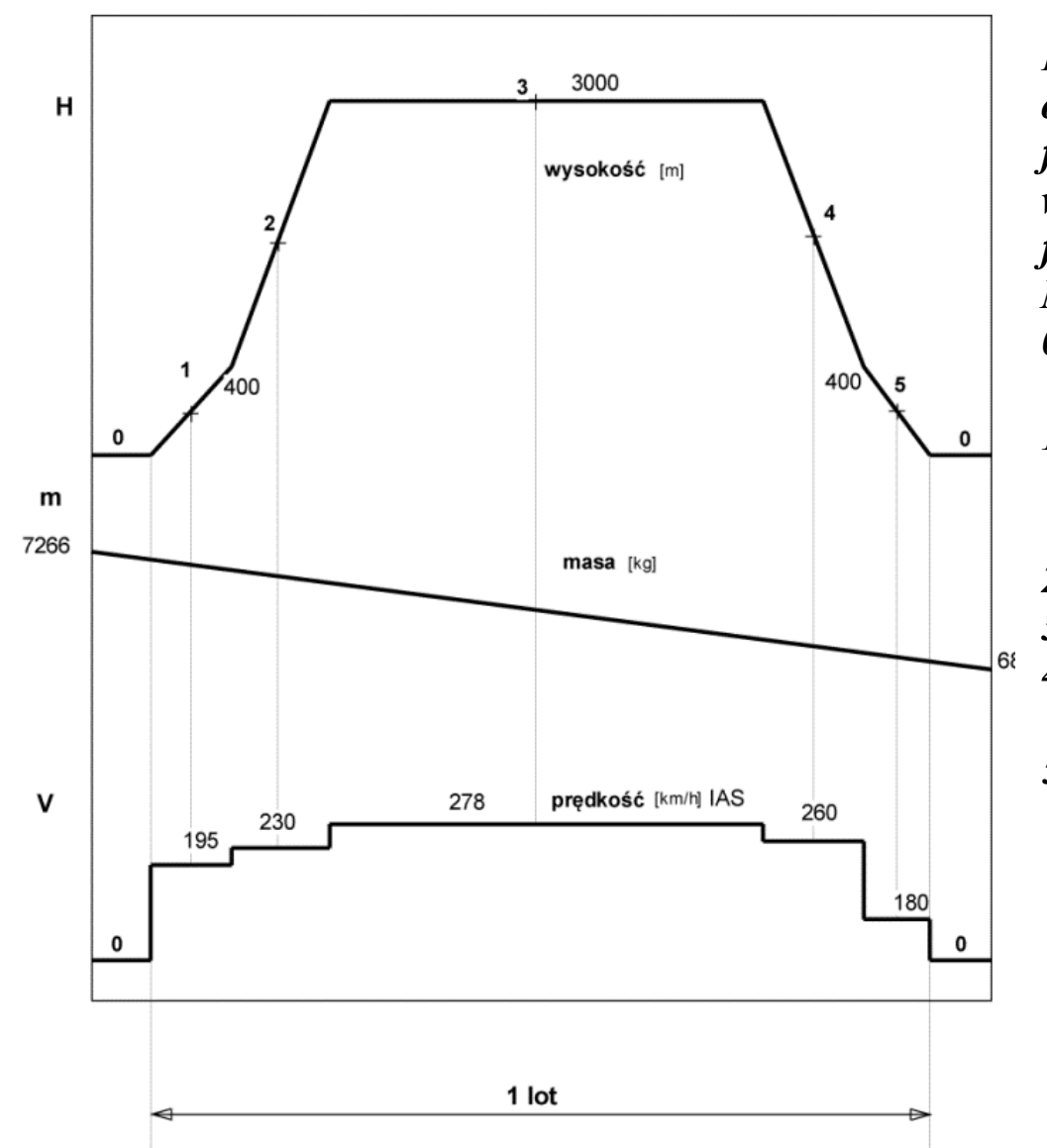

Fig. 1. A typical flight profile of the PZL M28 05. Airspeed, flight altitude and aircraft weight are shown. Assumed flight duration is one hour. Mission consists of: 0 -taxiing, ground roll before take-off and after landing, 1 - take-off and initial climb to $400 \mathrm{~m}$ above airfield altitude, 2 - climb to cruise altitude, 3 -cruise,

4 - descend to 400m above airfield altitude, 5 - go-around and landing.

As the airplane has the short take-off and landing (STOL) characteristics and is approved for operation from unpaved airstrips, it was assumed that:

- $50 \%$ of takeoff-landings were performed from paved airstrips,

- $50 \%$ of takeoff-landings were performed from unpaved airstrips.

This corresponds to flights from the base airfield to the operational one and back, given that refueling is performed every second flight (according to the information received from an operator). During short flights a controlled space is not entered, that is FL095 (9500 ft.) is not exceeded. Longer flights are performed in the controlled space, taking into account the limitations resulting from the non-pressurized fuselage.

The established model of the airplane's operation significantly affects fatigue damage of the empennage. In consequence, its fatigue test loads spectrum depends on the ground loads on the unpaved airstrip. Ground loads also contribute to the fatigue damage of the wing and wing loads carry-through structure though not so significantly as in the case of the empennage. Hence, the fatigue test load spectrum is dominated by flight loads resulting from maneuvers and gusts.

Typical flight load spectra resulting from manoeuvres and gusts as well as ground loads spectra resulting from taxiing and landing were determined according to the FAA advisory circular AC-23-13A, and were validated by measurements during test flights. As a result, continuous load spectra were established. For the fatigue tests purposes, these spectra had to be replaced with several load levels, with adequate number of cycles. The fatigue test economy requires that the number of cycles should be as low as possible, bearing in mind test accuracy - see AC-23-13A. 
The fatigue analysis showed that about $25 \%$ of the wing's fatigue damage was GAG result. So, in the fatigue tests of wing and wing loads carry-through structure the ground loads were also taken into account. The selection of load levels for fatigue tests was done by iteration for different load levels sets while preserving the basic assumptions. The final result was 11 load levels with loads occurring at 100 flights considered as shown in Fig. 2. Of course, total fatigue damage for test load spectrum was the same as for the continuous load spectrum.

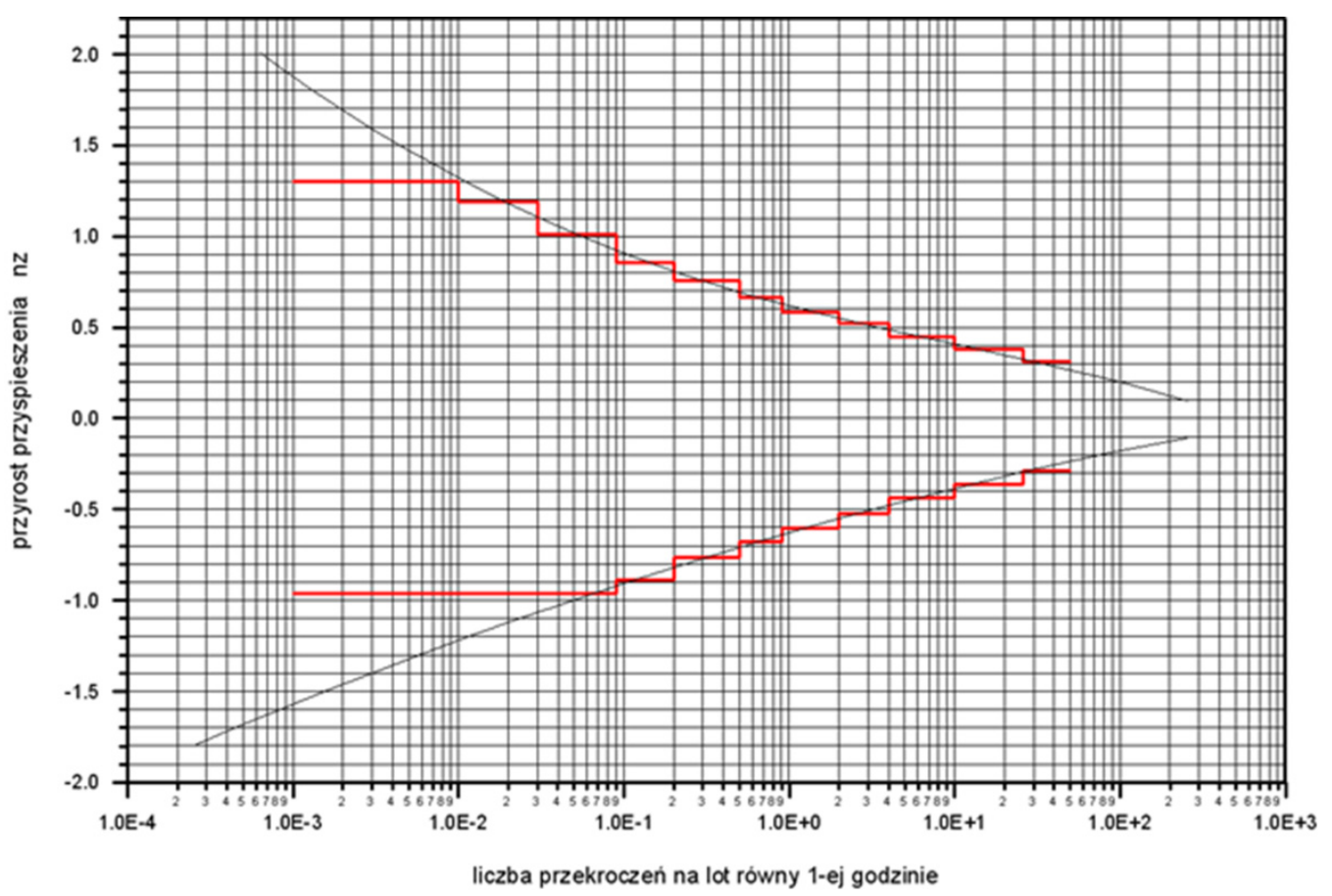

Fig. 2. Discretised load spectrum applied in fatigue test (red line). Base continuous load spectrum is also shown.

The fatigue test plan of the wing and wing load carry-through structure of the PZL M28 05 was conducted without any significant modifications. The test plan enabled performing 100 flights within approximately 8 hours.

\section{Preparation of Fatigue Tests}

The cooperation between the author of a fatigue test plan and the team involved in the test preparation should be established as early as possible, long before the test plan has been finished.

Figure 3 presents the PZL M28's wing and wing load carry-through structure fatigue test scheme. There were 12 actuators of the MTS Aero system used. Active forces were applied to the wing (6 actuators), main landing gear (2 actuators for vertical forces and one actuator for horizontal force) and the engines frames ( 2 actuators for applying torque from each engine separately and one actuator for applying the power plant vertical load, LH and RH). 

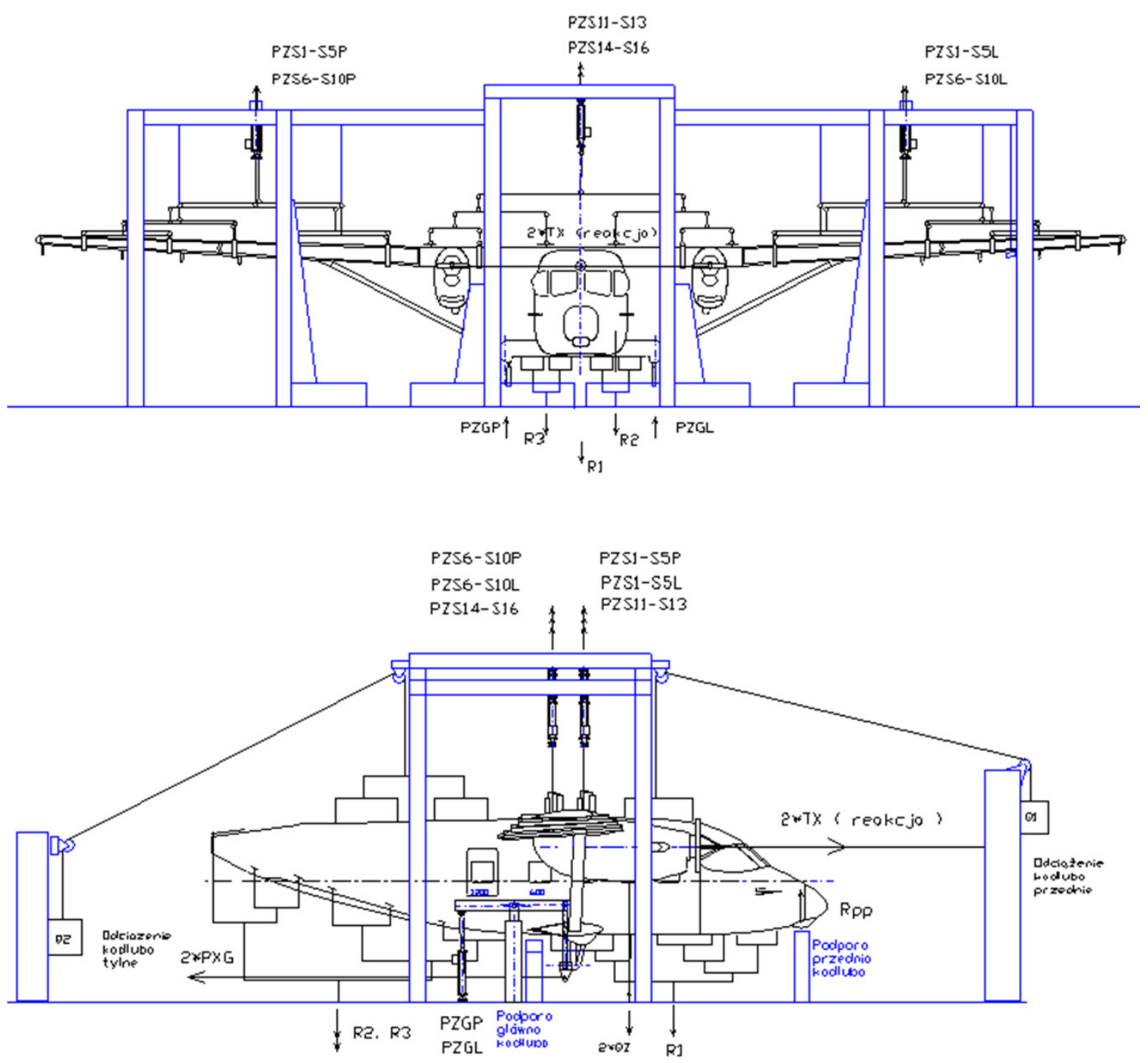

Fig. 3. The PZL M28 05 wing and wing load carry-through structure fatigue test scheme. In total, 12 actuators were used:

- 6 for wing loading,

- 2 for main landing gear vertical force,

- 1 for main landing gear horizontal force ( $\mathrm{LH}$ and $\mathrm{RH}$ summarized),

- 2 for engines torque,

- 1 for power plant vertical loads (LH and RH summarized) - for clarity not shown on the scheme.

Balancing reactions were applied to the fuselage, nose landing gear fitting, and engines frames.

Balancing reactions were applied to the fuselage, nose landing gear fitting and engine frames (horizontal force balanced by the engines' thrust). Wing loads were usually applied through clamps - see Fig. 4. 


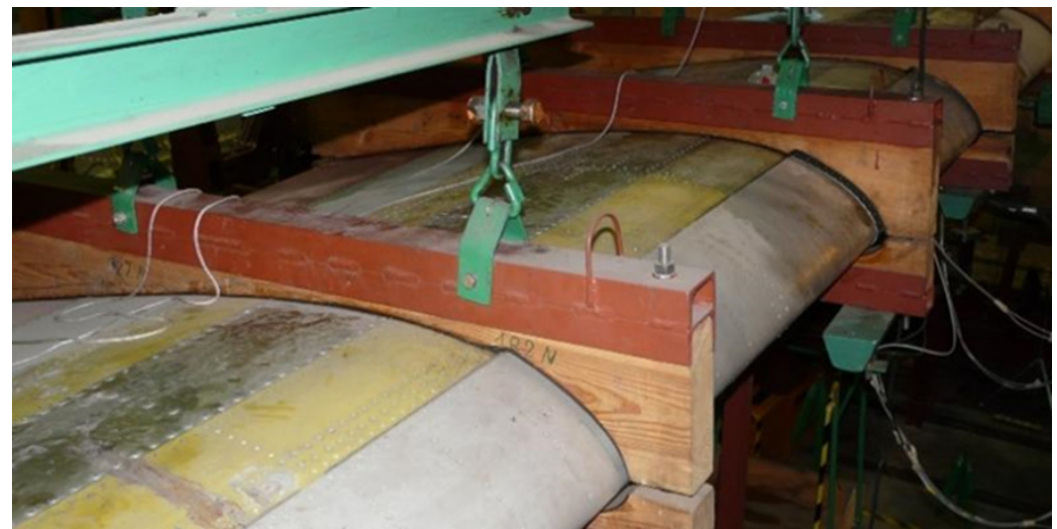

Fig. 4. PZL M28 05's wing and wing load carry-through structure fatigue test fixture. Clamps introducing loads to the wing are shown.

There were 12 clamps in total applied to introduce loads at 12 spanwise stations. At 4 wing stations, loads were applied by glued tapes. Fuselage loads were applied through glued tapes - see Fig. 5.

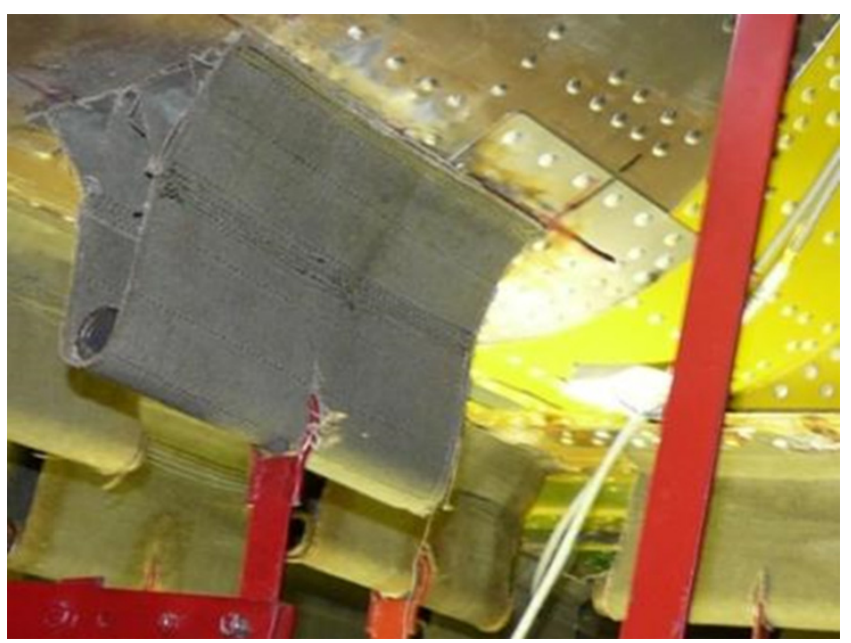

Fig. 5. PZL M28 05's wing and wing load carry-through structure fatigue test fixture. Sample tapes glued on the fuselage are shown.

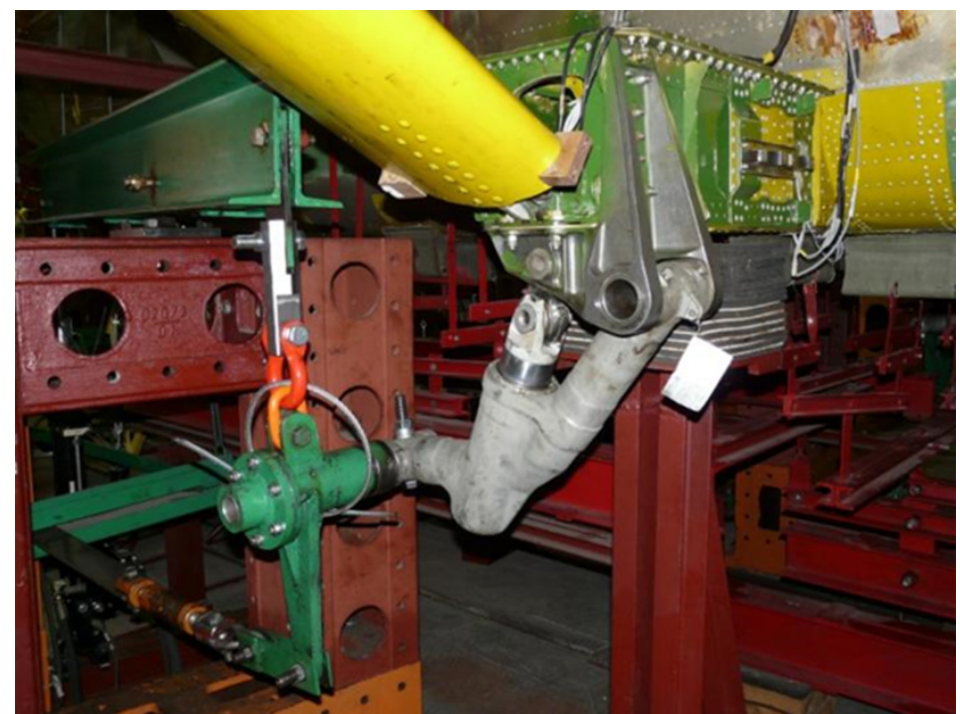

Fig. 6. PZL M28 05's wing and wing load carry-through structure fatigue test fixture. 
Tapes were arranged in a way which helps avoid excessive load concentration, nonexistent in reality, and likely to introduce damage to the thin-walled fuselage structure. This rule was applied to all the loads introduced. The main landing gear leg is a convenient element to introduce ground loads, of significant effect on the fatigue damage of the airframe. Vertical and horizontal loads were applied to each leg - see Fig. 6.

Note that horizontal force is shifted from the wheel axle in order to simulate the wheel braking effect. The engine frame was a convenient element to introduce engine torque, the vertical force resulting from power plant inertia, and prop thrust force - see Fig. 7.

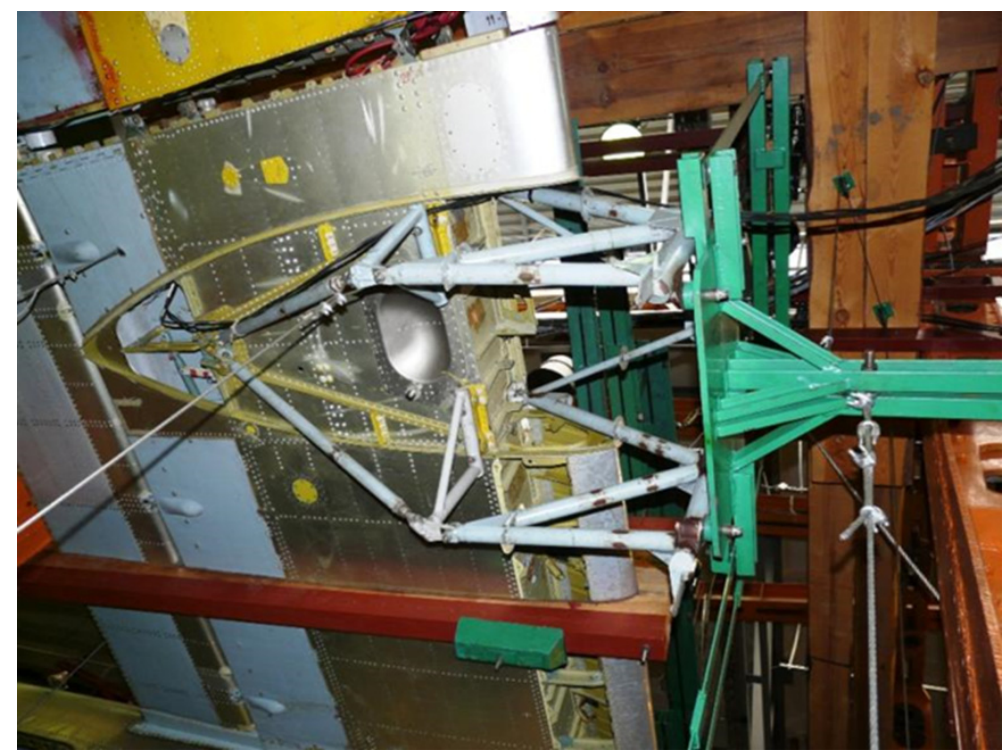

Fig. 7. PZL M28 05 wing and wing load carry-through structure fatigue test fixture. The engine frame is loaded by vertical power plant inertia force, engine torque and balancing prop thrust force.

In the case of the empennage, the tested item was the empennage and fuselage attached structure. The question arose what part of the fuselage should be in the test fixture. After performing structural analysis, it was decided to cut the fuselage at station two frames before forward stabilizer fittings - see Fig. 8 .

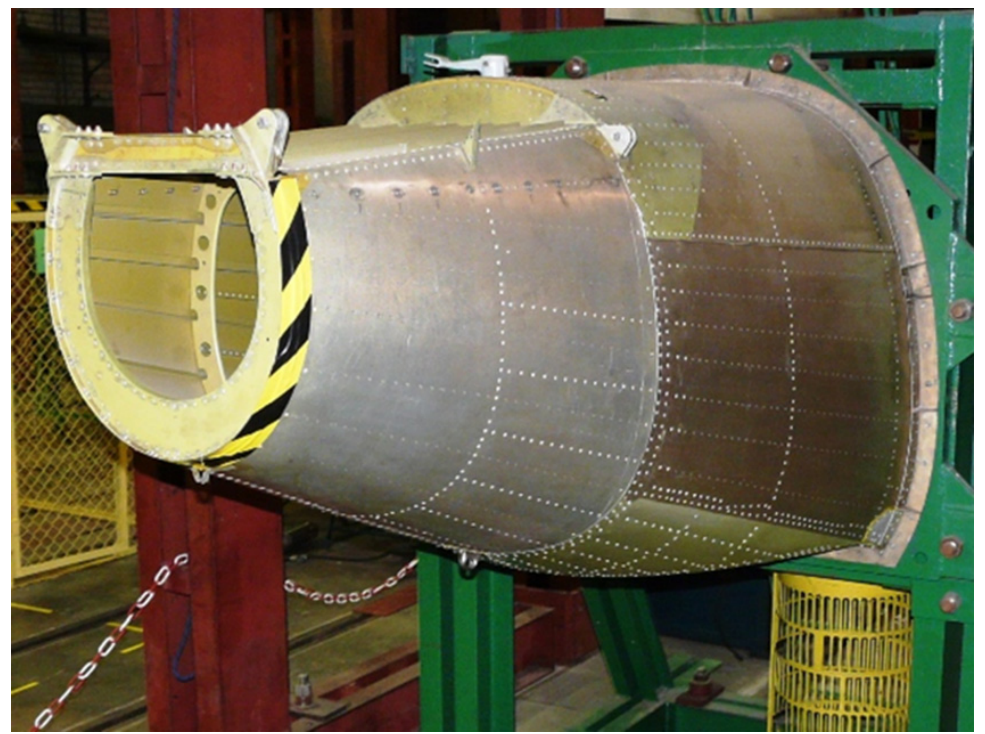

Fig. 8. PZL M28 05's empennage fatigue test fixture. In the picture there is a fuselage part used in test (empennage is dismantled). 
The empennage fatigue test plan was prepared by the Institute of Aviation in Warsaw. The first phase of the fatigue test was also performed by the Institute of Aviation in Warsaw.

\section{Applied Loads Control}

During fatigue tests of the wing and wing load carry-through structure, the accuracy of applied loads was kept within an error margin of $2 \%$. This margin relates to the maximum force in a given channel in the test. An example of the command and feedback force course in the channels is shown in Fig. 9.
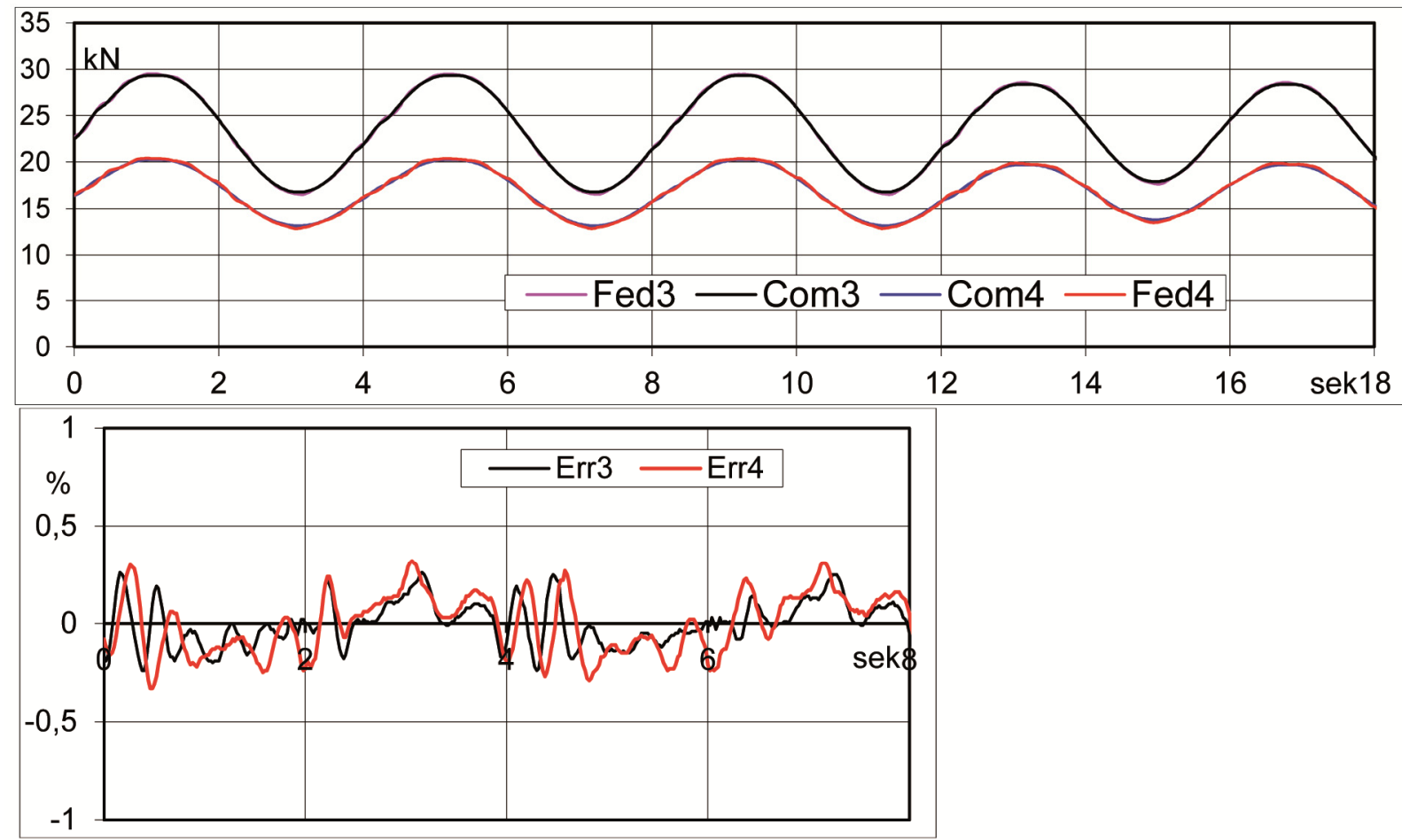

Fig. 9. Fatigue test of the PZL M28 05's wing and wing load carry-through structure. Illustration of command (in blue) and feedback (in red) forces registered for several seconds of the test in channels 3 and 4. Force errors in these channels as difference between command and feedback forces, expressed in percentage of maximum force in the load transducers, are also shown.

No significant difference between the forces is visible in the graphs. The error, expressed in percentage terms as a difference between command and feedback forces, is also shown. It can be seen that within the presented time the error in both channels is not greater than $0.4 \%$, relating maximum allowable force in a load transducer, which is about twice of that maximum in the test.

In order to keep the error within the accepted margin, it was sometimes necessary to slow the test run. During fatigue tests of the wing and wing load carry-through structure it was applied only when the maximum or close to maximum loads were executed. As these loads represent only a small percentage of the total load spectrum, no significant influence on the test efficiency was observed. 


\section{Stress Analysis of the PZL M28's Airframe Subjected to Repairs During Fatigue Tests}

The PZL M28's service life is determined based on the fatigue tests of the wing and wing loads-carry-through structure. During the fatigue test, the first occurrence of significance was the appearance of $\mathrm{a}$ in the area of the wing where loads are applied from the strut. It was demonstrated during further activities that repairs of the wing and other basic assemblies enabled, when performed at an appropriate time, the airplane's service life to be significantly increased.

In the case of each design change implemented in the airframe subject to the fatigue testing, a stress analysis of the airframe was required in order to check if local changes, i.e. local repairs, did not affect the stress level in other tested areas. This helped to avoid significant stress redistribution in the airframe after the repair, so the fatigue test was still valid for all areas of interest.

During fatigue testing, the airframe was visually inspected in order to find any cracks. This procedure was supported by the strain gauges indications analysis. Strain gauges were located in the areas of the significant stress level, primarily exposed to fatigue damage according to the fatigue analysis. All cracks detected in the test were analysed and categorized as any of the following:

- damage of main structural members, threatening with catastrophic failure of the airplane (critical damage);

- damage of secondary structural members, not affecting safety of flight in the time interval up to their detection (not critical damage);

- damage in dummy areas, which are not of interest.

Detection of a crack in the main structural member (critical damage) determines the limit of its operation. A damaged element may be replaced by a new one and the test may be continued, counting time for a new element from 0 . This procedure makes the continuation of the test possible on the condition that such a replacement can be performed during the airplane's operation. If this is not feasible, the damaged area may be repaired in order to continue the test with the repaired area treated as a dummy. A detailed stress analysis is required in this case as the repair may redistribute stresses in tested elements. In case of a stress level change in the tested area, the fatigue life must be recalculated.

After a not critical damage of the tested airframe was detected, a detailed stress analysis was performed in order to establish the repair procedure that can be performed during airplane's operation in the case of crack detection, and to check the effect of the repair on the stress distribution in the tested element, e.g. the wing structure. In case of the stress level change in the tested area, the fatigue life must be recalculated.

\section{The crack at the wing rib 15}

The first significant event in the test was a crack in the wing, in the area where wing strut loads are introduced at rib 15. The crack was caused by the fatigue damage of the wing in the area of the local stress concentration (holes for bolts in the wing strut fitting mounting). The test was terminated before the damage of the tested wing could spread - see Fig. 10. 


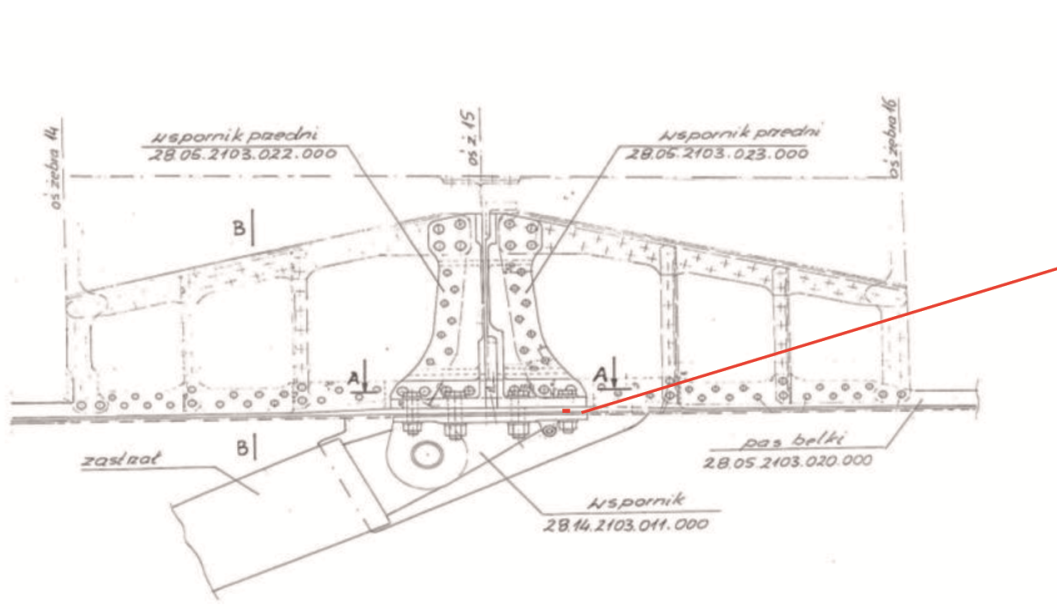

a)

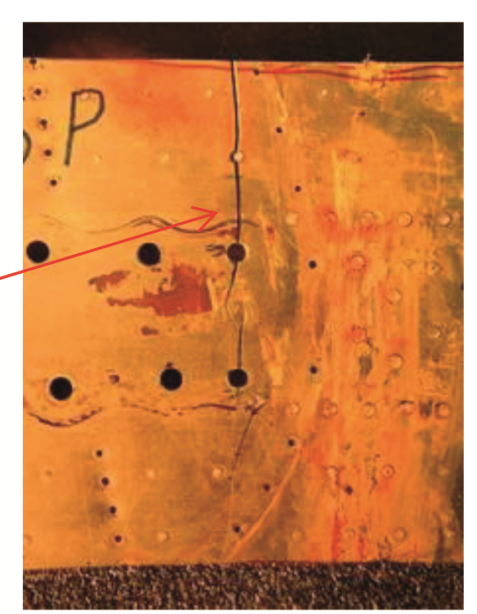

b)

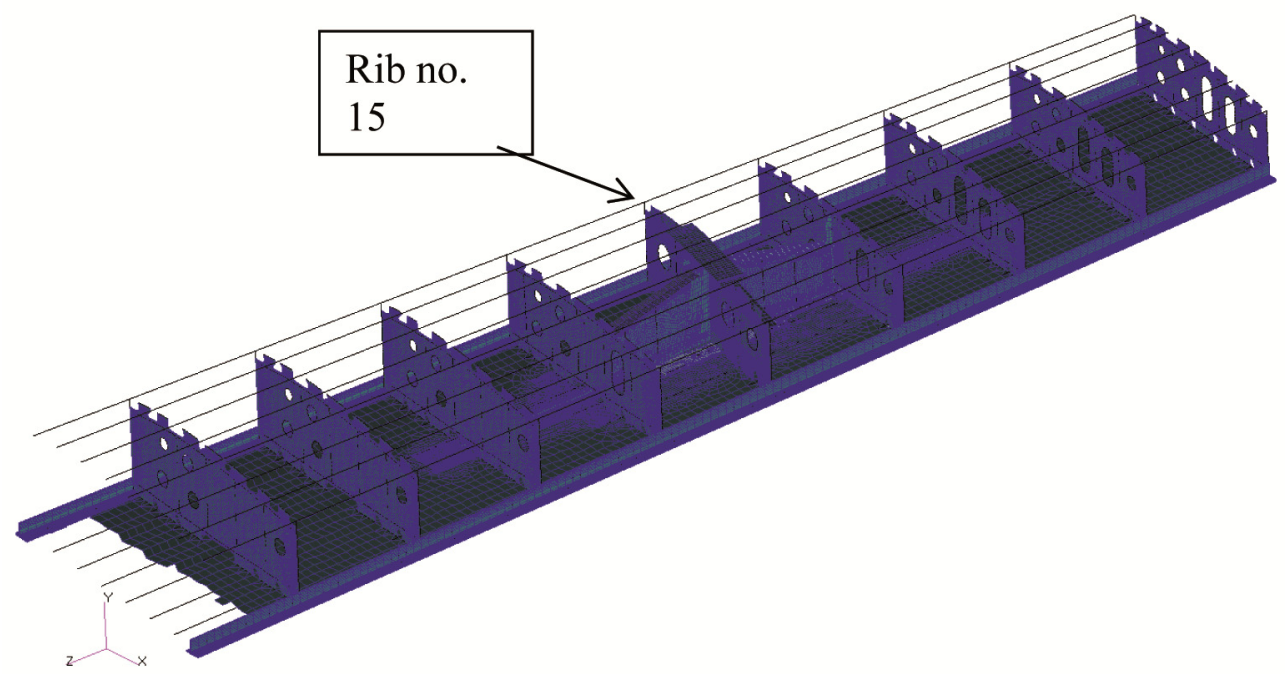

c)

Fig. 10. PZL M28 wing area of rib 15:

a) Sketch of the area of rib 15 with the crack indicated.

b) Cracked wing skin after removal of a wing strut fitting.

c) The FEM model of the wing, general view.

The subsequent analysis showed that it was possible to repair the critical wing area on the airplane in operation, thus significantly extending the airplane's service life. A careful stress analysis was performed for the PZL M28's outer wing, in which the most interesting area was rib 15, where the wing strut loads were introduced. A detailed FEM model represents the wing area from rib 10 (the root rib of the outer wing, with four fittings of the junction with the centerwing) to rib 19 - see Fig. 10(c) and Fig. 11. 


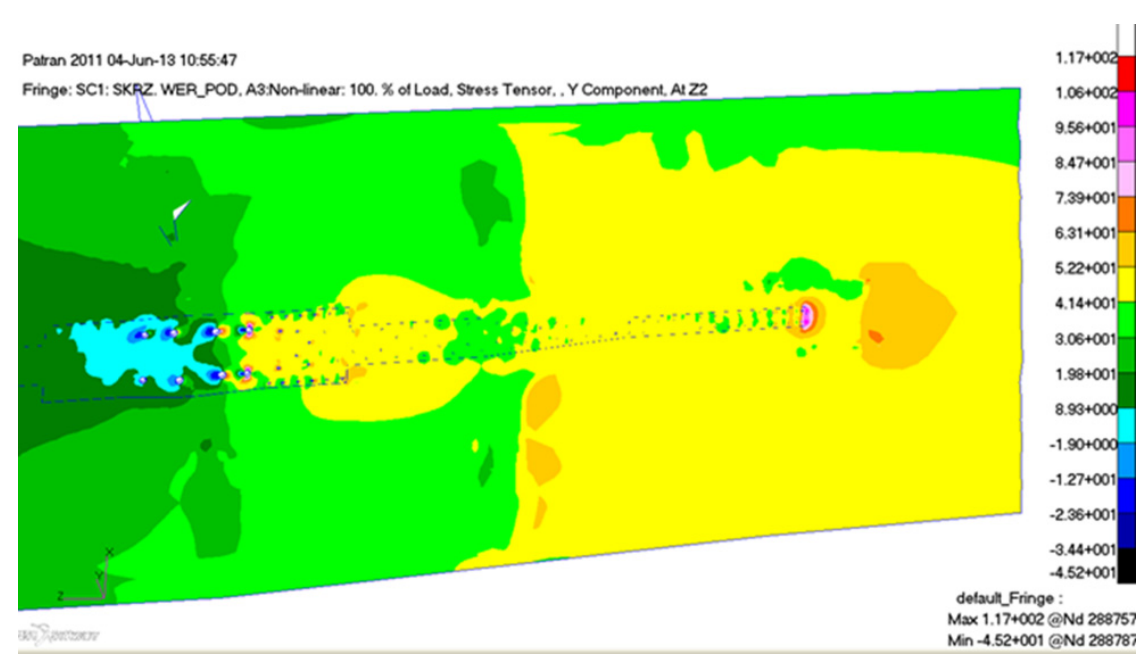

a)

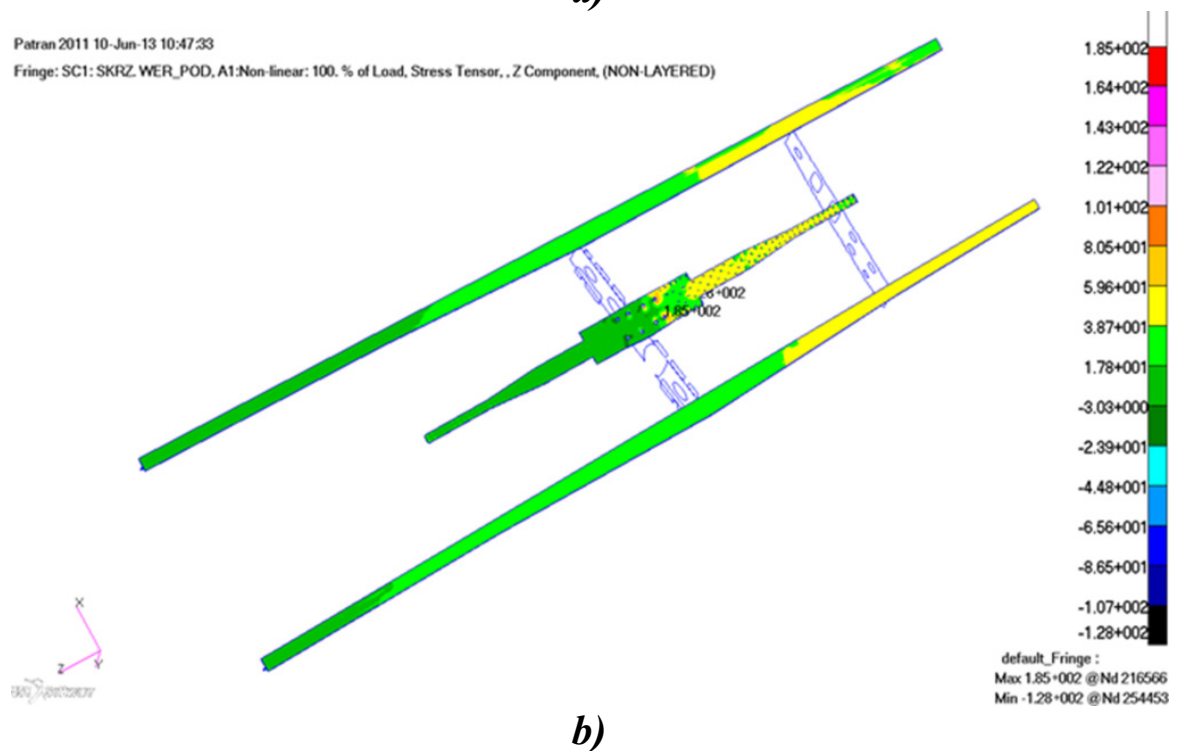

Fig. 11. Stress distribution in the PZL M28 critical wing area according to the FEM analysis at a maximum load level during the fatigue test:

a) Stress in the lower skin critical area.

b) Stress in the wing spars' lower caps and the beam's lower cap.

The wing area aft of rib 19 was modelled as a beam. Design changes implemented in the structural beam lying between the front and rear wingspans considerably increased the service life of the wing. These changes can be introduced to the wing removed from the airplane in operation during the repair process.

The fatigue test was continued after the repair of the wing critical area, with separate design solutions implemented in the LH outer wing and the RH outer wing. This resulted in increasing the test scatter factor for the wing.

\section{The crack at wing rib 17}

Another crack in the wing was observed at rib 17. The crack was in the wing skin only, so it was assessed as not critical. As it is the area of the integral fuel tank, a crack occurrence is signalized by a fuel leakage. Repair on the airplane in operation is possible, so such repair was made in the tested wing. The FEM stress analysis was performed in order to check the effect of the repair on the stress level in the wing spars - see Fig. 12. 
Widok z dołu no pokrycie dolne skrzydio lewego.

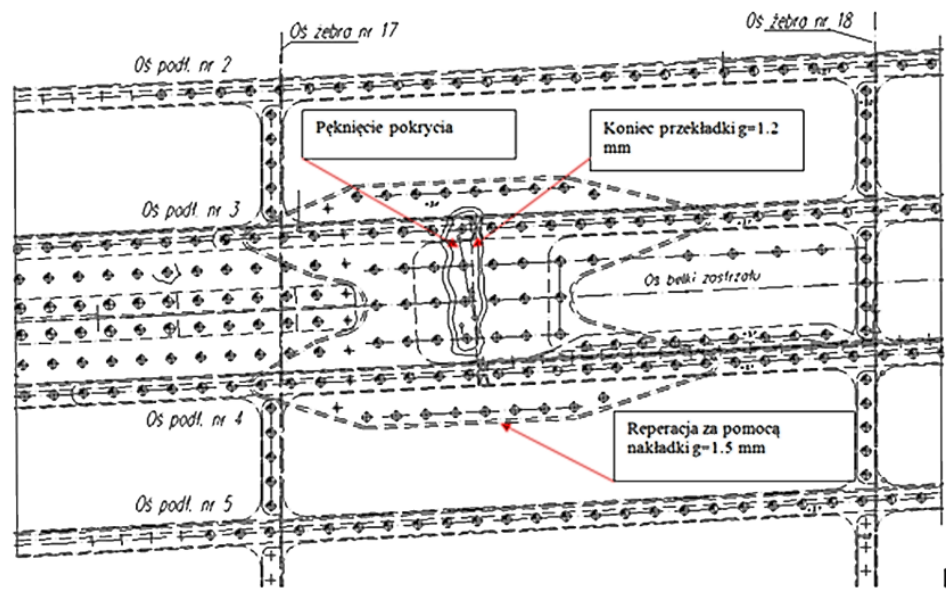

a)

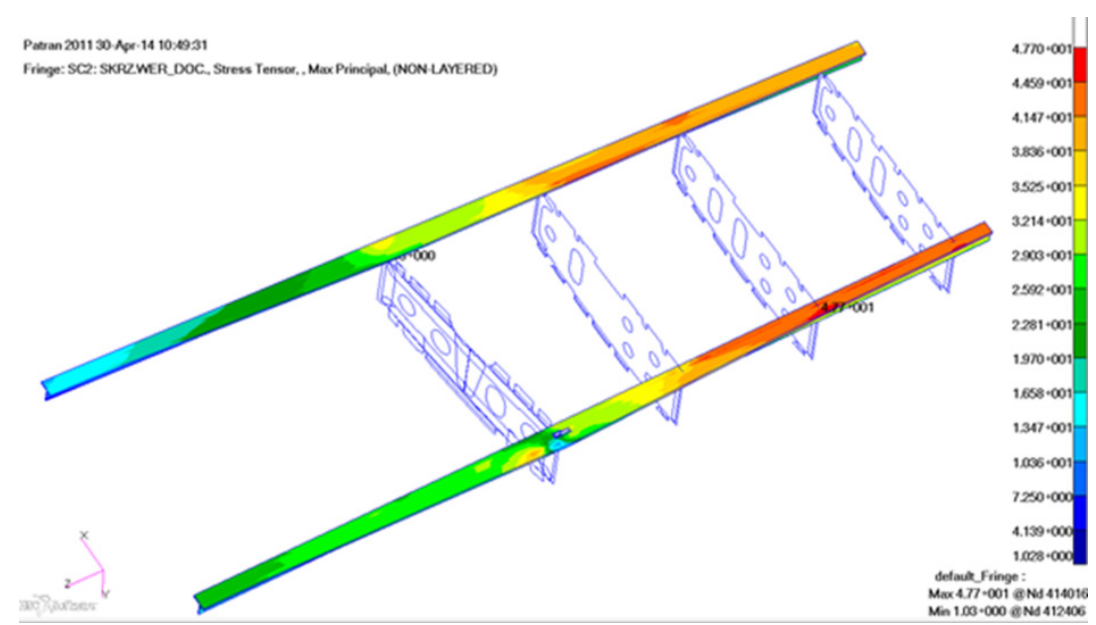

b)

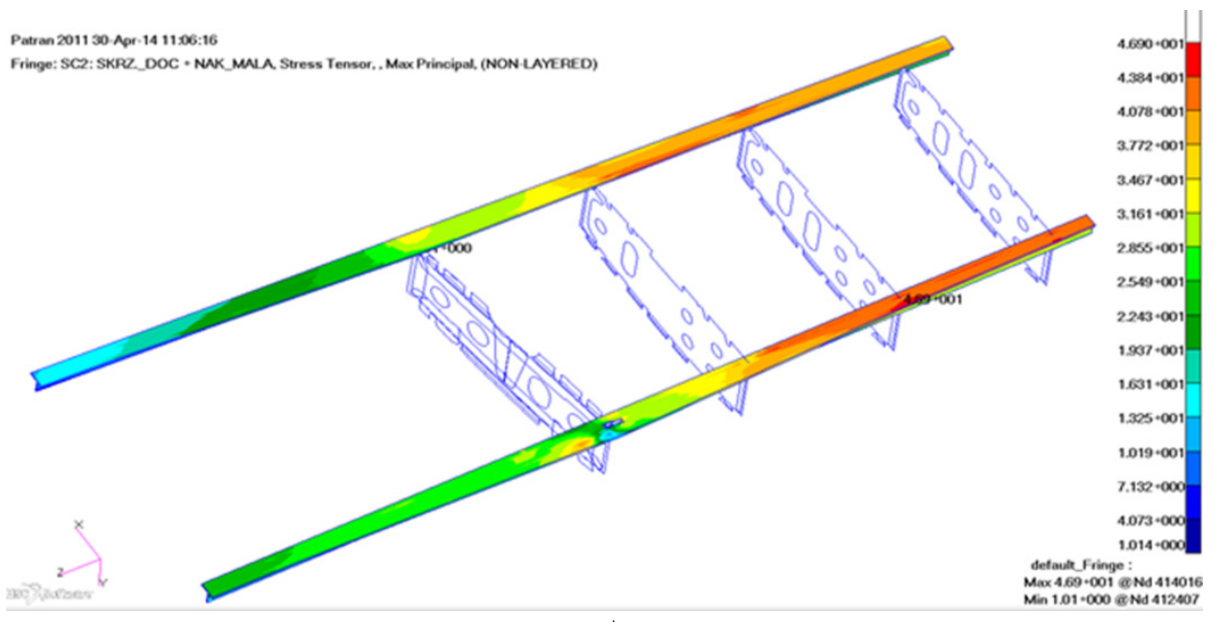

c)

Fig. 12. The FEM analysis of a crack in the PZL M28 wing area of rib 17 during fatigue testing:

a) Sketch of the cracked area of the skin between ribs 17 and 18 with a strap.

b) Stresses in the wing spars' lower caps for level flight $\left(n_{z}=1 \mathrm{~g}\right)$ load before the repair.

c) Stresses in the wing spars' lower caps for level flight $\left(n_{z}=1 \mathrm{~g}\right)$ load after the repair. 


\section{INVESTIGATIONS INTO RIVETING PROCESSES}

Although new materials such as composites and new joining techniques such as friction stir welding, have been successfully used in aerospace structures, riveting still remains the most popular and basic method of joining metal parts. This technique has been used since the very beginning of the aircraft history resulting in the accumulation of an enormous body of relevant knowledge and experience. Some published research findings have indicated that the fatigue life of riveted joints can be significantly increased, leading to extended aircraft service life and a decrease in operational costs.

\section{Local Phenomena During Riveting Processes}

The fatigue life of riveted joints directly depends on the existing stress state. This stress state is a result of residual stresses introduced in manufacturing (sheet rolling, riveting), modified by external loads to which a structure is exposed. Residual stresses induced by riveting represent a large proportion of total stresses since typically they exceed the yield point near the holes.

The experiment with strain gauge measurements during the riveting process was designed and performed to investigate the strain state induced during the riveting process for several rivet types. The specimens used are presented in Fig. 13.
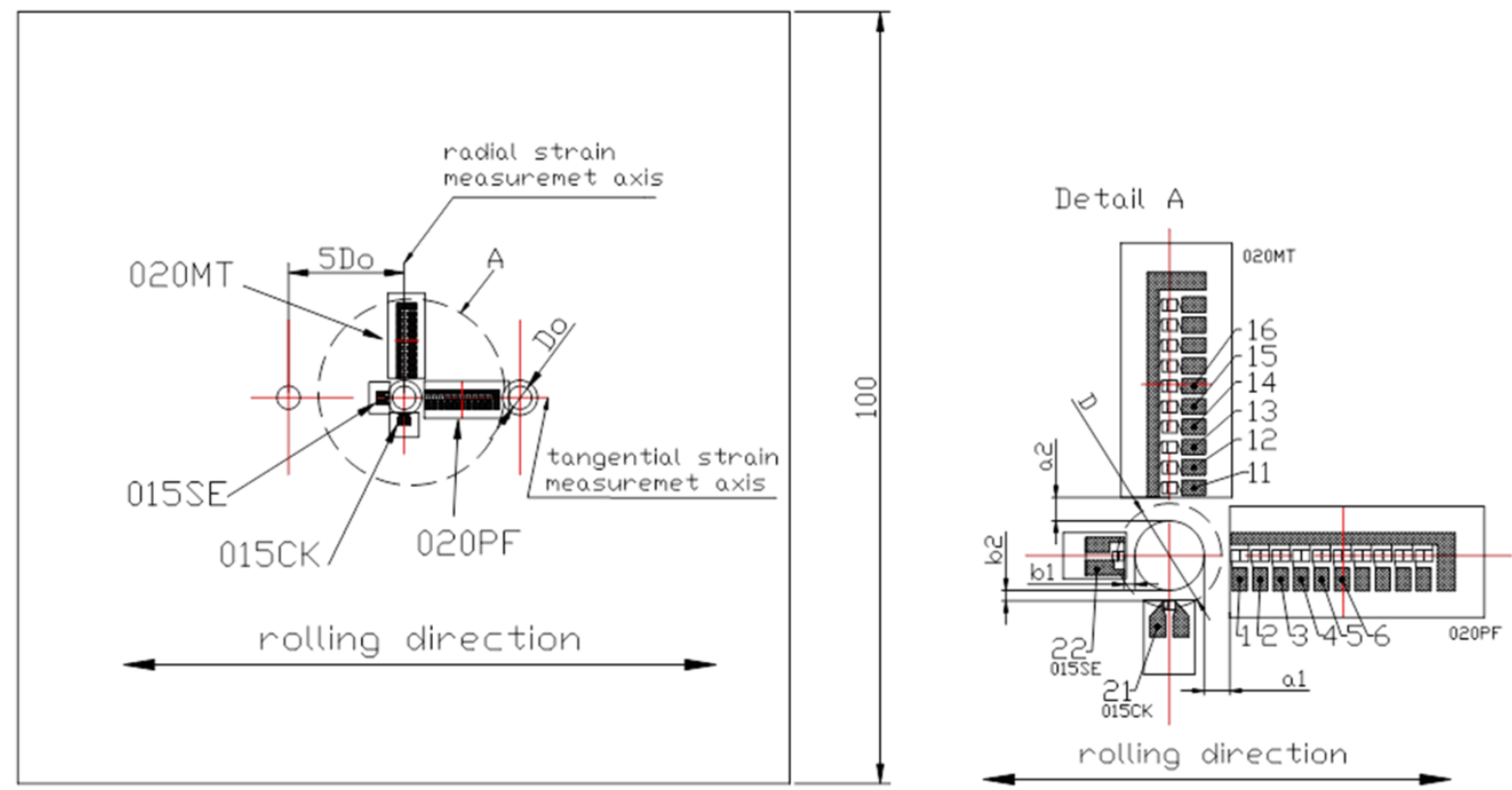

Fig. 13. Specimen geometry

The experiment was performed for four types of rivets (Fig. 14):

a) typical $90^{\circ}$ countersunk rivet (according to Polish aerospace standard BN-70/1121-04),

b) $90^{\circ}$ countersunk rivet with a compensator (according to Russian aerospace standard ANU 301)

c) typical brazier rivet (according to Polish aerospace standard BN-70/1121-06)

d) brazier rivet with a compensator (according to Russian aerospace standard OST 134040 79). 
a)

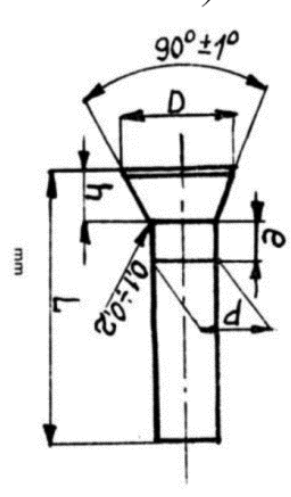

b)

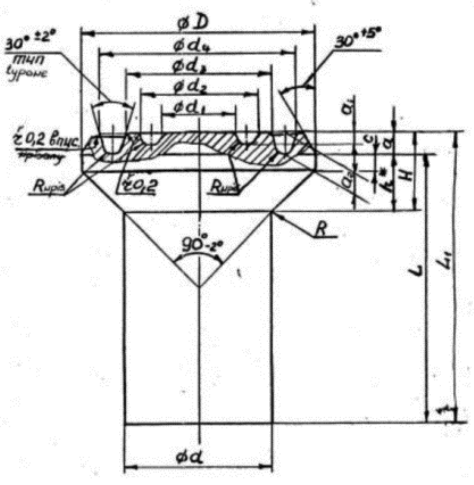

c)

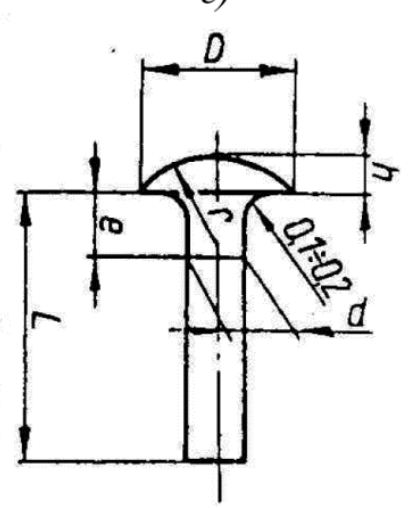

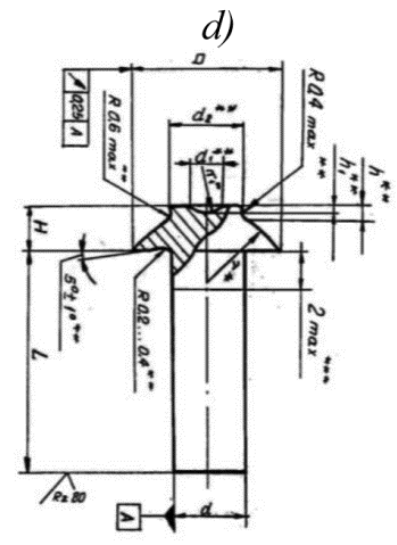

Fig. 14. Rivets used in the experiment

Figure 15 presents strain progress during the riveting process for the typical countersunk rivet.
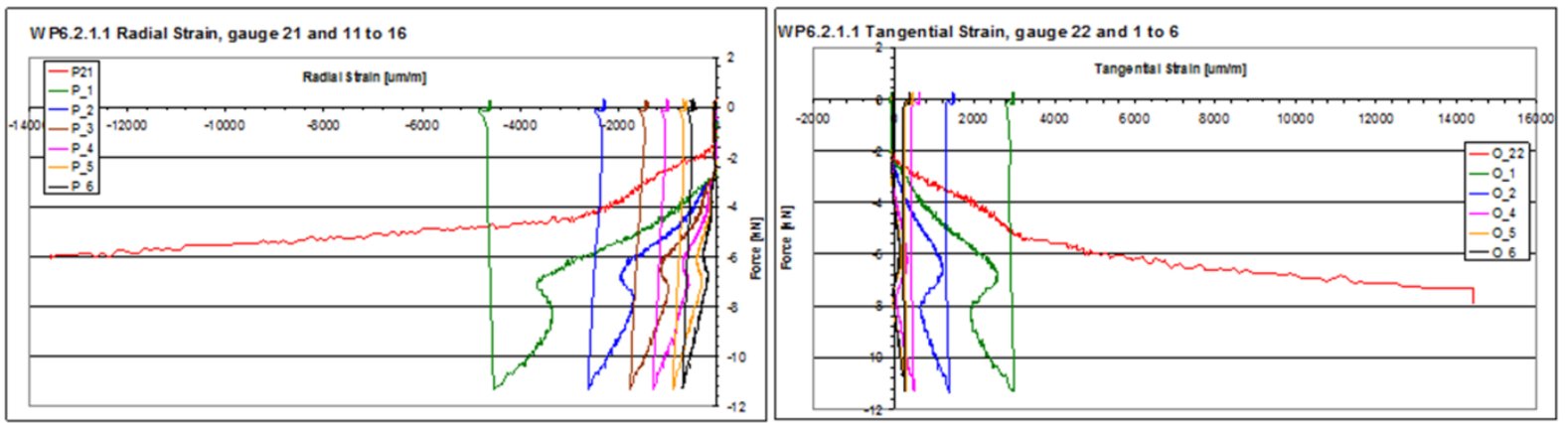

a)
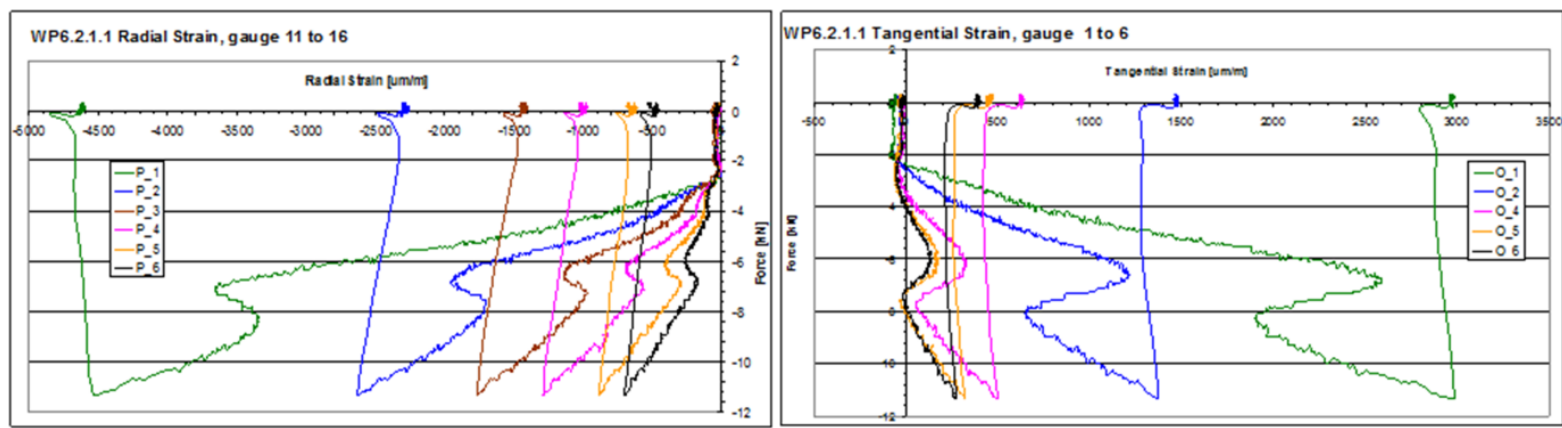

b)

Fig. 15. Strains recorded during the riveting process for the normal countersunk rivet, a) all gauges, b) without micro-gauges

The experiment described above was analysed with FEM. Nonlinear implicit algorithms were used to simulate the quasi-static riveting process (MSC MARC). Geometrical and material nonlinearity as well as contact phenomena were taken into account. Special boundary conditions resulting from the use of the special riveting set were modelled.

Strain progress during the riveting process was experimentally investigated for four types of rivets. Measurements confirmed very high strains near the driven head. For some types of rivets the reversal strain signal was recorded. Several numerical models were used to investigate the riveting process. Agreement between experimental and numerical results was good in some cases, while in other cases the numerical models demanded further development. As the reversal strain 
effect was not obtained in calculations it might be resulting from a phenomenon that was not taken into account in numerical calculations.

It was assumed as a working hypothesis that during the riveting process the adhesive joints (called cold welding) were formed and destroyed during the process, which was the reason why the reversal strain signal had been observed. During the preliminary investigation this hypothesis was not confirmed experimentally (the marks of the destroyed cold welding were not found). This issue will be further investigated in the future.

\section{The Analysis of the Influence of Riveting Parameters on Residual Stresses}

The fatigue life of riveted joints depends on the joint geometry, including the rivet shape and a range of technological factors, of which squeezing force is particularly important. The clearance between the rivet shank and the hole is also considered an important factor. This is connected with residual stresses induced during riveting around the rivet hole. Radial stresses are always compressive. The sign of the tangential stresses depends on squeezing force, rivet type, clearance and distance from the rivet. Compressive stresses are beneficial because they restrict fatigue crack nucleation and growth, which consequently increases the fatigue life of a joint.

The influence of the riveting technological parameters has been investigated by a number of researchers. Here, the authors analysed a range of a stress variation when the requirements of the instructions are fulfilled for a selected rivet type, diameter and sheet thickness. The analysis concerned a hole diameter, rivet length, driven head diameter and height specified in the instructions as well as the rivet shank diameter specified in the rivet standard. The analysis was performed with FE calculations.

The FE model of the riveted joint was prepared with the use of four-node axisymmetric elements (Fig. 16). It contained the rivet and the surrounding area within a radius of $50 \mathrm{~mm}$. The model consisted of about 6, 500 elements and 7, 000 nodes.

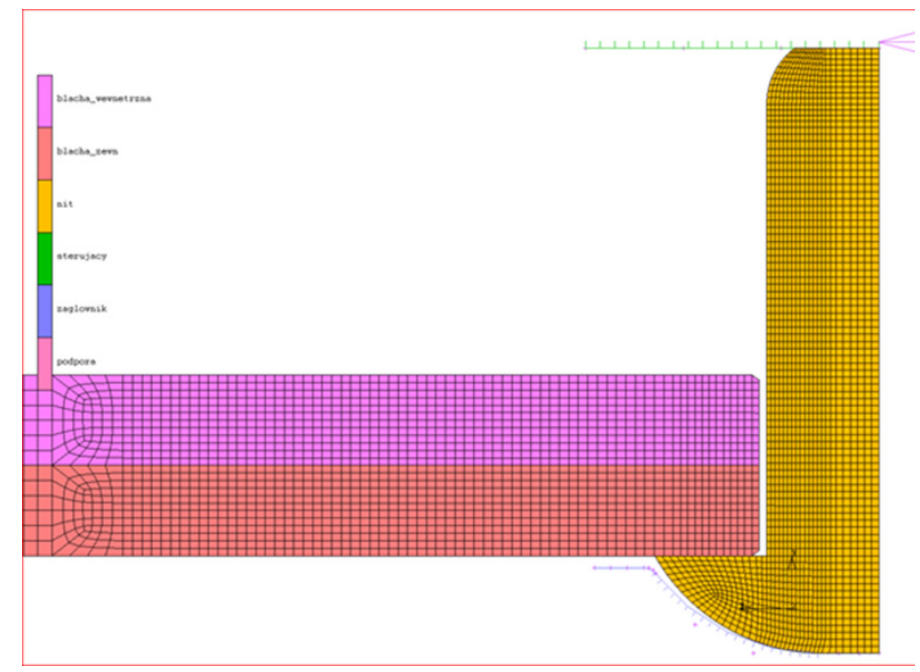

a)

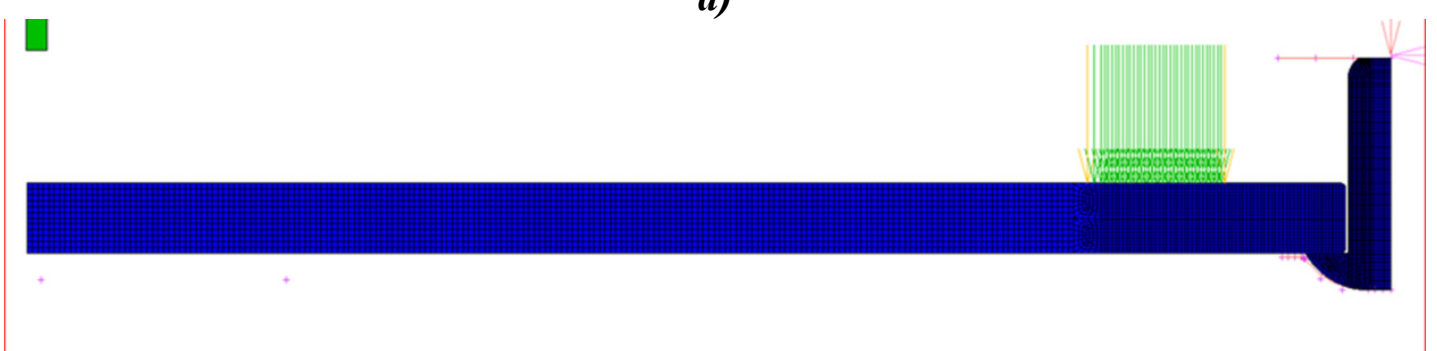

b)

Fig. 16. The FE model, a) central part, b) whole model and boundary conditions 
The nonlinear implicit algorithm (MSC MARC) was used to simulate quasi-static riveting on the press. Contact phenomena including friction and elastic-plastic properties of the materials were taken into account. The stick-slip friction model was used with the friction coefficient equal to 0.42 for kinematic and 0.34 for static friction.

The tools used in riveting (hold-on and press stamp) were modelled as rigid surfaces. The hold-on was fixed. At first, sheets were clamped near the rivet by forces distributed on the sheet surface to simulate the effect of the sleeve used in the riveting set. Then, the force controlled stamp started to squeeze the rivet. The squeezing force rose to its maximum value and then decreased to zero. The force values were selected such as to obtain the required dimensions of a driven head.

\section{Influence of the driven head's dimensions and clearance}

The radial ( $\mathrm{Sr}$ ) and tangential $(\mathrm{St})$ stresses on the sheet surface near the driven head for the cases of clearance and driven head dimensions influence analysis are presented in Fig. 17-18.

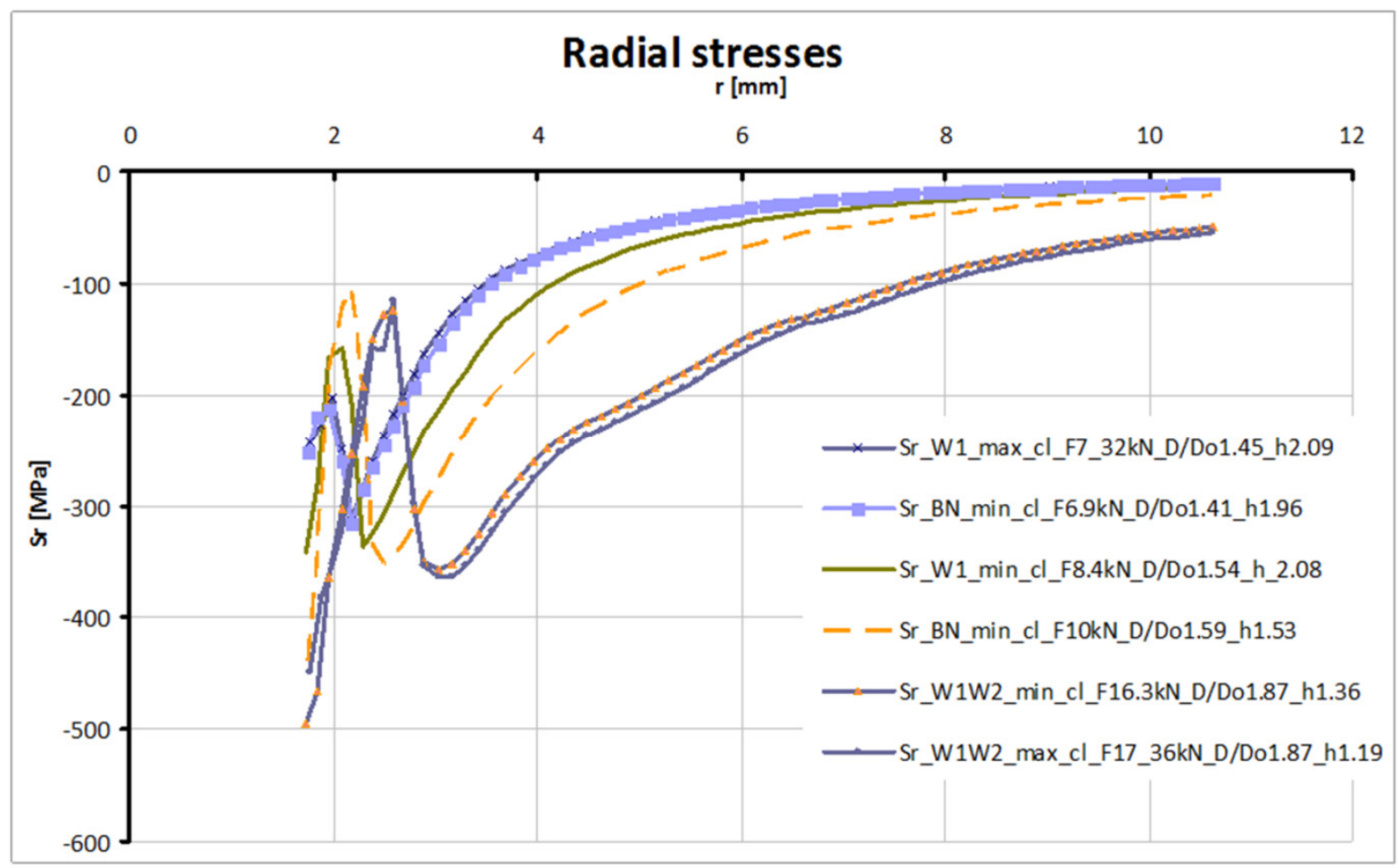

Fig. 17. Radial stresses on the sheet surface near the driven head - clearance and force influence

The results show that residual stresses around the rivet can vary significantly within allowable riveting parameters defined in the investigated standards and instructions. This has a strong impact on the fatigue life of a joint. It is particularly visible in the case of tangential stresses since the area where the tangential stresses are compressive and the place of maximum value depend on the riveting parameters. The most affective factor is the squeezing force level. Stress courses in the case of maximal and minimal clearance are similar if the squeezing force level is approximately the same. Some differences exist for low forces while in the case of high forces stress courses are almost the same. 


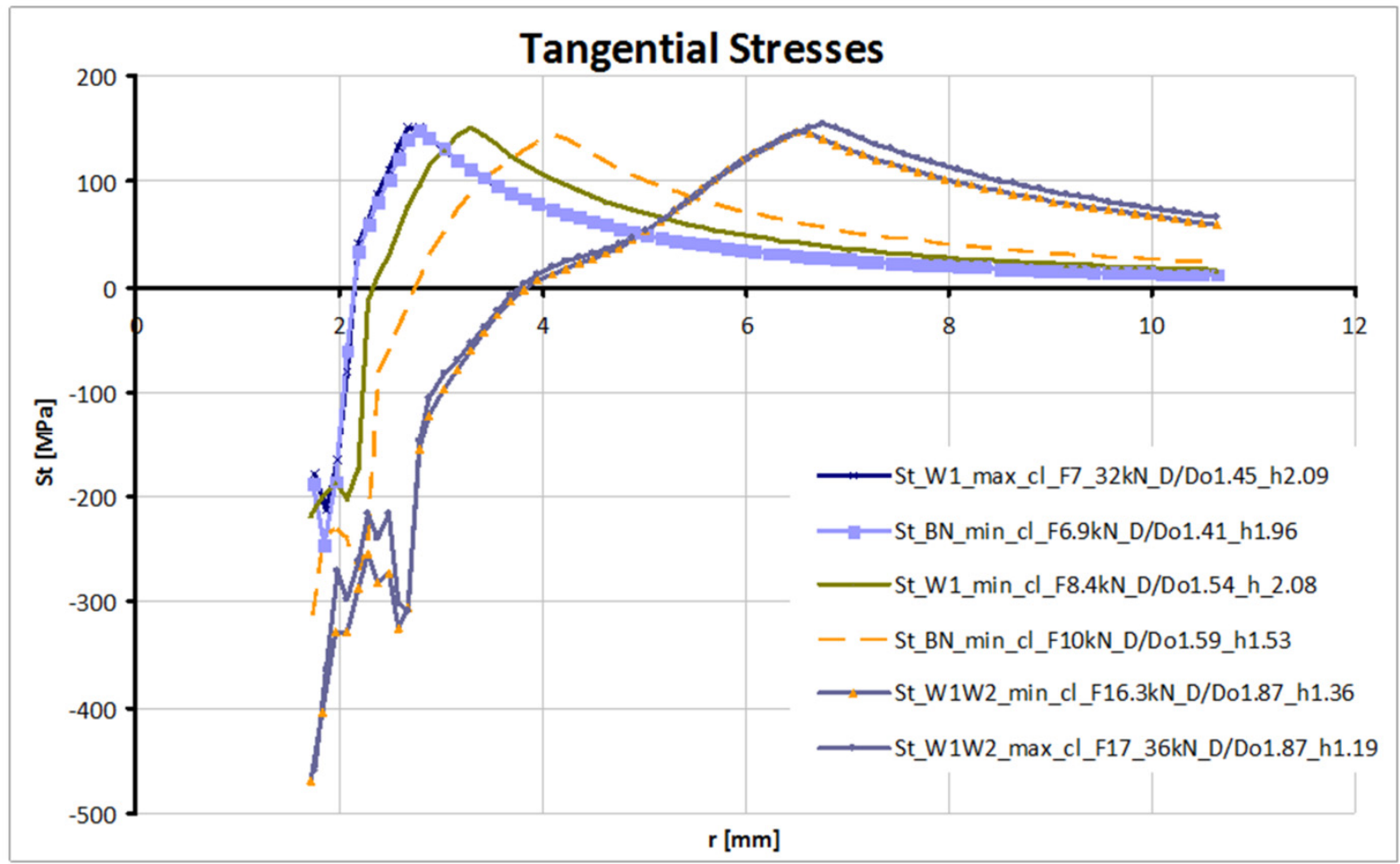

Fig. 18. Tangential stresses on the sheet surface near the driven head - clearance and force influence

$\underline{\text { Influence of length }}$

Figs. 19-20 present radial and tangential stress courses on the sheet surface near the driven head for the cases of the length influence analysis. For the same squeezing force, neither the difference of one length interval nor the shape of the shank end, have any significant influence on the residual stresses. The biggest difference is in the local maximum stress level near the rivet.

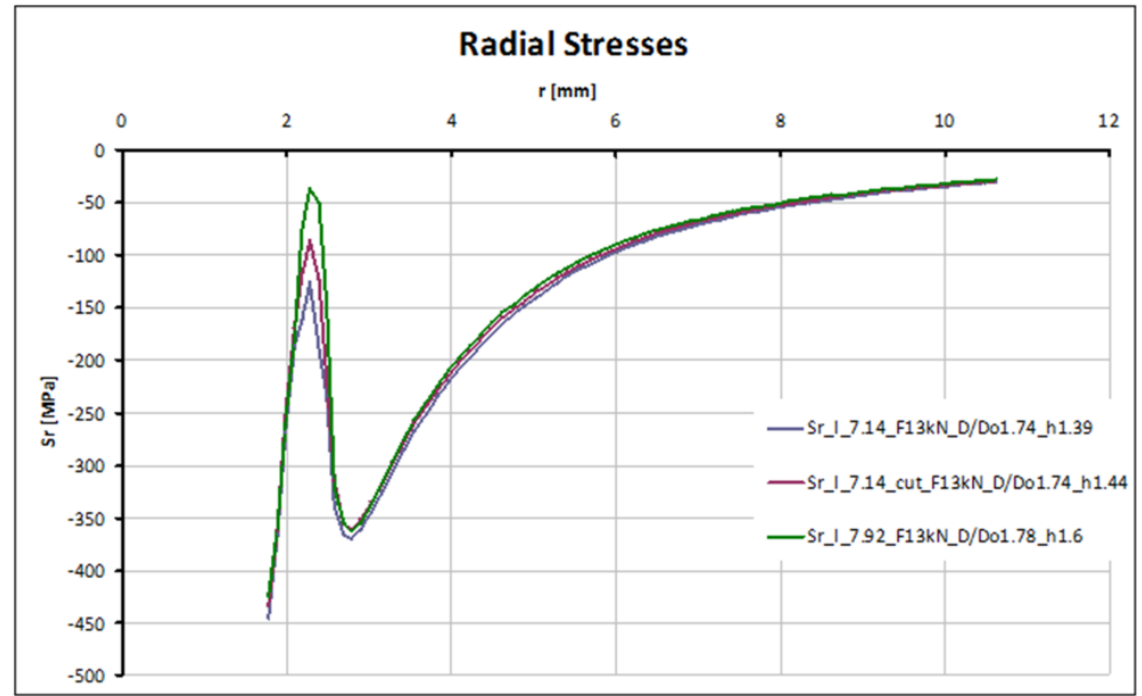

Fig. 19. The influence of radial stresses on the sheet surface near the driven head-rivet length 


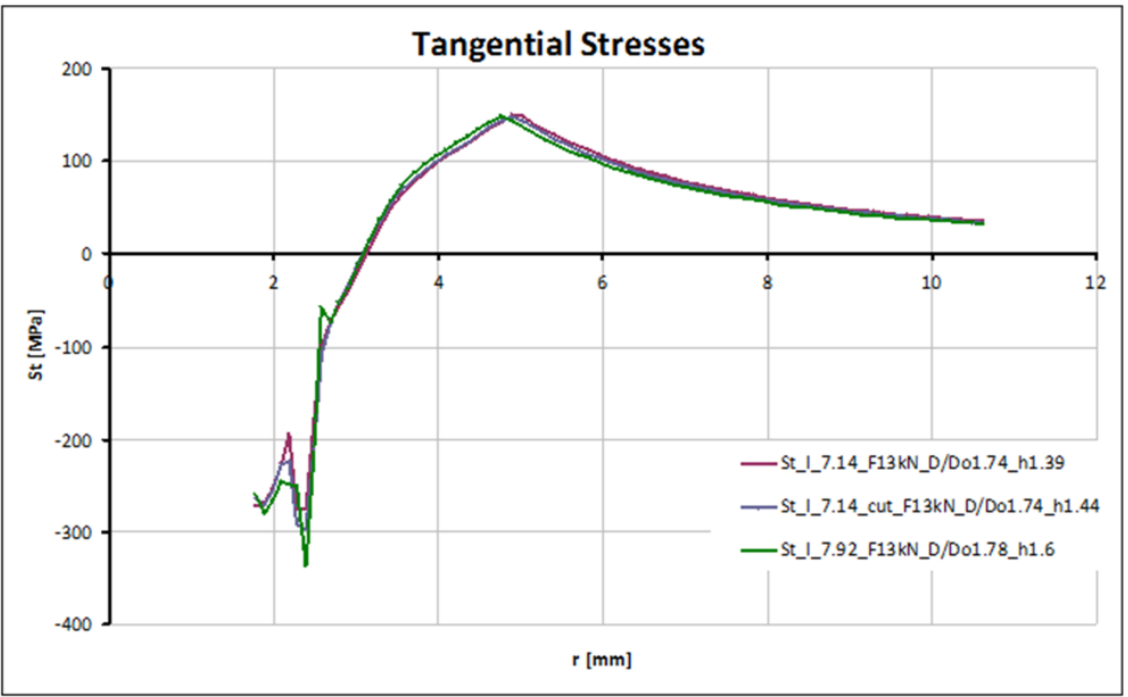

Fig. 20. The influence of tangential stresses on the sheet surface near the driven head-rivet length

The results show that the stress courses can vary considerably depending on riveting parameters. This is important since the residual stress system is directly connected with the fatigue life of joints.

The results show that the most decisive parameter is the squeezing force value. The clearance between the rivet shank and the hole does not affect stress courses significantly when the squeezing force (driven head dimensions) is similar.

\section{INVESTIGATIONS INTO LOAD SPECTRA OF UAVS AIRCRAFT}

A novel approach to the load spectra estimation applied to UAVs has been investigated. The researchers have developed a number of tools in the LabVIEW environment enabling an in-depth analysis of flight-log data. One major achievement was the separation of the load spectra induced by steering and the load spectra induced by turbulence. The authors have shown a significant influence of both of the main load sources on the fatigue life of the UAV airframe, calculated based on the P-M hypothesis. This approach to fatigue testing of composite UAV airframes needs to take into account the rate of load variations as these may affect the fatigue life of tested structures.

In order to estimate the fatigue life either by calculation or in an experimental way, the airframe load spectra must be known (Fig. 21).

The investigations have been carried out to test the loads of UAVs in different weather conditions and different operating modes. The qualitative nature of the loads in the manual and automatic control mode is shown in Figures 22 and 23.

Loads caused by air turbulence are essentially independent of the manual control mode. Atmospheric turbulence causes changes in flow and transient increases or decreases in the angles of attack resulting in increases or decreases in aerodynamic forces. The nature of the load is shown in Figure 24. 


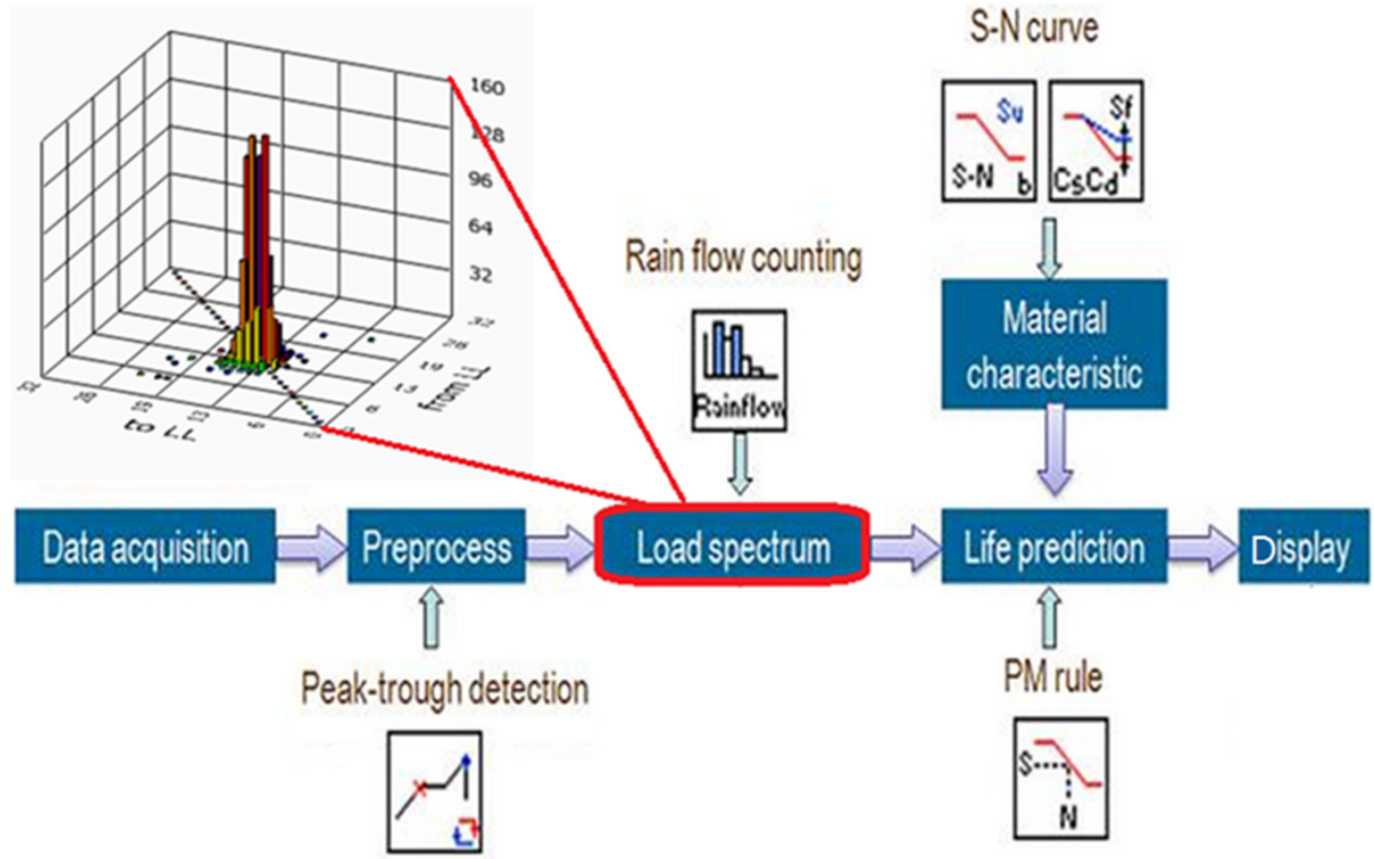

Fig. 21. A scheme for calculating fatigue life
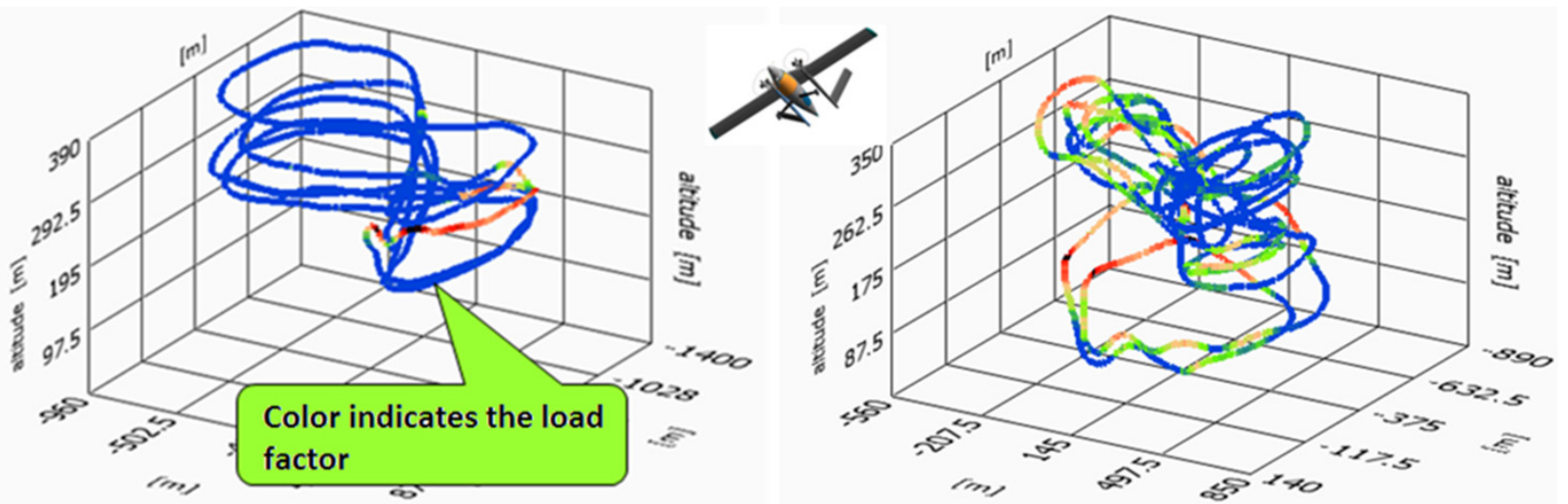

Fig. 22. Differences in the Load Spectra: Auto control mode (left), Manual control mode (right)

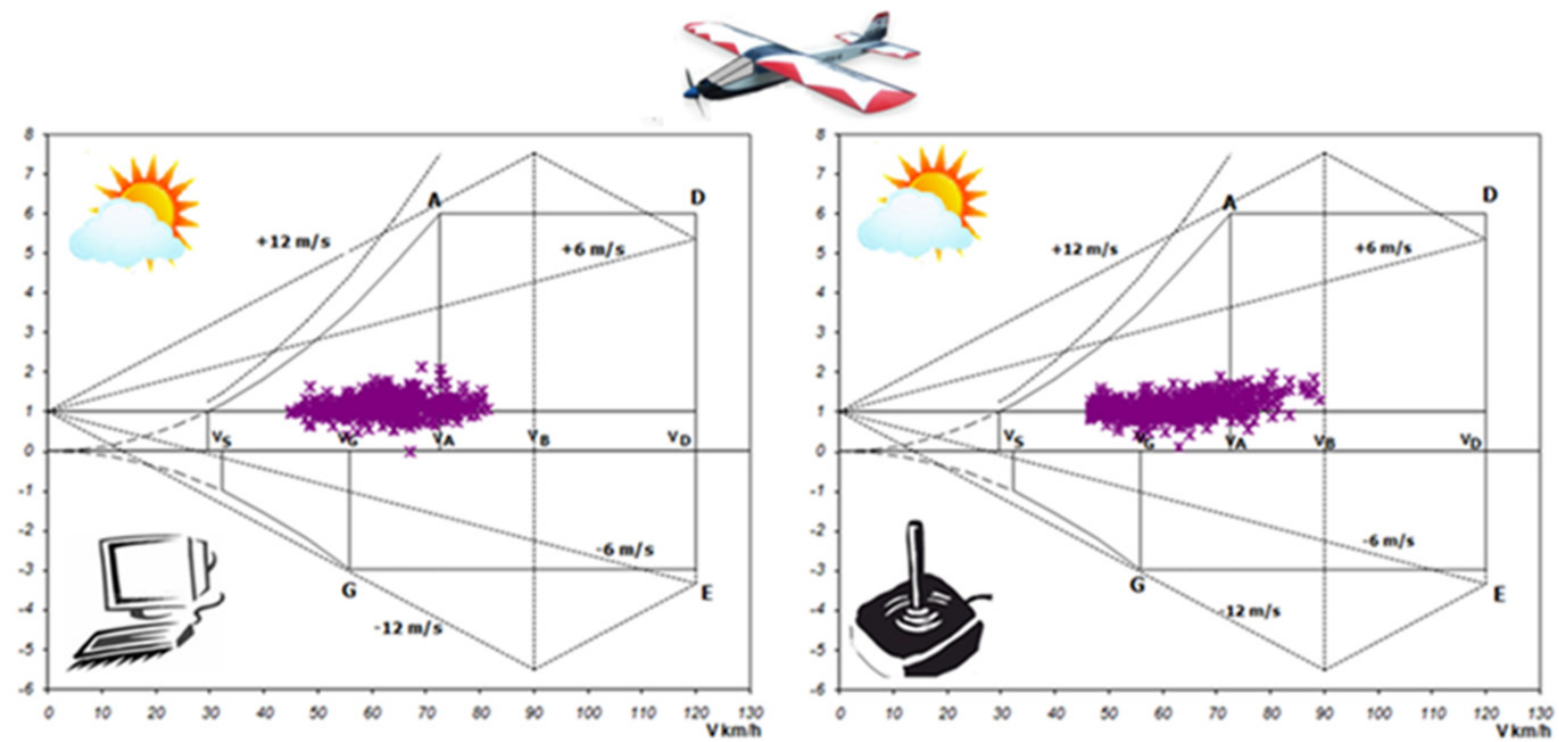

Fig. 23. Loads of a “WorldStar" UAV in different control conditions 


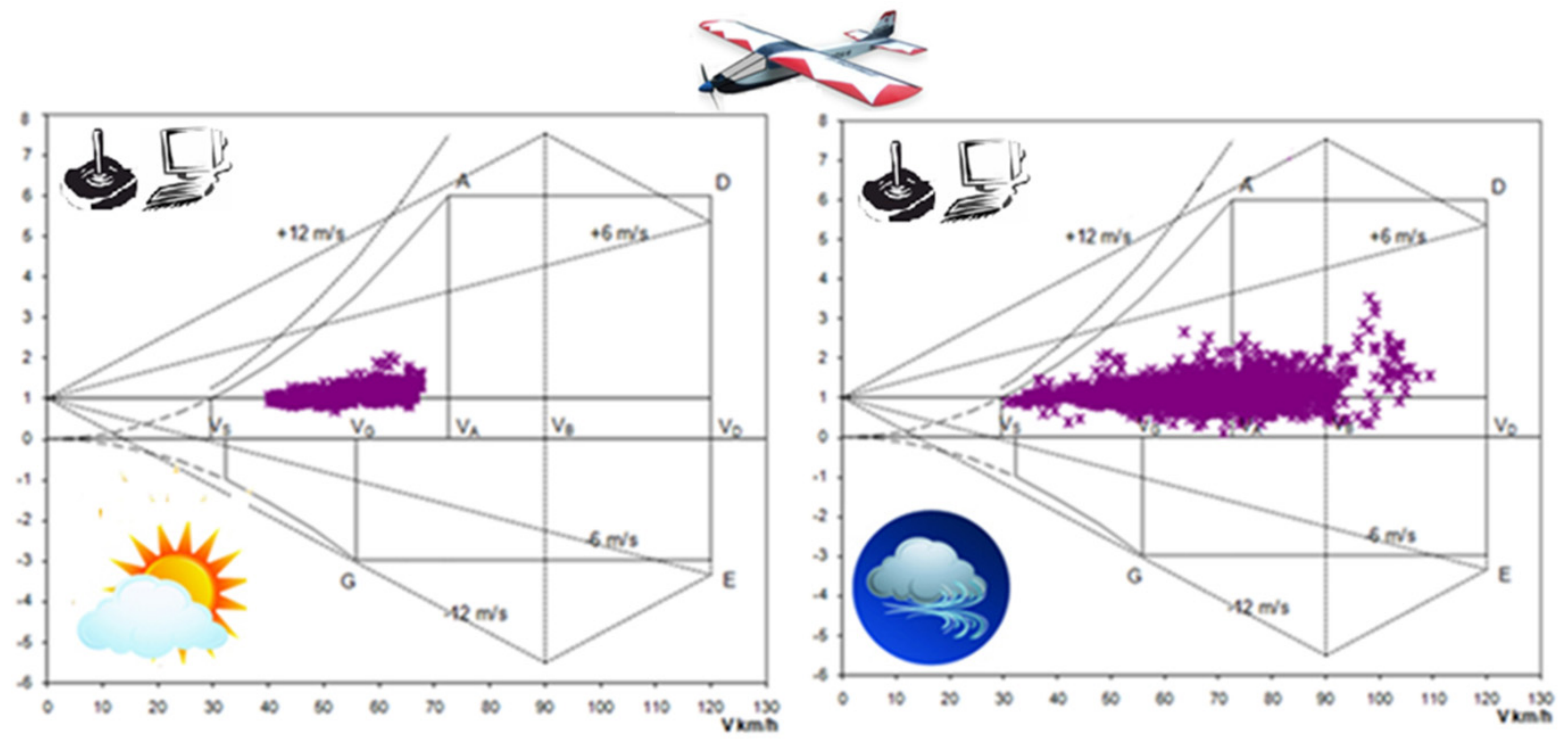

Fig. 24. Loads of a "WorldStar" UAV in different weather conditions

The researchers have developed a method for separating the load spectrum derived from control from that derived from external, atmospheric turbulence. For this purpose, a simulation model described by a transfer function was built. The input signal was the angle of the elevator deflection, whereas the output was the load factor. The transfer function (transmittance) was determined by flight-testing in calm weather. The plane was subjected to sudden change of the elevator angle and then the resulting vertical acceleration was recorded. Transmittance identification was based on a special procedure developed in LabVIEW. Having the transmittance and taking the elevator deflection recorded in the flight-log as the input signal it was possible to simulate the load-signal caused purely by steering. Subsequently, by comparing the simulated load-signal and the real load-signal recorded in the flight-log it was possible to separate loads caused by steering from those caused by turbulence (or other sources). Both of the incremental load spectra were juxtaposed for comparison in Figure 25. The visible difference between the measured signal and the simulated one is due to external turbulence and the non-linearity of the model.

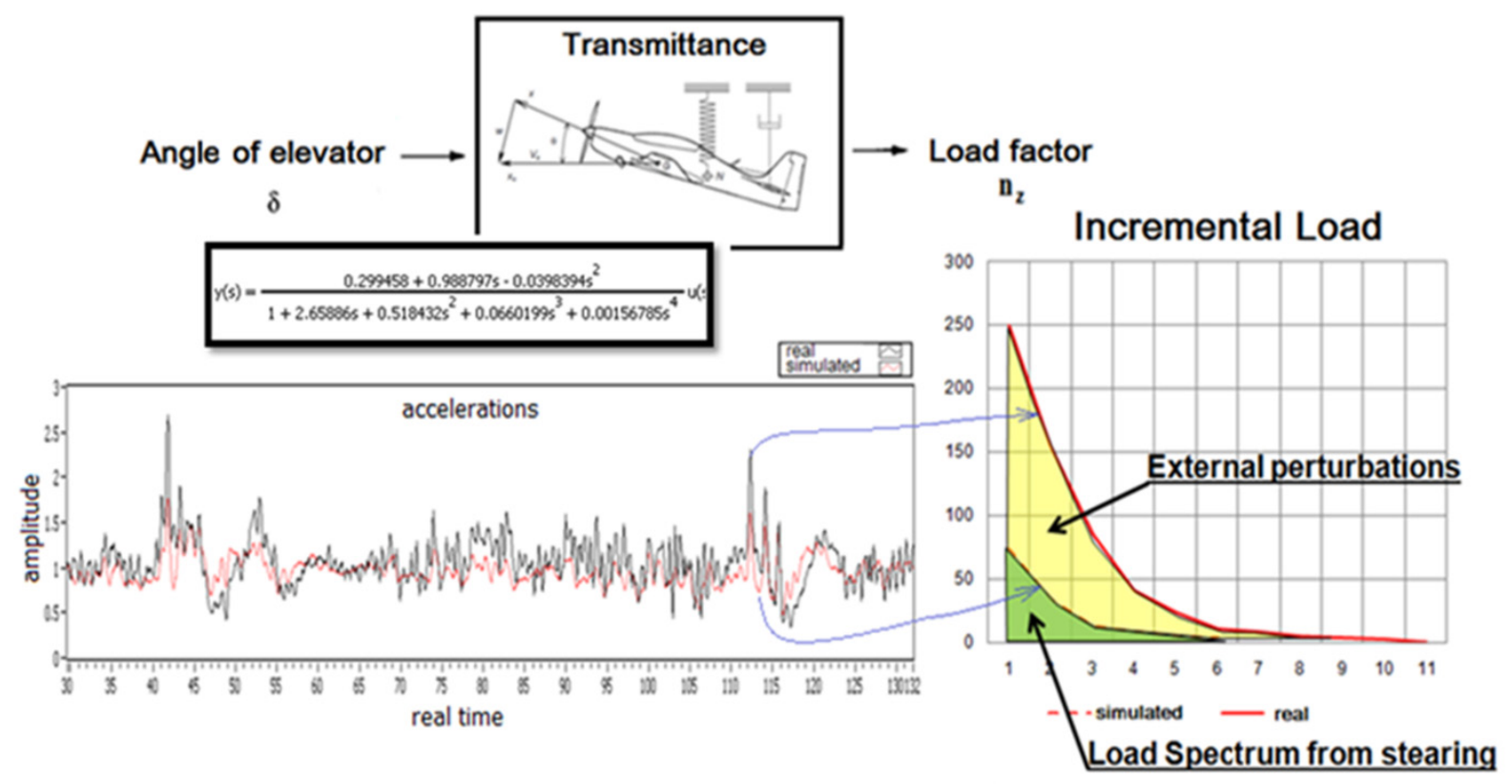

Fig. 25. Comparison of simulated and measured Output signal 
The results of calculations for different conditions in which the WorldStar aircraft was tested are shown in Figure 26. It was observed that in the case of high turbulence, greater load values correspond to an increase in the rate of load variations, which might possibly be an important factor in reducing the fatigue life. However, in calm weather conditions, the load increase was accompanied by a decrease in the rate of load variations.

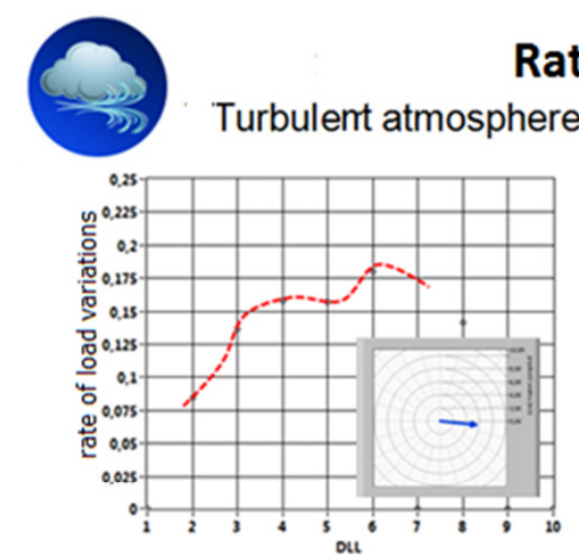

\section{Automatic mode}

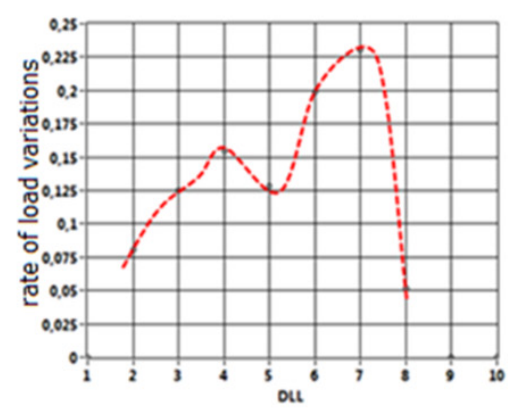

\section{Manual mode}
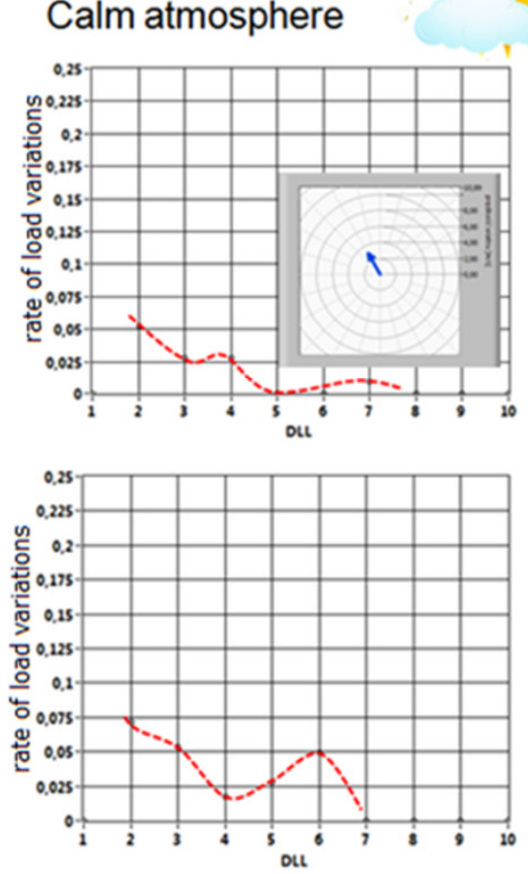

Fig. 26. Rate of load variations recorded during flight tests of the WorldStar

Conclusions:

- Control mode has a big influence on the Load Spectrum.

- The basis for Load Spectra estimations is a statistical analysis of several similar flight mission and consideration of the dispersions of load occurrences number for each load level as well as the dispersion of maximum load increments recorded during flight missions.

- The elaboration process of the model load spectra for fatigue testing of the UAV structure should be based on statistical analysis of possible dispersions of two main parameters: Number of Appearances for each Load Level increment, and the dispersion of maximum load increments values.

- A modern approach to fatigue testing requires that rheological properties of composites structures are considered.

- Significant differences in the load spectrum between the manual and automatic control modes of the UAV were observed. Those differences bear a strong influence on the fatigue life of an UAV structure.

- The determination of UAVs load spectra is of utmost importance for the elaboration of airworthiness requirements for this category of aircraft.

- In order to determine the airworthiness requirements regarding fatigue safety of the UAV structure it is necessary to increase the number of analysed flights - taking into consideration different flight scenarios, different weather and terrain conditions, different pilots, etc. 


\section{INVESTIGATIONS INTO DIFFRACTION METHODS}

Diffraction methods are commonly used for the determination of the elastic lattice deformation and distortion from the displacement and broadening of the diffraction peak. These methods enable researchers to measure stresses and elastic properties of polycrystalline materials. The main advantages of diffraction methods are their non-destructive character and the possibility of macrostress and microstress analysis for multiphase and anisotropic materials. Measurements are performed selectively only for crystallites contributing to the measured diffraction peak, i.e. for the grains having lattice orientations for which the Bragg condition is satisfied. When several phases are present in the sample, measurements of separate diffraction peaks allow for the behaviour of each phase to be investigated independently. This method can be applied without any limitations to flat specimens.

\section{General rules of methodology}

\section{$\underline{\text { Stress in polycrystalline materials - classification }}$}

Residual, or internal stress, is a type of stress caused by persistent strain which remained in the material e.g. after the treatment. This kind of stress can be defined as a derivate of elastic strains remaining after technological treatment and processing of the material. Residual stresses remain in the material after lightening the specimen (e.g. in the case of plastic deformation). Residual stresses remain in the material when the surface of the specimen was deformed to a considerably bigger extent than the inner part of the specimen. This type of stress can be also observed in the case of the two-phase composites due to a different thermal expansion coefficient of each individual composite phase. In this case, in each phase a different strain appears. Another reason for the appearance of residual stresses is the laser treatment of the surface.

Depending on the stress changes vs. distance there are three types of residual stresses:

- First Order Stresses: they represent the constant part for a relatively big proportion of the specimen, for a large quantity of grains. Values of First Order Stresses do not depend on the position of the measurement point. Normally, First Order Stresses appear in the rolled specimen where a stress component parallel and perpendicular to the rolling direction appears (Fig. 27a).

- Second Order Stresses: they vary from grain to grain. Second Order Stresses can be observed in a rolled specimen, too. They originate from different plastic deformations of an individual grain. Average in the whole volume of the specimen for stresses of this type is zero (Fig. 27b).

- Third Order Stresses: their values vary inside every individual grain. They describe the stress field originating from dislocations or grain boundaries. The average value of Third Order Stresses in the whole volume of the grain is zero (Fig. 27c).

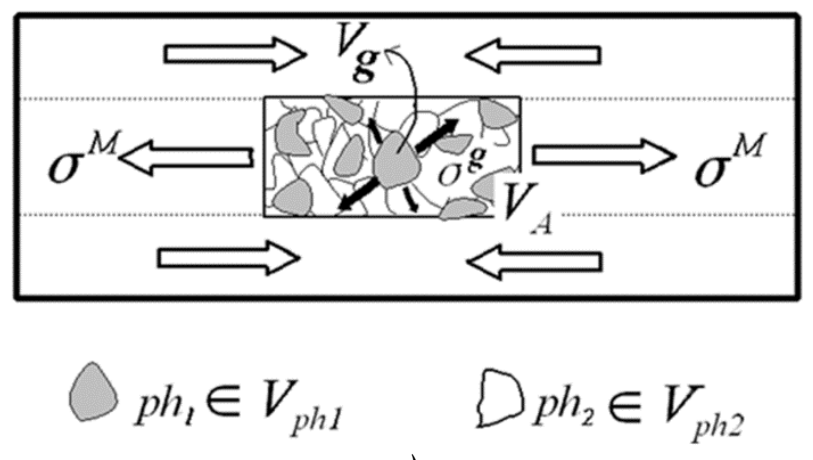

a) 


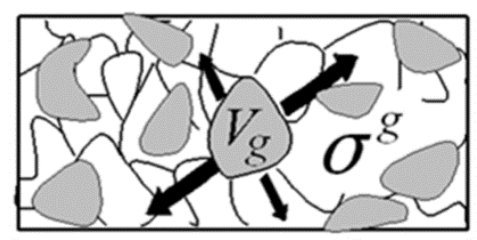

b)

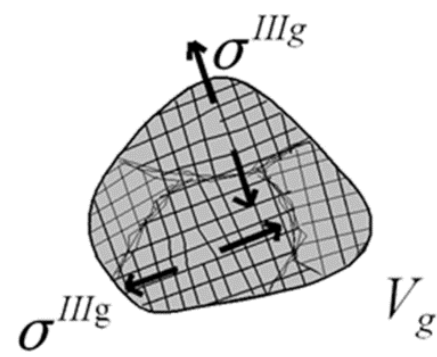

c)

Fig. 27. Stress classification: a) first order stresses, b) second order stresses, c) third order stresses

The effect of residual strain and stress on the diffraction image

First and Second Order Stresses cause a systematic shift of the diffraction peaks visible in the intensity vs. $2 \theta$ graph (Fig. 28). Diffraction peaks originate from many grains so the information about the measured strain is averaged information. It is important to note that not every grain gives diffraction peaks, but only these with an appropriate orientation and which meet Braggs' law. Third Order Stresses originate from dislocations of the atoms (atoms are not placed in their nodes) (Fig. 29a). Third Order stresses cause the broadening of the diffraction peaks (Fig. 29b). The same phenomenon appears for specimens made of materials with different grain sizes. There are some methods (Sherrer's or Williamson-Hall 's formulas) which enable calculating the grain size from the diffraction peak broadening.

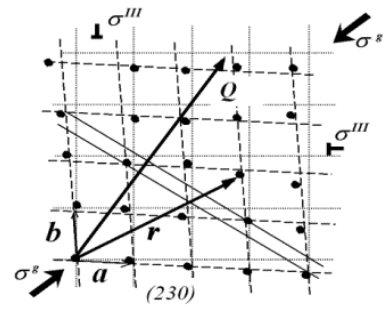

a)

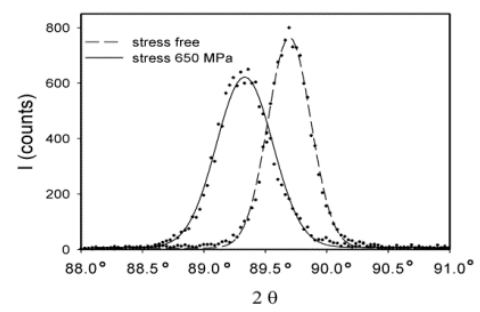

b)

Fig. 28. Deformation of the crystal lattice in case of first and second order stresses (a) and its influence on the position of diffraction peaks (b)

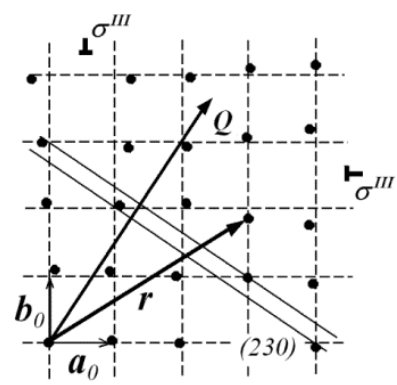

a)

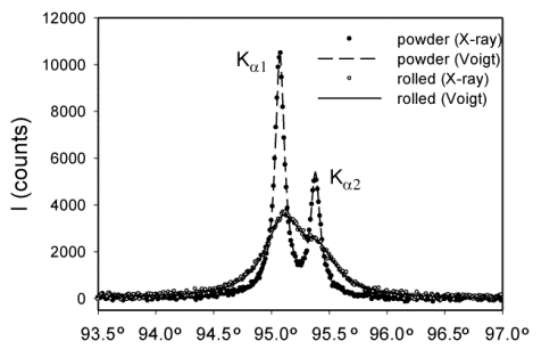

b)

Fig. 29. Deformation of the crystal lattice in case of third order stresses (a) and its influence on the broadening of diffraction peaks (b) 


\section{Measurement techniques}

While measuring strain one can employ three types of radiation: $\mathrm{X}$, neutron and synchrotron radiation. Measurements with $\mathrm{X}$ radiation are the most popular in engineering applications because of its accessibility. Measurements with every individual type of radiation vary with respect to the geometry, penetration depth, shape and volume of the examined material.

- X-radiation: the penetration depth is relatively small - about several micrometers depending on the material, the type of X-radiation and the angle between the incident beam and the specimen surface. This type of radiation enables measurements of stress values on the surface only - the assumption is that the stress component perpendicular to the specimen surface equals zero (Fig. 30).

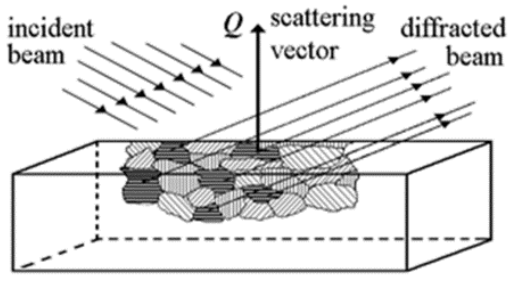

Fig. 30. X-ray diffraction for grains which hkl planes are perpendicular to the scattering vector

- Neutron radiation: the penetration depth is bigger than in the case of X-radiation, it can be even a few centimeters. Typically, the examined volume is a cube whose dimension is about $1 \mathrm{~mm}$ or more (Fig. 31).

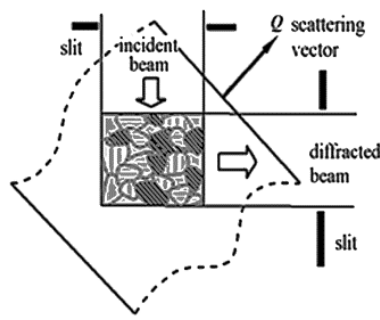

Fig. 31. Examined volume and its shape for neutron radiation

- Synchrotron radiation: the penetration depth is about several millimeters, centimeters and the measured volume is diamond shape with width reaching even several micrometers (fig. 32). It allows perform strain measurements considerably faster than in case of $\mathrm{X}$ radiation and with a better resolution.

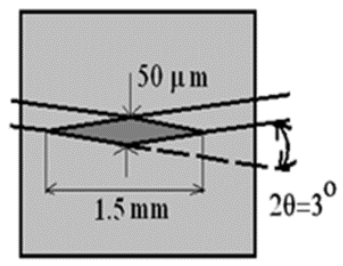

Fig. 32. Examined volume and its shape for synchrotron radiation 


\section{Chosen experiments}

Measurements of the stress gradient around the rivets with X-radiation, strain gauges and FE modeling

The specimen geometry is presented in Fig. 33. The specimen consisted of two sheets of PA7 aluminum alloy, which is the Polish equivalent of 2024T3 alloy, riveted with a press. The sheets were $1.27 \mathrm{~mm}$ thick and without any protective layer such as cladding or an anodized layer (except for a thin layer of technological cladding approximately several micrometers thick).
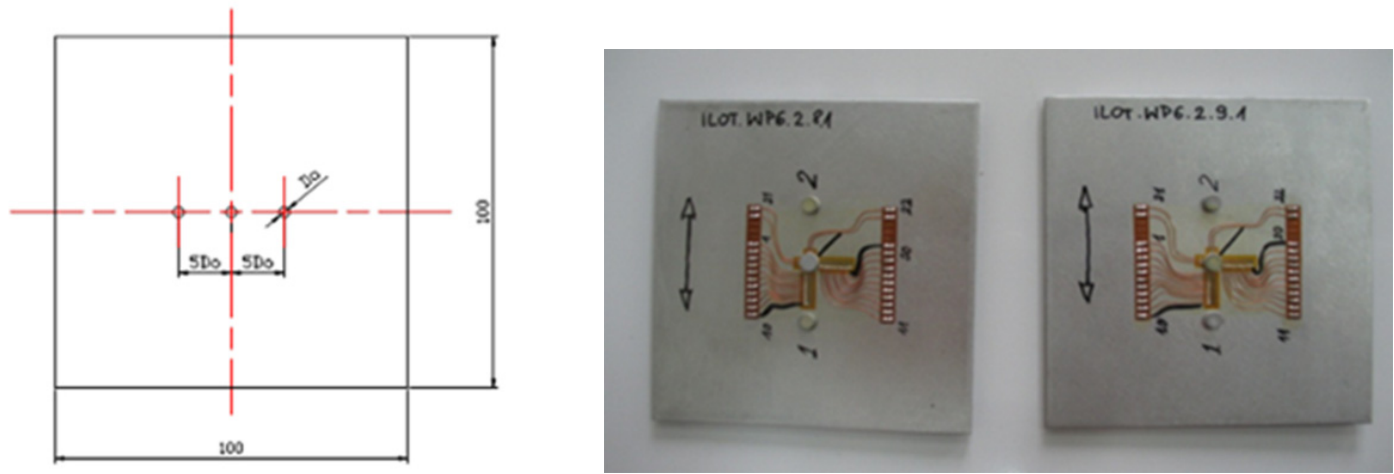

Fig. 33. Geometry of specimen for residual stress gradient measurements

The strain gauges experiment was performed with the strip gauge patterns. Two different strain gauges were used - one of them measured tangential stresses while the other radial stresses. The measurement was performed during the riveting process with the riveting force controlled. The central rivets were riveted with a force giving the ratio between the driven rivet head and the rivet shank equal to 1.55. The riveted sample with strain gauges mounted is shown in Fig. 34, and the example of strain measurement during riveting is presented in Fig. 35. Two types of gauges were used: strip and micro gauges. Strip miniature gauges contained ten gauges, each with a length of $0.51 \mathrm{~mm}$, and were located outside the driven head. They worked during the whole riveting process. Additionally, two micro strain gauges with a length of $0.38 \mathrm{~mm}$ were applied very close to the rivet hole, in the area under the driven head after the riveting process. The gauges recorded strains until they were destroyed by the driven head.

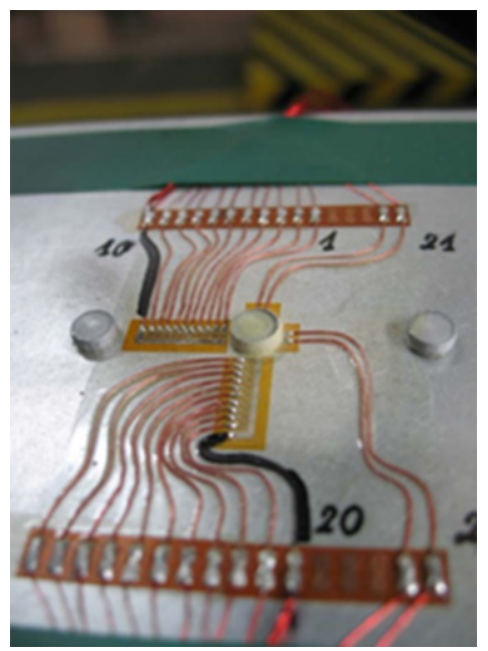

Fig. 34. Riveted specimen with strain gauges 


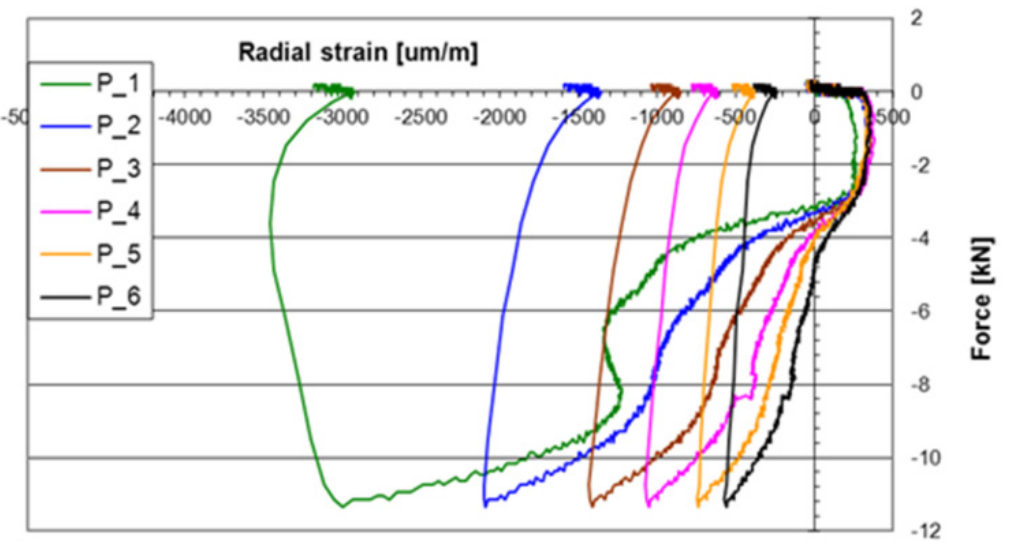

Fig. 35. Example of strain gauges measurement results during the riveting process

In finite element modeling, the axisymmetric models were developed. Each model consisted of six contact bodies: three deformable and three rigid ones and about 2,000 linear elements.

Exemplary results of diffraction measurements compared to strain gauges measurements and finite elements modelling are presented in Fig. 36.
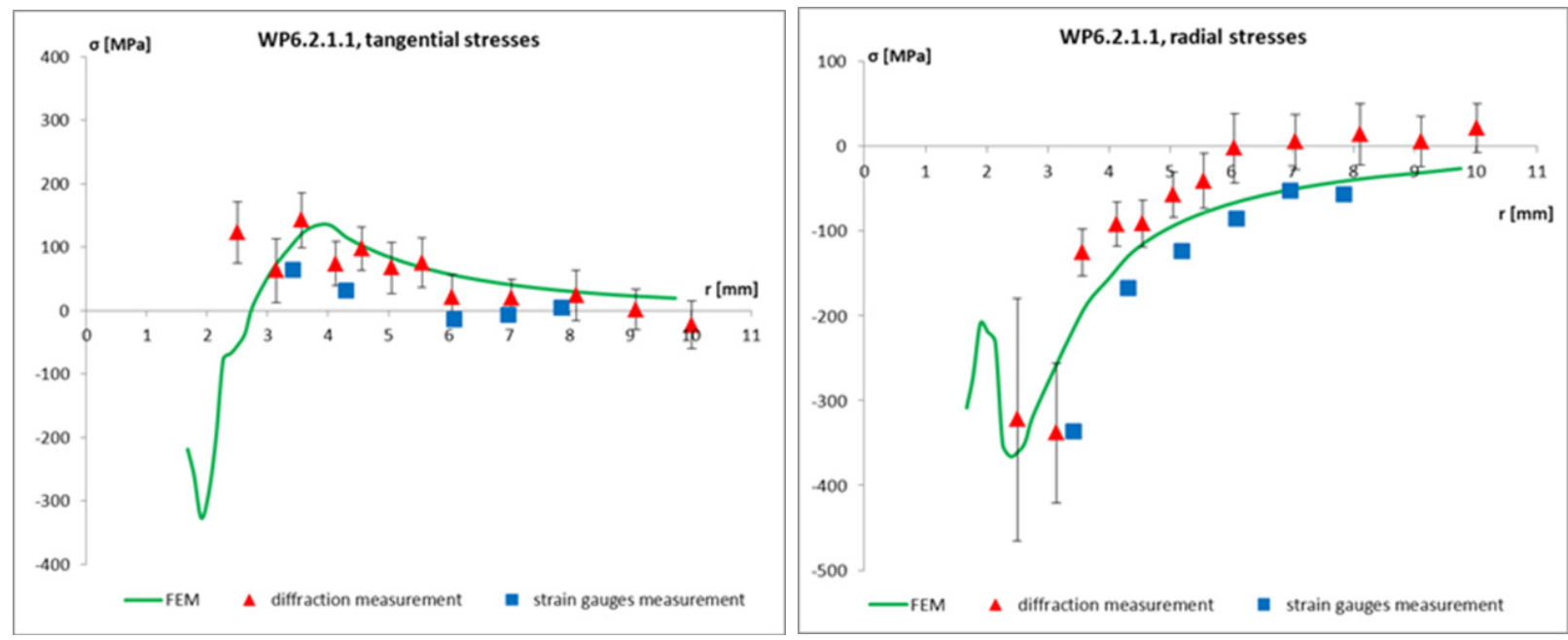

Fig. 36. Tangential and radial stress gradient around the countersunk rivet without a compensator. Comparison of diffraction, strain gauges measurements and FE modelling

Good agreement between stress measurement results obtained with different techniques (X-ray diffractometry and strain gauges) and the FE modelling gives strong evidence of the suitability of the applied methodology of X-ray stress measurements.

\section{$\underline{\text { Determination of local stress tensor }}$}

The aim of this experiment was to determine the evolution of the stress tensor for preferred orientations of grains in duplex steel during tensile testing. Stresses for these orientations (i.e. $\{001\}<011>$ in ferrite and (i.e. $\{001\}<100>,\{011\}<211>$ in austenite) can be calculated from strains measured for different orientations of the scattering vector (poles) with respect to the sample. This can be achieved by changing the sample orientation in the Eulerian cradle and selecting $h k l$ reflections by choosing appropriate values at $2 \Theta$ scattering angle.

The inter-planar spacings were measured with a wavelength of about $1.159 \mathrm{~A}$ and a slit aperture of $10 \times 10 \mathrm{~mm}^{2}$ (6T1 diffractometer) for the bone shape sample (cross section $4 \times 4 \mathrm{~mm}^{2}$ in the gauge 
part) under different loads applied by the tensile machine. Relative lattice strains were calculated with respect to the initial inter-planar spacings measured when the load was not applied to the sample. To analyse the experimental results, the crystallite group method was used in order to calculate stresses related to the measured strains according to the relation:

$<\varepsilon(\phi, \psi)>_{\{h k l\}}=\gamma_{3 i} \gamma_{3 j} s_{i j k l} \sigma_{\mathrm{kl}}$

Where: $\sigma_{\mathrm{kl}}$ are the components of stress tensor for a given orientation $\{\mathrm{uvw}\}<$ mno $>$ related to the set of strains $<\varepsilon(\phi, \psi)>_{\{h k l\}}$ measured in the directions of scattering vector, $s_{i j k l}$ are the single crystal compliances calculated from stiffness and transformed to the sample frame, and $\gamma_{3 i}$ are the direction cosines transforming the grain strains into the direction of scattering vector.

The dependence of six stress components determined according to eq. (1) for three studied orientations is shown in Fig. 37 alongside the prediction of the elastoplastic model. The theoretical result was adjusted to the experimental data and the plastic parameters were found for both phases of the studied steel. The Voce law describing the hardening process at the grain scale was used and the plastic parameters were defined for each phase of the steel separately, i.e.:

$$
\tau^{g r}=\tau_{0}^{p h}+\left(\tau_{1}^{p h}+\theta_{1}^{p h} \xi^{g r}\right)\left[1-\exp \left(-\frac{\theta_{0}^{p h}}{\tau_{1}^{p h}} \xi^{g r}\right)\right]
$$

where: $\tau_{0}{ }^{(p h)}, \tau_{1}{ }^{(p h)}, \theta_{0}{ }^{(p h)}$ and $\theta_{1}{ }^{(p h)}$ are the adjusting parameters defined independently for each phase $p h$, while the plastic shear strain $\vartheta^{(g r)}=\sum_{t} \gamma^{t}$ is defined as the sum of total shear strains $\gamma^{t}$

for all slip systems $t$ in the grain $g r$.

Analysing the plots presented in Fig. 37 it can be seen that there is a significant difference in the stresses localised in different phases. The evolution of the stress component parallel to the applied load (reflects the behaviour of the phases. The ranges in which both phases are elastic and both phases are plastic can be easily distinguished. The positions of the thresholds precisely determine yield stresses for each phase, which can be easily read from the presented plots. These thresholds are used to adjust the parameters of the Voce law. It can be noted that, in the purely elastic range, all the components of the stresses are predicted very accurately by the model.

To conclude, the presented methodology for the experimental determination of local stresses for crystallites having the preferred texture orientations was found effective. Using the presented methodology, the localisation of stresses on polycrystalline grains, used in the scale transition models, can be verified. It should be noted that the analysis of the experimental data with the crystallite group method can only be performed for strongly textured samples exhibiting pronounced preferred texture orientations. 

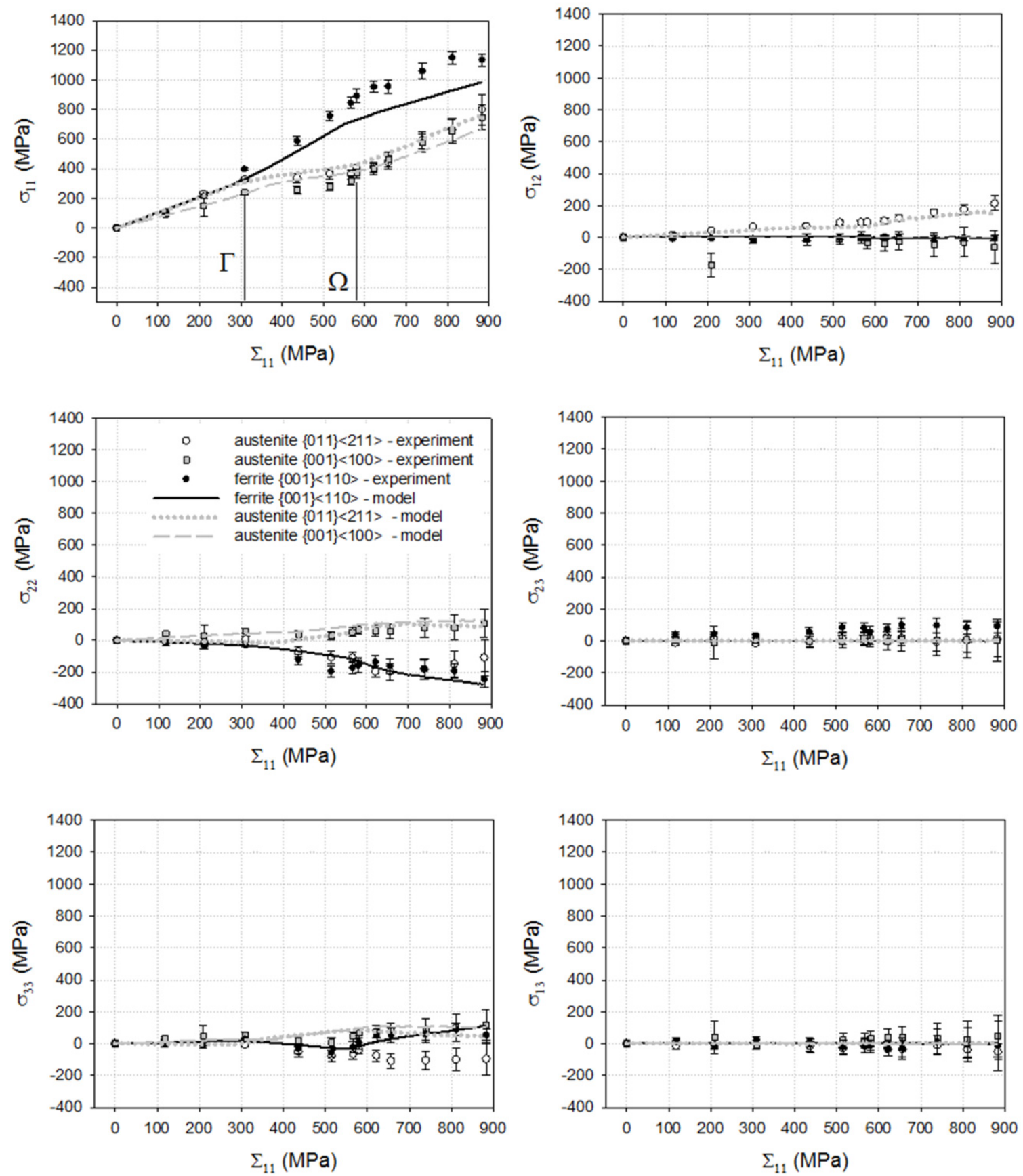

Fig. 37. Components of stress tensor localised on the group of grains having the three studied texture orientations vs. applied macrostress. Experimental results obtained using the crystalline group method (points) are juxtaposed with the self-consistent prediction (lines)

\section{Future research}

Our activities so far and in the future have been and will be focused on investigating two-phase materials and on developing a methodology that will enable us to study the properties of every single phase and the phenomena that take place on a mesoscopic scale. Our methodological aims are:

- to develop a methodology of investigating the polycrystalline materials properties on the mesoscopic scale and for different phases - using diffraction measurements, crystallographic models and FE calculations; 
- to determine a stress concentration tensor experimentally and to compare the experiment results with the theoretical predictions;

- to model the description of the damage phenomenon (mesoscopic scale and between phases);

- to employ the developed methodology for other two-phases materials (e.g. metal matrix composite).

Our future research will concern:

- small deformation and stress concentration tensor;

- large deformation and damage;

- development of a methodology for metal-matrix composites (MMC).

\section{INVESTIGATIONS IN MILITARY AVIATION}

\section{THE PROGRAMME OF SERVICE LIFE EXTENSION FOR THE HELICOPTER MAIN ROTOR BLADES}

The Polish Military Fleet of Helicopters is largely made up of Russian-made helicopters such as: Mi-2, Mi-8, Mi-17, Mi-14, and Mi-24. The approach to the maintenance of the main rotor blades (MRB) of these helicopters is based on service life. There are two criteria vital from the point of view of the maintenance of helicopters' MRBs:

- Service life based on hours known as Hour Service Life - HSL (measured in hours);

- Service life based on time interval known as Calendar Service Life - CSL (measured in years).

These two criteria determine the MRB service life. During service life measured in years the level of the use of service life measured in hours falls in the range of $30-40 \%$. It means that even the MRBs which are in good condition must be replaced due to aging (CSL). The Cost Benefit Analysis proved it necessary to introduce in the AFIT/ITWL a programme for the MRB service life extension.

There are two types of construction of main rotor blades used in the Polish Air Force, the Navy, and the Army: (i) with a single spar and a multisection honeycomb and (ii) with a single spar and a non-section honeycomb structure. Table 1 presents information about the main rotor blades used in the helicopters operated by the Polish Armed Forces. Most blades used in the Armed Forces are metallic with the multisection structure. The differences concern the size and spar manufacturer and are associated with that number of types (Q-ty) as well as HSL and CSL.

The maintenance procedures currently used in the Polish Armed Forces (not only) involve visual inspections supported with hammer (coin) tap testing. Those techniques are fast and fairly simple to use but not reliable. Another important issue is the fact that these procedures are heavily dependent on the human factor (operator dependent). Taking that into consideration as well as the data obtained from the failure analysis, the appropriate NDE work was performed. During that work selected enhanced NDI techniques were applied including Shearography, MIA, Pitch-Catch, Ultrasonic, Ultrasonic Phased Array, Eddy Current, and X-Ray. These techniques were supported with a PC interface enabling on-site as well as post-process data analysing. Other advantages of a PC based interface concerned: the possibility of data storing and comparing automated arm scanning procedures and enhanced visualization. The first step in the NDE work was to prepare special specimens from out of service MRBs as well as from those used in service. These 
specimens had damages inserted to mimic authentic damages in order to compare and describe detectability. The next step was to compare the condition of MRBs with reference to different working conditions and different CSL/ HSL.

Table 1 - Information about MRB used in Polish Air Force

\begin{tabular}{|c|c|c|c|c|c|}
\hline No & Hip & Construction & Q-ty & $\begin{array}{c}\text { HSL } \\
{[\mathrm{h}]}\end{array}$ & $\begin{array}{c}\text { CSL } \\
{[y]}\end{array}$ \\
\hline \multirow{4}{*}{1} & \multirow{4}{*}{ Mi-2 } & \multirow[t]{4}{*}{ metal, single spar, multisection } & \multirow{4}{*}{3} & 1000 & 6 \\
\hline & & & & 1500 & 6 \\
\hline & & & & 1000 & \multirow{2}{*}{$8^{(1)}$} \\
\hline & & & & 1500 & \\
\hline \multirow{2}{*}{2} & $\mathrm{~W}-3 "$ & \multirow[t]{2}{*}{ composite, single spar, non-section } & \multirow{2}{*}{4} & 1500 & 10 \\
\hline & W-3WA & & & 1500 & $13^{(2)}$ \\
\hline 3 & Mi-8 & metal, single spar, multisection & 5 & 2000 & 7 \\
\hline 4 & $\begin{array}{l}\text { Mi-14Ps } \\
\text { Mi-14Pt }\end{array}$ & metal, single spar, multisection & 5 & 750 & 6 \\
\hline 5 & Mi-17 & metal, single spar, multisection & 5 & 2000 & $\begin{array}{c}7 \\
6^{(3)}\end{array}$ \\
\hline 6 & $\begin{array}{l}\text { Mi-24D } \\
\text { Mi-24W }\end{array}$ & metal, single spar, multisection & 5 & 1200 & $\begin{array}{c}9 \\
6^{(3)}\end{array}$ \\
\hline
\end{tabular}

(1) - Spar manufactured in Poland, (2) - After detailed servicing, (3) - Sea area operating

Based on the extensive R\&D programmes, special test plans were elaborated. Special specimens were designed and the test scenario to detect damage was implemented.

The first step of that work was to determine the damages that could be detected and that occurred during the service life of the MRBs of the helicopters operated by the Polish Armed Forces. These damages could be classified as:

- Disbonds (skin to honeycomb, skin to spar);

- Cracks (in the spar);

- Corrosion;

- Water ingress (honeycomb cells).
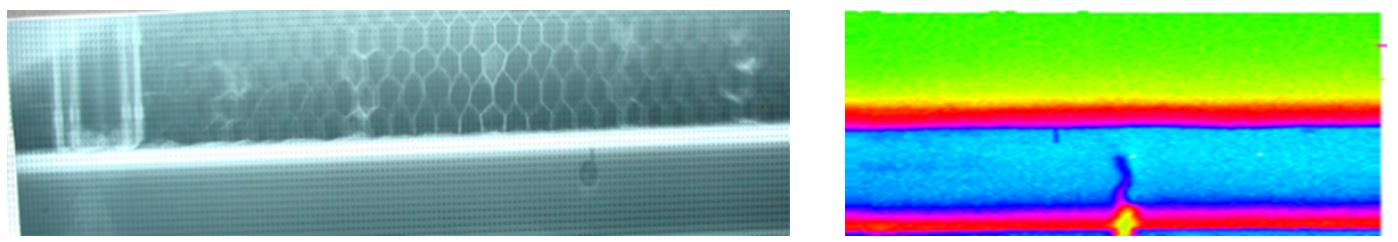

Fig. 1. X-Ray (left) and eddy current (right) inspection results of the crack in the main spar

Figure 1 presents the results of the X-Ray and eddy current inspection of the crack located in the main spar of the blade.
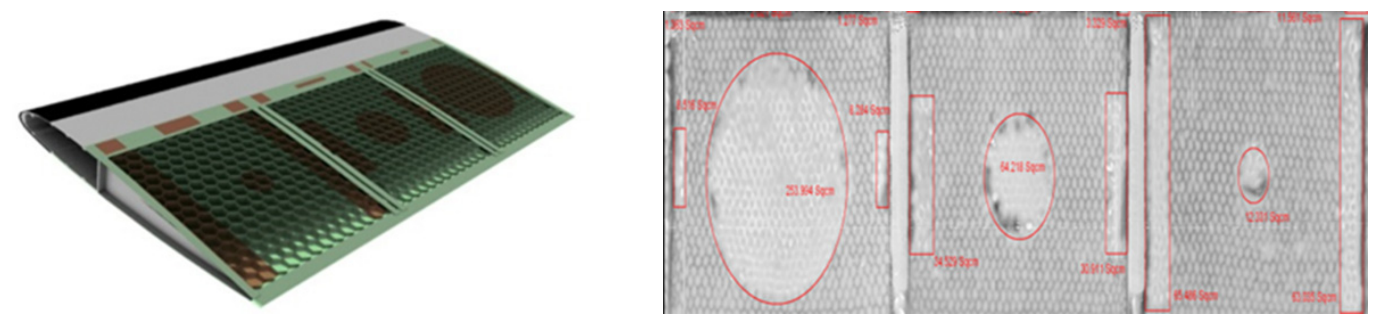

Fig. 2. Calibration specimen design (left) and MIA (right) inspection results of the disbonds 
Figure 2 presents the possibility of the skin-to-honeycomb as well as section-to-spar disbond detection based on the mechanical impedance analysis. Most selected inspection methods enable damage detection and damage sizing.

For most highlighted damage scenarios, several tests enabling damage detection description were performed. Based on the results of a three-year programme, several service inspection bulletins were devised and included in the service life extension programmes.

Service life extension programmes based on the NDI bulletins developed are currently being executed on selected helicopter blades in different types of helicopters to enable further helicopter operation.

\section{INSPECTION PROGRAMMES FOR THE MIG-29}

A MiG-29 is the basic fighter jet used in the Polish Air Force. The two main criteria in the maintenance approach of the MiG-29 are analogical to those used in the maintenance of helicopter MRBs and are based on HSL and CSL. The new maintenance approach called On Condition Maintenance (OCM) was introduced in connection with the possibility of extending service life of some airplanes. One of the primary tasks was NDT (Non Destructive Testing) work for critical components, as well as a corrosion inspection programme for the MiG-29. Activities connected with NDT and the corrosion inspection programmes are also being performed for other aging aircraft operated by the Polish Armed Forces. In this review, only a part of the NDT effort undertaken will be presented in relation to the composite skin of the vertical tail of the MiG-29. A MiG-29 is the aircraft with a double vertical tail construction. The vertical tail consists of the aluminium substructure and the composite skin made of CFRP (Carbon Fiber Reinforced Plastic). The skin is monolithic with a thickness in the range of $1.8 \mathrm{~mm}-3.2 \mathrm{~mm}$ and is joined to the substructure with use of bolts and adhesive.

The nondestructive testing of the vertical stabilizer was focused on the CFRP skin and damages were classified as:

- Delaminations - separation between layers of composite

- Disbonds - lack of adhesive

- Porosity - pores in the resin area

- Foreign object inclusions.

The techniques used for the inspection of the MiG-29's vertical stabilizer were also used for the F-16's horizontal and vertical stabilizer and are presented in the table below:

Table 2 - Information about NDT techniques used

\begin{tabular}{|c|c|c|c|}
\hline & Resonance & Shearography & UT \\
\hline Delamination & - & - & + \\
\hline Disbond & + & (core-skin disbond) & + \\
\hline Porosity & - & - & + \\
\hline Foreign Object Include & - & - & + \\
\hline
\end{tabular}

To perform structural integrity testing of the composite vertical stabilizer the ultrasonic method was used. The total surface area inspected in one aircraft covered approximately $11 \mathrm{sq} \mathrm{m}$. The aircraft population currently tested is made up of more than 30 airplanes. It follows that the total area inspected covered more than $600 \mathrm{sq} \mathrm{m}$. Classic tests with use of manual hand scanning were very difficult or impossible to perform due to work being done on a large area. Hence, an 
automated scanning procedure was applied. The MAUS ${ }^{\circledR} \mathrm{V}$ system was used. The MAUS ${ }^{\circledR}$ system (Mobile AUtomated System) is a hybrid construction enabling inspection with the following techniques: ultrasound, eddy current, MIA, Pitch-Catch, Resonance and with the Phased Array module for ultrasound. The system is fully portable and enables inspection on horizontal and vertical inverted surfaces thanks to a flexible track system equipped with a special handle. Figure 3 presents the inspection of the vertical stabilizer composite skin of the MiG-29.

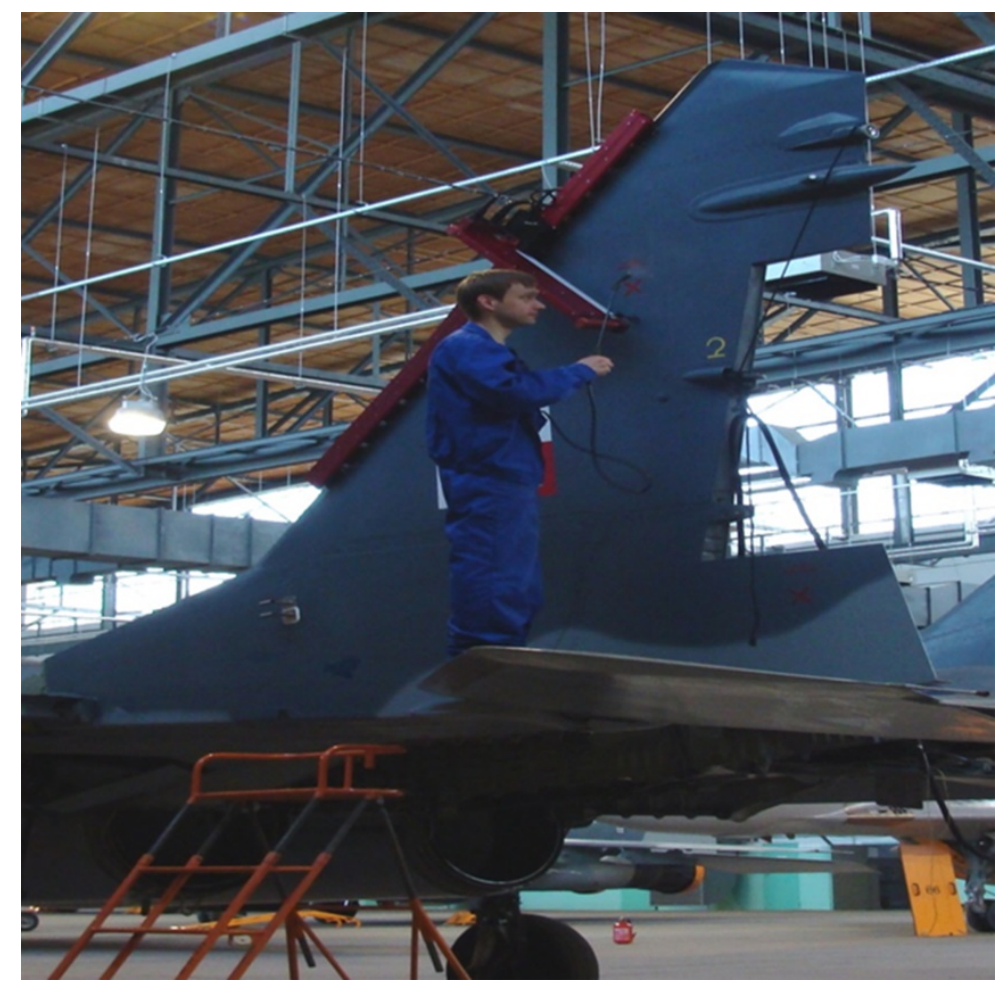

Fig. 3. Composite Vertical Stabilizer Inspection

The resonance and the ultrasonic inspections with the MAUS system are both quantitative methods. The results obtained are presented in the C-scans mode. The system's embedded interface enables the amplitude and ToF (Time Of Flight) C-Scan data presentation. Figure 4 below presents the amplitude C-scan of the F-16 horizontal stabilizer while Figure 5 shows the ToF C-scan of the MiG - 29 vertical stabilizer. On the amplitude data different colours are associated with different signal attenuation. The amplitude mode is useful for determination of the damage location.

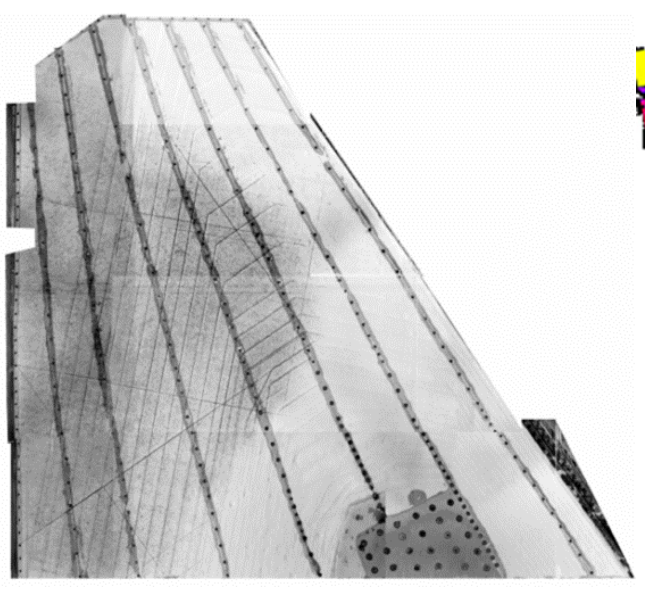

Fig. 4. Amplitude C-scan of F-16's horizontal stabilizer

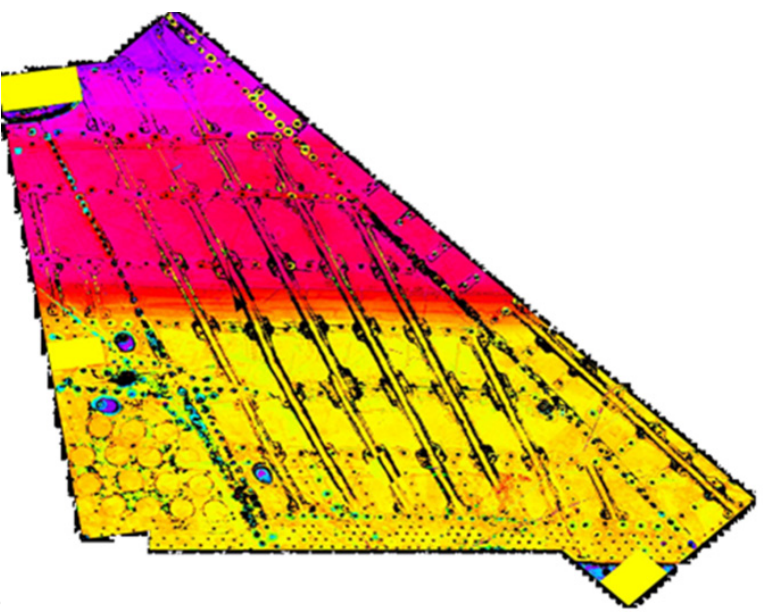

Fig. 5. TOF C-scan of MiG-29's vertical stabilizer 
Colours used in the representation of the TOF data refer to different composite skin thicknesses and to different depths of delamination location. This system of data presentation helps describe damage and quickly find its location. The damage location distribution relative to the side of the vertical tail (internal/external, left/right) was found to be relatively normal. Some inspection results of interest are presented below.

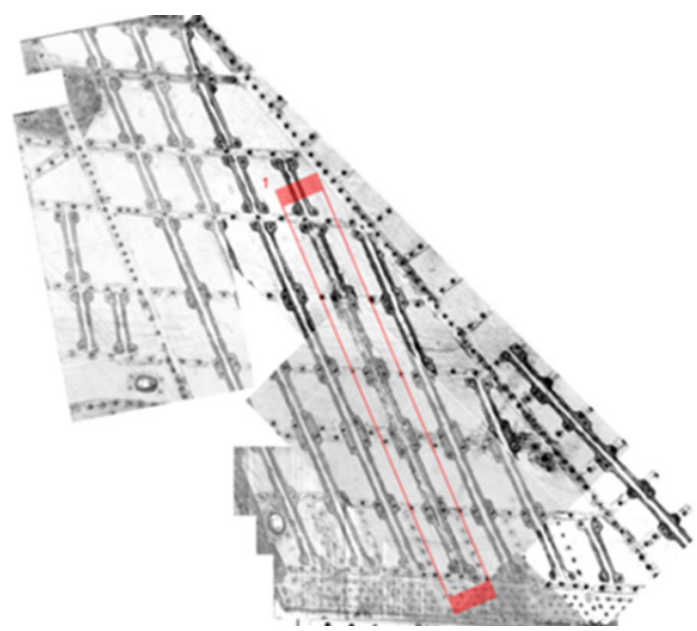

a) PE-Amplitude Mode C-scan

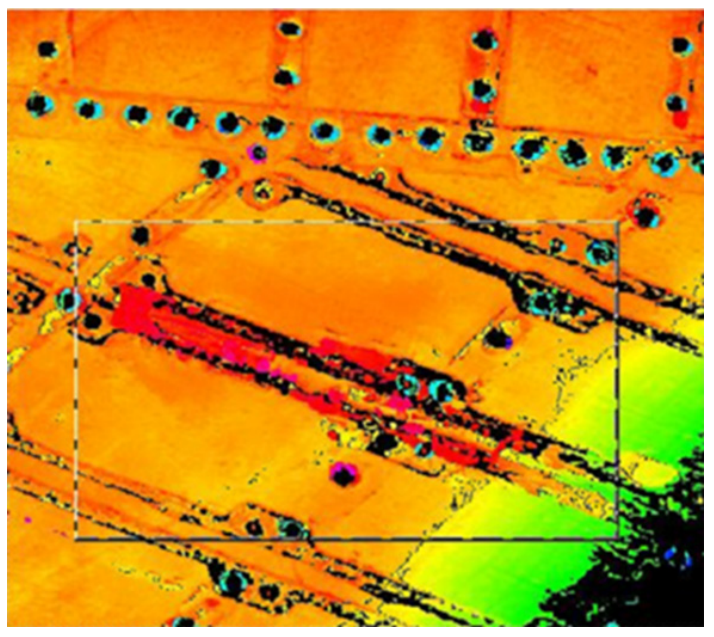

b) PE-TOF Mode C-scan

Fig. 6. Large delamination along the longeron of MiG-29's vertical fin

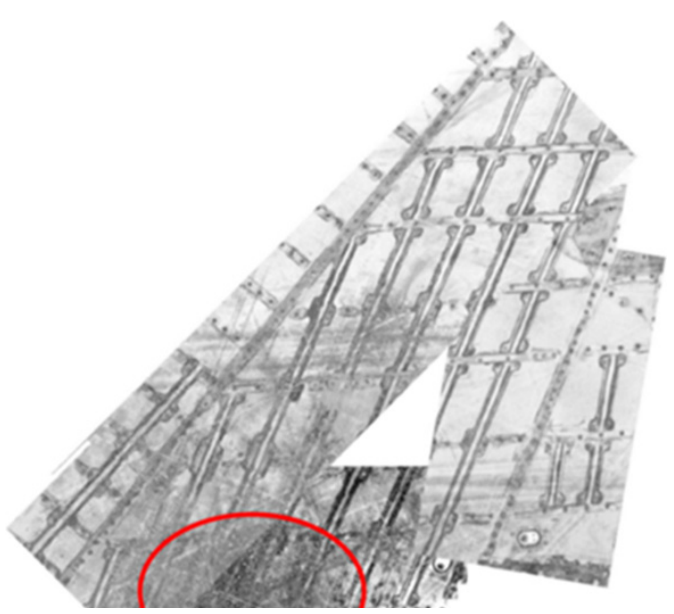

a) PE-Amplitude Mode C-scan

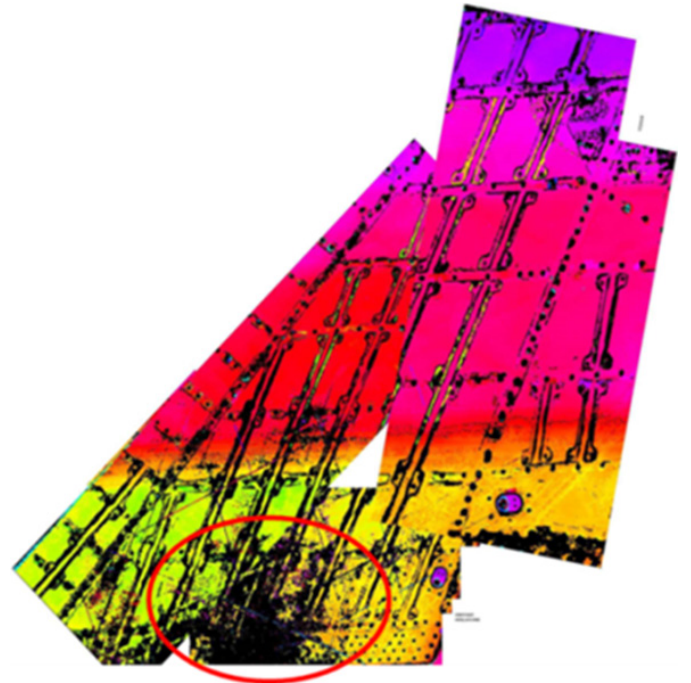

b) PE-TOF Mode C-scan

Fig. 7. Porosity location in MiG-29's vertical fin

Should the need arise for more detailed damage characterization, the additional full waveform capturing based on the B-scan visualization is conducted (as presented in Fig. 8). These results are used to detect delaminations and foreign object inclusions. A typical distribution of damages in the form of disbonds was found in the bottom part of the stabilizer (Fig. 9). At present, the monitoring of all aircraft operating under the designed in AFIT service bulletins has been implemented. 


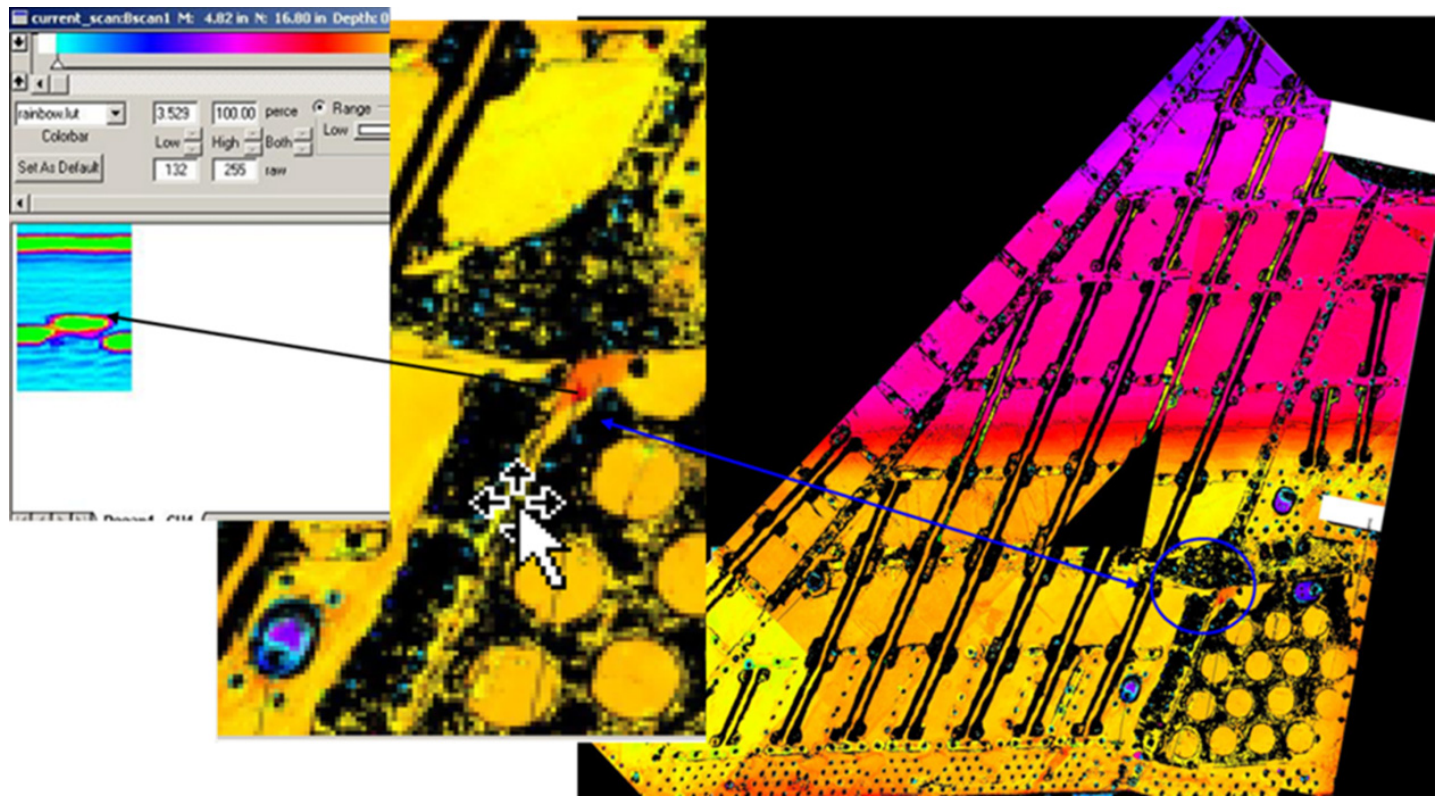

Fig. 8. Foreign object inclusion (embedded) in MiG-29's vertical fin
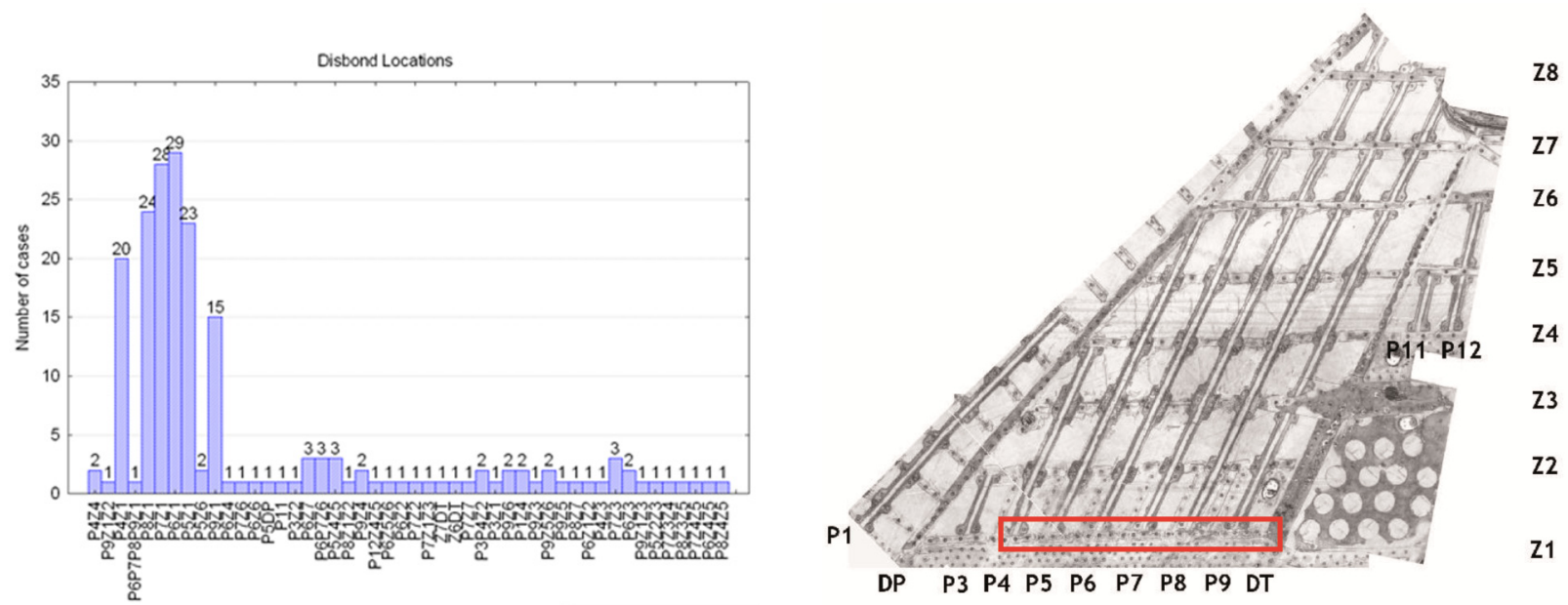

Fig. 9. Distribution of disbonds in the MiG-29's vertical stabilizer

Another important activity connected with further maintenance of the MiG-29 was the composite patch bonded repair of the engine air intake upper flaps.

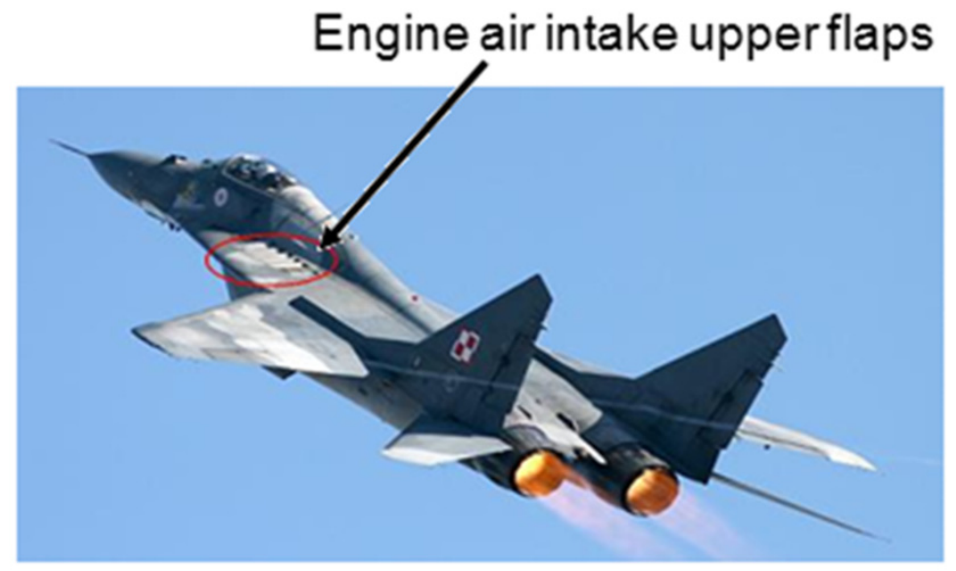

Fig. 10. Location of the engine air intake upper flaps 
Several RD-33 engines were damaged by ingesting failing rivets from the engine air intake upper flaps. The cost of the engine's repair is very high while the flight safety consequences of damage to the engine can be grave. Conventional repairs i.e. riveting proved ineffective due to high cycle vibrations and fretting fatigue.

In looking for a solution to this problem the AFIT came up with a new repair technology - the Composite Patch Bonded Repair. The prepreg technology was applied (bor and kevlar). In order to improve adhesion of the composite patch to the metal surface of the flap, a primer and an adhesive film were used.

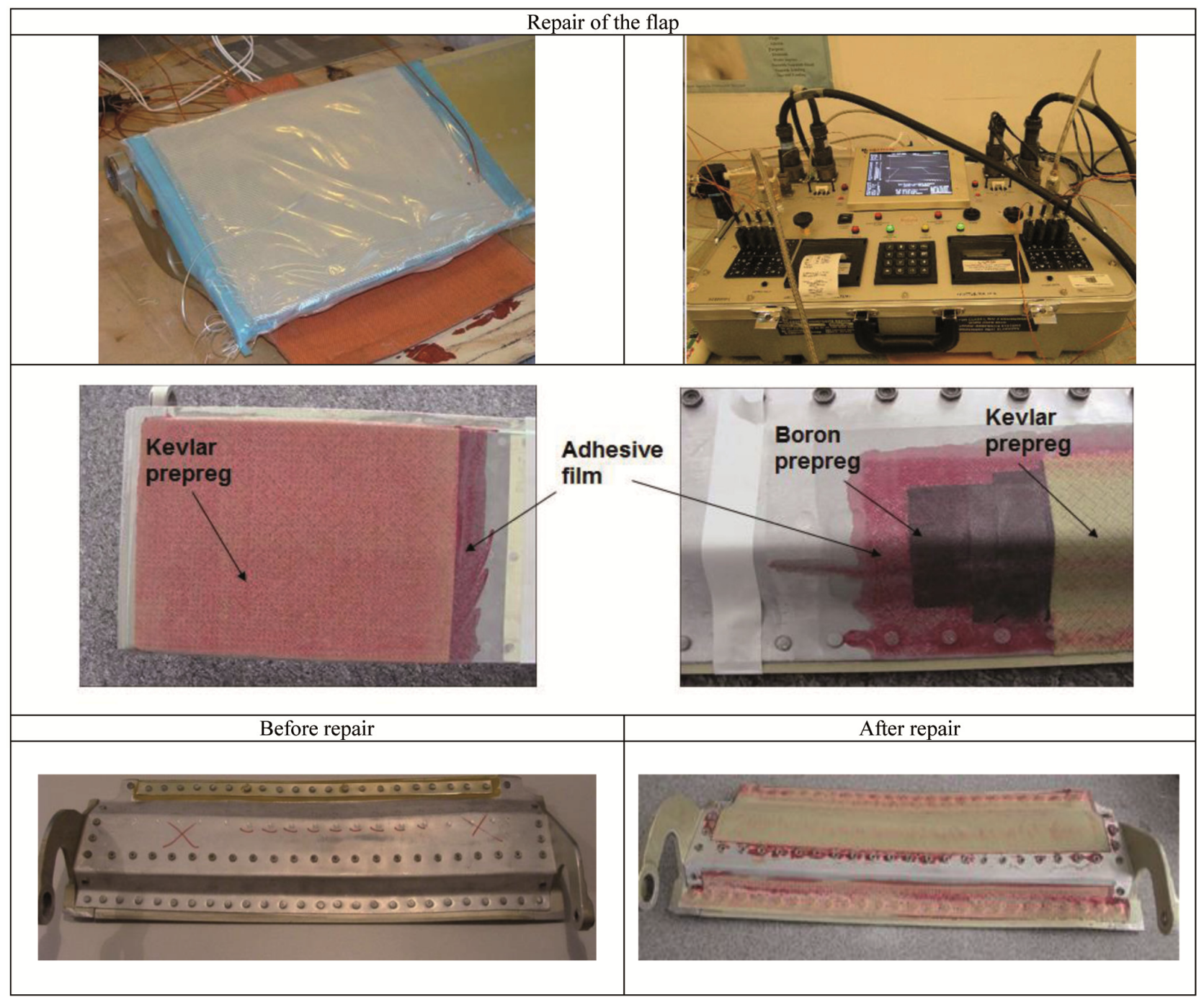

Fig. 11. Repair process of the engine intake flap

The repair was performed with the use of the vacuum bag and a heating blanket. The cure cycle was set based on the prepreg data sheet and previous experience. Necessary calculations and tensile tests were performed. The cure cycle was strictly monitored by the control unit. After the cure cycle the NDI was performed to check the bonding quality. After being modernized, the flaps were assembled on the plane, positively validated during flight tests and returned to service. At present there are more than 4 jets flying with repaired flaps. For the purpose of the bonding quality monitoring, a service inspection bulletin was prepared and implemented into maintenance procedures. 


\section{APPROACH TO SERVICE LIFE EXTENSION OF A SUKHOI SU-22}

The close air support aircraft Su-22 have been operated in Poland since 1980. Provided by Russia, the aircraft were produced in 1984-88. A Su-22 is a safe life aircraft with operation limits set by the manufacturer. Table 3 presents the summary of the service life limits of a Su-22 for a single-seater (S-54K) and a two-seater (UM3K) versions.

Tab. 3. Limits set by OLM

\begin{tabular}{|l|c|c|}
\hline Limits & Su-22 (single-seater) & Su-22 (two-seater) \\
\hline Total flight hours & 2000 & 2000 \\
\hline Total years & 20 & 20 \\
\hline Number of landings & 3000 & 4000 \\
\hline
\end{tabular}

In the early years the Su-22 aircraft have not been operated very intensively in Poland. In the period of political changes in the countries of Central and Eastern Europe the military spending in Poland was significantly reduced. As a result, a decrease in the number of annual flight hours per aircraft was observed. When the aircraft are nearing the end of service life as set by the manufacturer they will most probably accumulate only about $60 \%$ of the designed flight hours limit. With this in mind, it was decided to extend the service life of the Su-22. Some aircraft have been kept operational while the other have been retired. One reason behind the decision to operate the $\mathrm{Su}-22$ longer was the fact that there is an overhaul facility in Poland that could carry out repairs and modernization of these aircraft. The low level of wearing, the existence of the overhaul facility and the cutbacks in funds for the purchase of new equipment were all the factors that decided about extending the life of the Su-22.

The service life extension program for the Su-22 was developed by the Air Force Institute of Technology (ITWL) and Military Aviation Works No. 2 (WZL-2, overhaul facility). An important part of the program was to determine the usage profile for the Su-22 operated by the Polish Air Force. The program contained a series of durability studies of critical elements. For example, the lines of the aircraft control system were fatigue tested, new repair limits for the windscreen were established, and the fatigue life of the most important nodes in the structure of the aircraft was estimated. Each aircraft operated under the SLEP (Service Life Extension Programme) was subjected to an additional cyclic (every two years or 100 flight hours) special maintenance service according to the technical order manuals devised by the AFIT and WZL-2 staff. Additional activities comprised mostly additional controls and checks. Important part of these were NDT inspections. Besides, the procedure involved extended checks of the hydraulic system and the avionics and a corrosion prevention program. The system developed proved to be effective as the entire fleet of aircraft selected for use under the SLEP were operated successfully. There was no increase in the level of damage to aircraft. The efficiency and readiness were maintained at the current level. The programme has also brought cost benefits.

According to the former schedule the Su-22 were to be withdrawn from service in 2016.

Withdrawing an aircraft from service is a relatively simple process. Putting in place new equipment is more difficult. The withdrawal date for the Su-22 coincides with the implementation of a large armament programme including purchasing approx. 70 multi-role and attack helicopters as well as a system of modern air defence and anti-missile defence. As the armament programme takes priority over other projects, the replacement of the Su-22 platform with a newer one must be postponed. If Su-22s were retired now, it would mean the shutting down of the air base, loss of human resources and devastation of infrastructure. It may be suspected that these factors inspired the decision to postpone the withdrawal of Su-22s from the Air Force for another 10 years.

Although it was decided to keep and overhaul only a portion of the previously operated fleet, the task is much more difficult than the former SLEP programmes. 
Within the scheduled period, most aircraft will have exceeded the limits specified by the manufacturer. The two-seater aircraft will have exceeded the total landing number limit by far. In addition to the problems associated with the aging of the structure (corrosion), fatigue damage must be taken into consideration.

Time available for the preparation and execution of relevant research is very short. There are two pillars of the new SLEP for Su-22s operated in Poland. The first one involves a dedicated overhaul performed by the WZL-2 with the support of the ITWL. The overhaul should refresh the structure. Many components should be verified, inspected and adjusted. But even very sophisticated diagnostics cannot predict fatigue. So the second pillar of the new SLEP is a Full Scale Fatigue Test. To monitor loads during flight and landing all of the two-seater aircraft will be equipped with the HUMS system. This system will consists of strain gauge sensors and the recorder SSR-500 (Curtiss Wright).

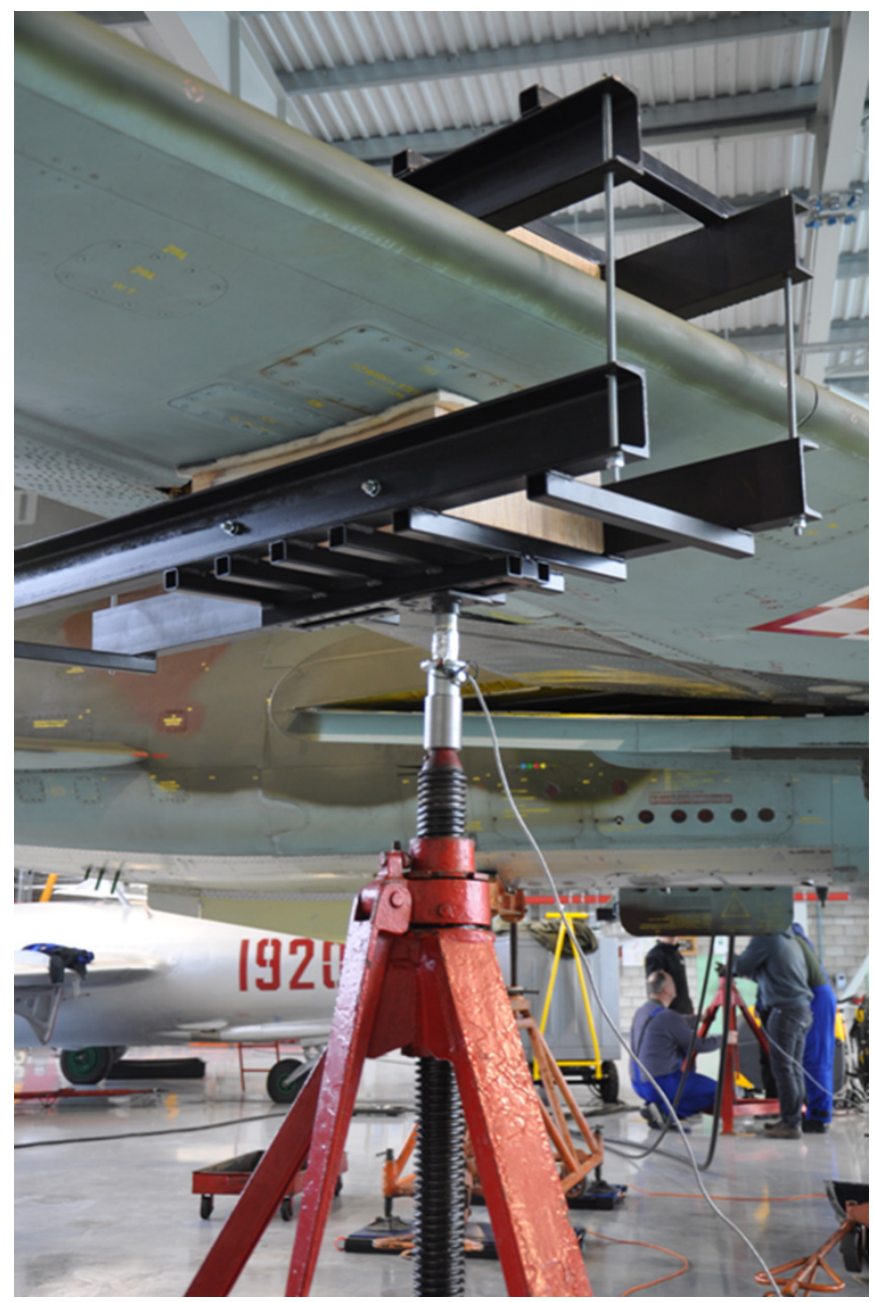

Fig. 12. Scaling of strain gauges - loading of the wing

In the second half of 2014 one of the two-seater aircraft was prepared for a flight test. The aim of the flight test was to measure the loads on the key elements of the structure during flight manoeuvres and landing. The instrumentation comprised a dozen of strain gauges and the KAM-500 recorder. An additional element of the measuring system consisted of sensors measuring vertical speed during landing. The test flights were performed at the beginning of 2015 . The recorded data provided information about the loads acting on the structure. Part of this task was the scaling process of the embedded strain gauges. Scaling was performed in a simplified manner in the field. The aircraft structure was loaded in a controlled manner while the indications 
of strain gauges were being recorded. During the scaling process the structure was loaded in such a way that a known level of forces in certain parts of the structure was obtained. To achieve this, relatively simple methods were used: filling the fuel tanks (integrated and external), attaching external equipment, using hydraulic actuators. During the scale procedure different variants of aircraft support were used. Throughout the process forces acting on the structure from the supports were controlled by means of scales and strain gauges sensors. To scale sensors placed on the chassis of the aircraft engine thrust was used during the check of the engine. Examples of the activities performed are pictured above.

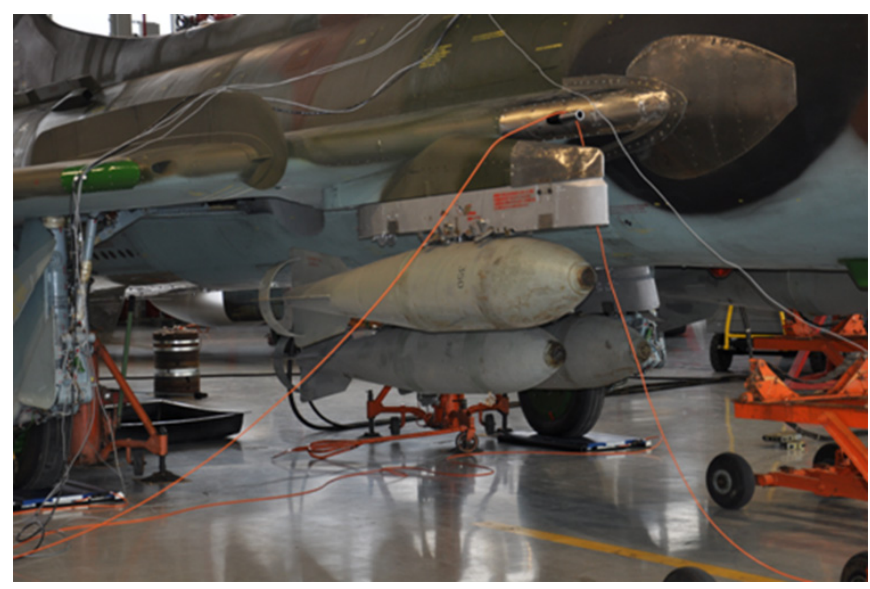

Fig. 13. Scaling of strain gauges - loading of the fuselage

The loads for the FSFT are determined based on the knowledge of operational loads during flight and landing and the knowledge of the operation profile. The major part of the FSFT is planned to be done in 2015. The Aerospace Research and Test Establishment (VZLU) in Prague is a contractor responsible for the execution of the test. The object of the FSFT is the structure of the aircraft withdrawn from service. A major difficulty in conducting the test is the lack of design documentation. The AFIT and the VZLU have undertaken considerable effort to replace the lacking documentation with reverse engineering.

In view of the duration of the programme and the resources available it was decided to adopt a significant simplification of the fatigue test. This simplification could dispense with negative loads (negative g) and the adoption of the load block (not flight by flight).

The conduct of the programme and its results will be presented at a future ICAF conference.

\section{DESIGN OF THE CONDITION BASED MAINTENANCE PROGRAMME FOR THE PZL - 130 ORLIK (SEWST)}

The PZL-130 ORLIK is a light, turbo-prop (single-engine) aircraft used for pilot training.

The aircraft was designed in the 1980s, in Poland. 36 aircraft have been used by the Polish Air Force since 1995. In 2010 the Polish Air Force ordered modernization of 16 aircraft to meet the TC II version standard. This modernization consisted of the engine and wings conversion and the avionics upgrade. Simultaneously with the modernization a major change in the maintenance system was also contracted. The old maintenance system had required that the main overhaul be performed periodically. As a result, the old system had been too expensive and aircraft had low availability rate. The new maintenance system was established following a research program (SEWST) carried out by the EADS PZL-Okęcie (manufacturer) and the ITWL (Air Force Institute of Technology). 


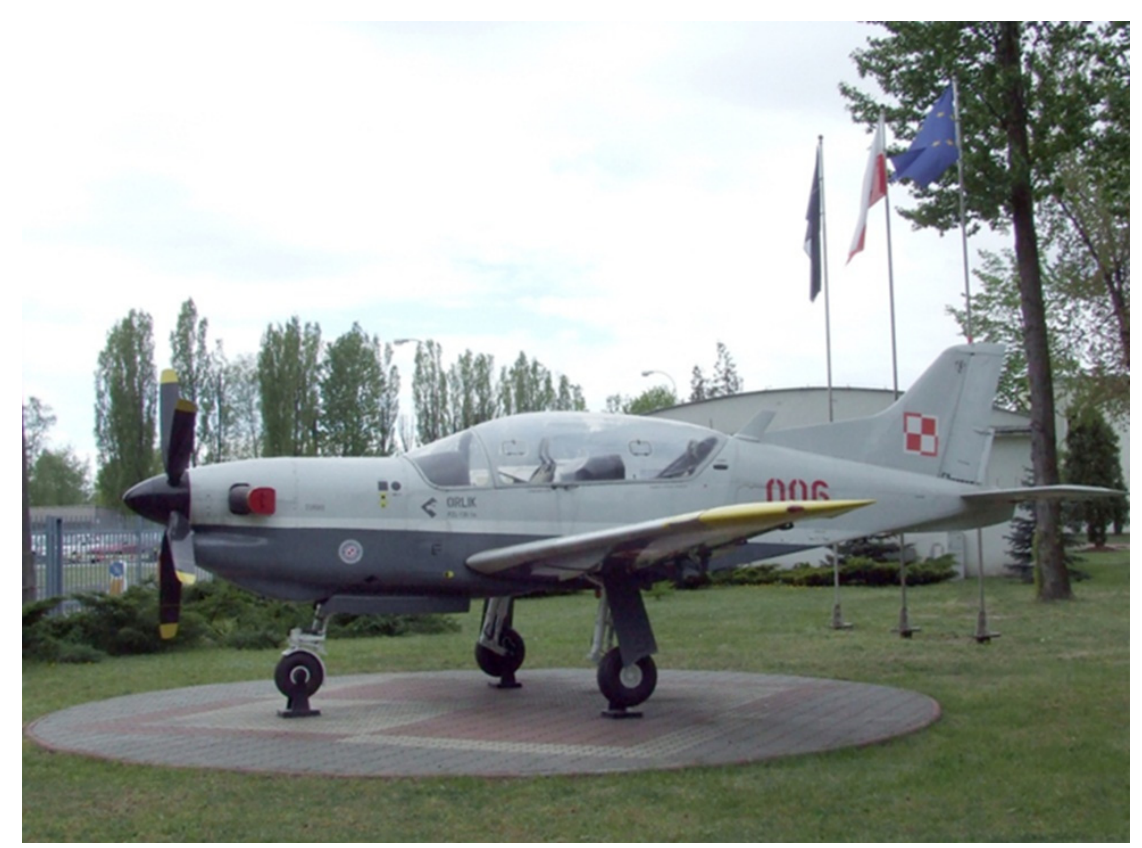

Fig. 14. The PZL-130 ORLIK in front of the AFIT

The SEWST programme consisted of many tasks and subtasks. One of the major program tasks was to determine the fatigue life of the upgraded structure by means of a Full Scale Fatigue Test (FSFT) of the airframe. Supplementary tasks included a risk analysis and analysis of the corrosion influence on the structure's integrity. It must be stated that the complete definition of the whole programme with all the tasks included took almost 2 years prior to the start of the programme. During the planning phase all available sources of information were taken into account including the results of similar programmes. Good scheduling and preparation resulted in successful completion of the project on time and within the budget assigned.

The determination of the fatigue life was accomplished in four steps through:

- determining the usage profile.

- measuring loads acting on the structure during flights and landings.

- defining the load sequence for FSFT.

- teardown Inspections.

Data collected for the aircraft operated by the Polish Air Force provided useful information about the actual usage profile. There were over 40,000 digital files with data recorded by the flight data recorder. Statistical analysis of data collected was carried out with commercial software and a dedicated code, which enabled calculating all necessary statistics and determining the mean usage profile. Other important information obtained included the mean number of landings per flight hour, the mean number of touch-and-go landings per flight hour, and the mean number of spins per flight hour.

The next step was to measure loads during flights and landings. The instrumentation of the aircraft was preceded by developing a concept of measurement and developing a service bulletin. Previous experience was taken into account in designing the deployment of strain gauges on the structure. An important subtask was the calibration of strain gauges. To determine the relation between the load and the strain gauge signal, the structure was loaded by means of actuators and clamps while strain gauges signals were recorded. In parallel with the instrumentation a dedicated flight test programme was prepared. In the next step the flight tests were performed. 


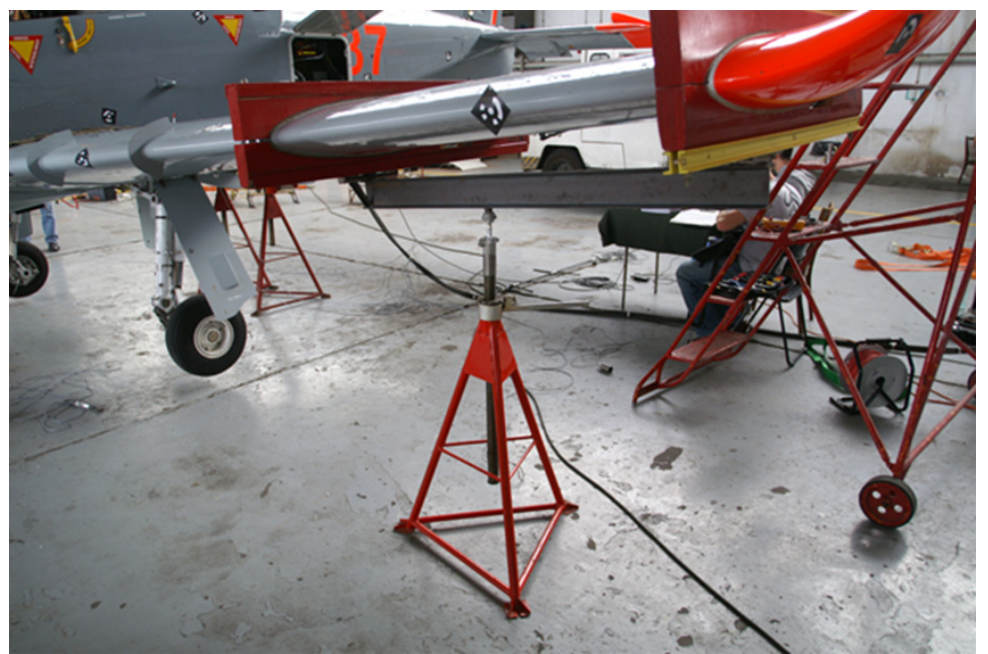

Fig. 15. Calibration of strain gages - loading of the wing

The main source of knowledge about the fatigue life limit of a structure is a Full Scale Fatigue Test. The FSFT of the PZL-130 ORLIK was performed by the VZLU Prague (Czech Republic). The loading system consisted of 20 actuators. The load sequence was prepared to meet the defined usage profile. The load sequence consisted of 26,000 unique sets of loads equivalent to the loads accumulated within 200 flight hours.

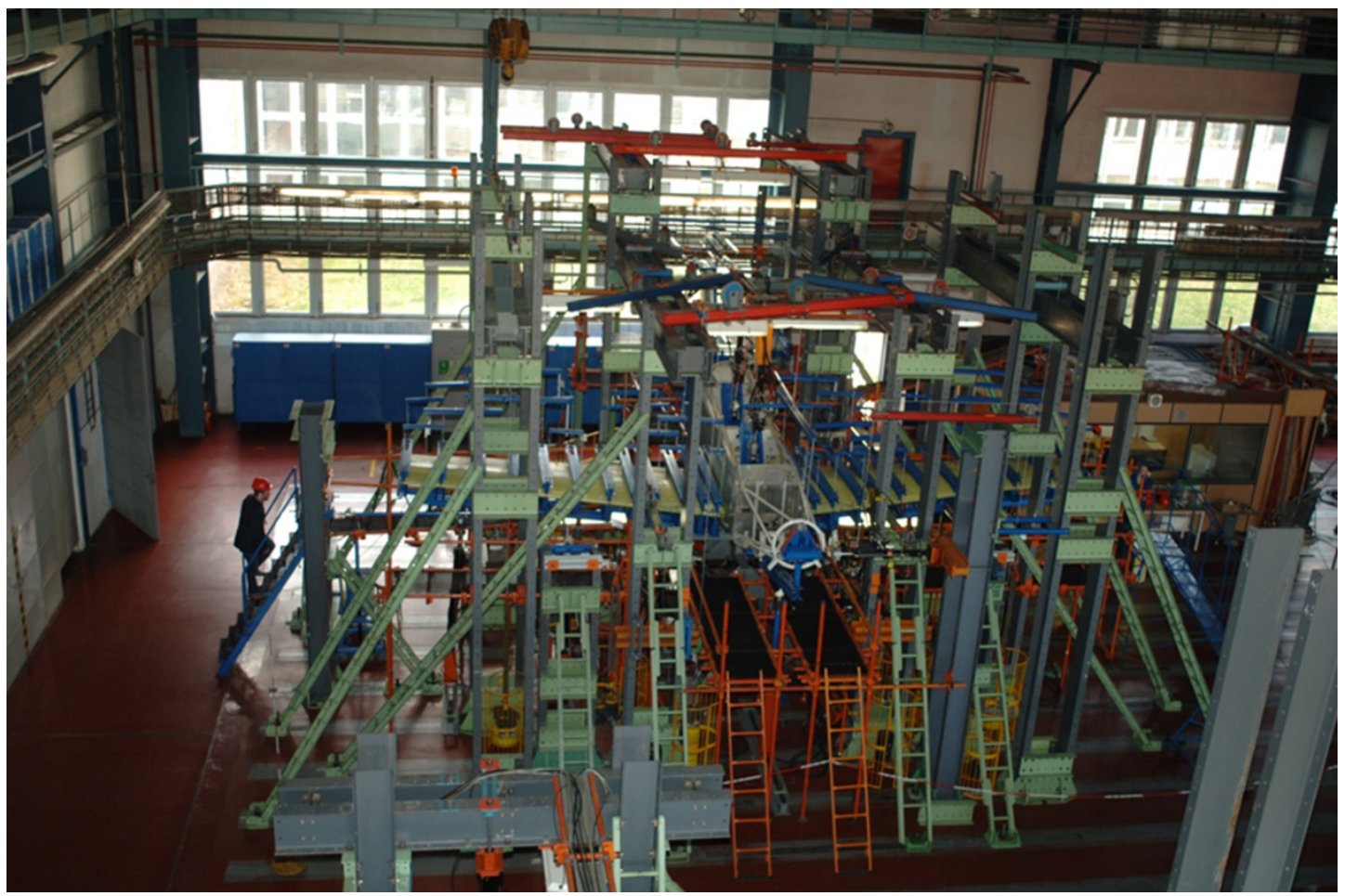

Fig. 16 Full Scale Fatigue Test Bed

The FSFT included three levels of NDT inspections:

- 1st-level inspection - daily inspection,

- 2nd-level inspection - basic inspection,

- 3rd-level inspection - enhanced inspection.

A 1st-level inspection was mainly based on visual inspections, with the 2nd-level inspection including an eddy current inspection of the structure and a 3rd-level inspection performed after partial disassembly of the airframe. The FSFT continued over the span of two and half years 
during which time four 3rd-level and over ten 2nd-level inspections were carried out. More than 800 damages were found.

After the FSFT (accumulated 36,000 simulated flight hours) a Teardown Inspection (TI) was completed. The aim of the TI was to check the structure in the areas inaccessible by ordinary NDT methods and to validate the NDT inspection plan. During TI additional 100 minor damages were found.

Among additional supplementary analyses the Durability and Damage Tolerance Analysis (DADTA) was of special importance. In the DADTA, the crack propagation rate for several critical points was determined based on numerical and analytical calculations. The aim of the DADTA was to assess time the cracks needed to reach a dangerous size. A global Finite Element (FE) model and a series of submodels were used to obtain the stress distribution. As a next step, the detailed model was modified and cracks were introduced to the FE models. Using the Virtual Crack Closure Technique (VCCT) the stress intensity factor was calculated for each crack length. Based on values of stress intensity factor for different crack lengths numerical simulation of crack growth was carried out. The results of computer simulations were validated by the FSFT results.

The DADTA results fed the Risk Analysis (RA). The RA can determine the change in time of probability of fatigue damage evidence. The RA results were taken into account in devising the new maintenance system.

Since it's not only fatigue damage that limits the life of an aircraft structure, the SEWST programme also included a new Corrosion Prevention and Control Plan (CPCP) and the evaluation of the corrosion susceptibility. The results of those activities were incorporated into a service bulletin when the new maintenance system was defined. The service bulletin describes the new maintenance system and contains technical orders for NDT inspections.

The new maintenance system includes the Operational Loads Monitoring (OLM). After each flight the acquired data are sent to the Data Processing Centre and evaluated to determine the fatigue damage accumulated by the structure.

The SEWST programme was completed at the end of 2014. The new maintenance system was put into effect at the beginning of 2015 .

\section{THE SYSTEM FOR MONITORING CRACK GROWTH DURING THE FSFT OF THE PZL - 130 ORLIK}

Below the authors discuss an approach to damage monitoring conducted with use of elastic waves excitation in the structure of an aircraft subjected to the FSFT. Depending on their source and the geometry of the structure under consideration, the elastic waves can propagate over a significant distance. They are also sensitive to local structural discontinuities and deformations providing a tool to detect local damage in large aerospace structures. A major obstacle in the direct application of this method is however the complexity of signals excited in aircraft structures. A reliable system should therefore provide different types of damage assessment allowing for the cross-validated evaluation of the structure:

- qualitative data - damage presence in a given network cell, its type and the degree of criticality;

- $\quad$ quantitative data - exact location and size of a damage.

A brief overview of a system for the aircraft structure monitoring during the FSFT is presented below. The system building blocks are schematically presented in Figure 17 and include:

- PZT transducers network divided into several measuring nodes;

- Remote Monitoring Unit (RMU) - based on DSP architecture CPU;

- Data Storage Unit (DSU);

- Graphical User Interface (GUI). 


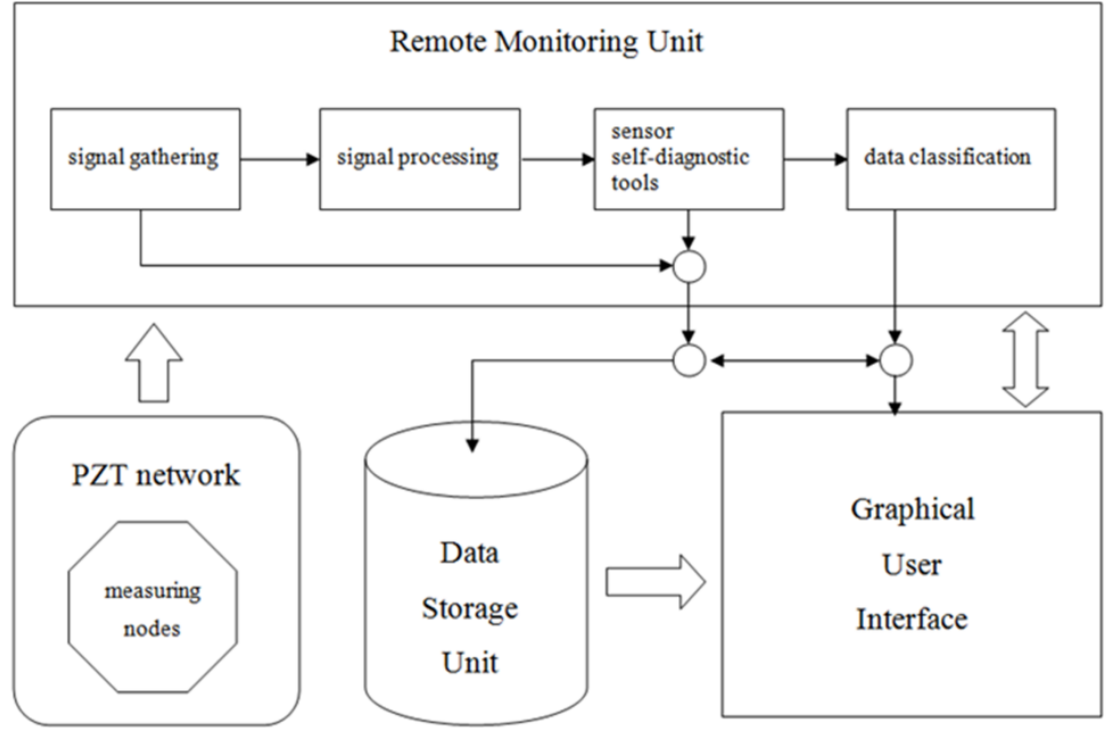

Fig. 17. The system block diagram

Selected 'hot-spots', where the measuring nodes of the network were deployed, are presented in Figure 18. The core of the RMU consists of four subsequent routines:

- signal collecting and its storage in DSU is indicated by a sensor self-diagnostics component (Figure 17);

- signal processing based on several signal Damage Indices (DIs) correlated with the fatigue crack growth;

- sensor self-diagnostic component validating the PZT network, e.g. noise detection, sensors' surface coupling strength, detection of changes by significant sensor working conditions;

- data classification methods for damage growth assessment.

One of the key issues in applying the piezoelectric transducers-based monitoring systems to structures used in aerospace is to ensure the sensor network durability in extremely varying environmental conditions. Thus a network self-diagnostic tool allowing signal decoherence to be tracked in time is a vital component in any of such applications.

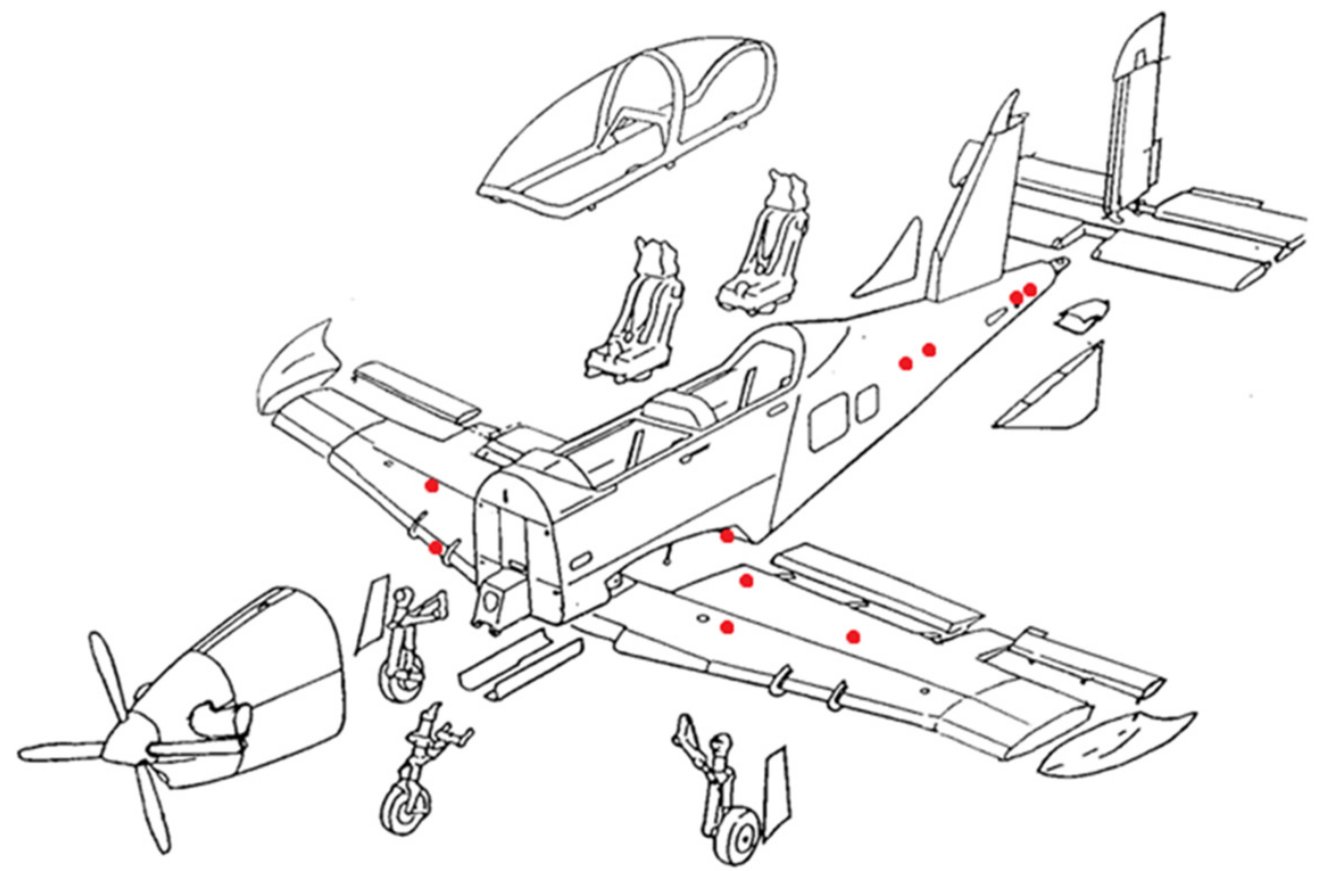

Fig. 18. Selected hot-spots on the aircraft structure 
Furthermore, most data classification models are sensitive to outlying observations, rendering an efficient sensor self-diagnostic procedure conducted prior to the structure evaluation crucial for the system's working as intended, e.g. false calls avoidance. In the proposed approach, signals which do not pass the sensor self-diagnostic check are stored in the DSU for further expert assessment as depicted in Figure 17 in order to validate a sensor failure mode. The results of structure monitoring are presented in Figure 19. Two chosen Damage Indices are plotted:

$$
\text { - } \quad D I_{1}(g, s)=1-\operatorname{cor}\left(f_{g s}^{e n v}, f_{g s, b}^{e n v}\right) \quad, \quad D I_{2}(g, s)=\left|\frac{\int\left(f_{g s}^{e n v}-f_{g s, b}^{e n v}\right)^{2} d t}{\int\left(f_{g s, b}^{e n v}\right)^{2} d t}\right|
$$

where: $f_{g s}^{e n v}, f_{g s, b}^{e n v}$ denotes the envelope of the signal received on a sensing path formed by a generator $g$ and a sensor $s$ and the envelope of the corresponding baseline, respectively while $\operatorname{cor}\left(f_{g s}^{e n v}, f_{g s, b}^{e n v}\right)$ stands for the sample correlation of $f_{g s}^{e n v}, f_{g s, b}^{e n v}$. The indices were averaged with respect to all sensing paths in a given network.
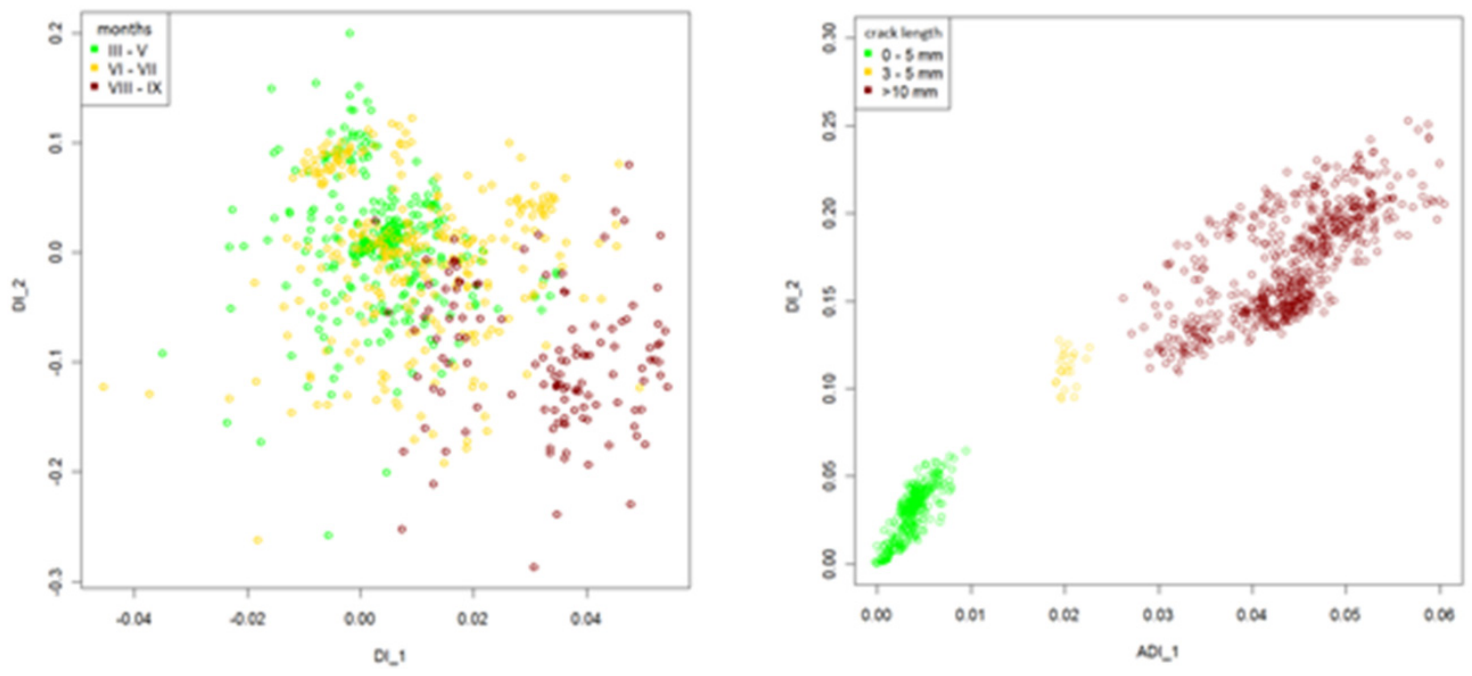

a) Unchanged hot-spot location

b) Crack propagating within the network

Fig. 19. Damage Indices obtained during the full scale fatigue test for the two PZT networks

The presented data were collected over a six-month period. The crack was developing in the network shown in Figure 20(b) while the other hot-spot (Fig. 20 (a)) remained unchanged during the test. The data collected for different periods of time for the undamaged spot are not separated (Fig. 20(a)), whereas the propagating crack results in data separation (Fig. 20(b)) and provides indications as to different stages of damage development. 


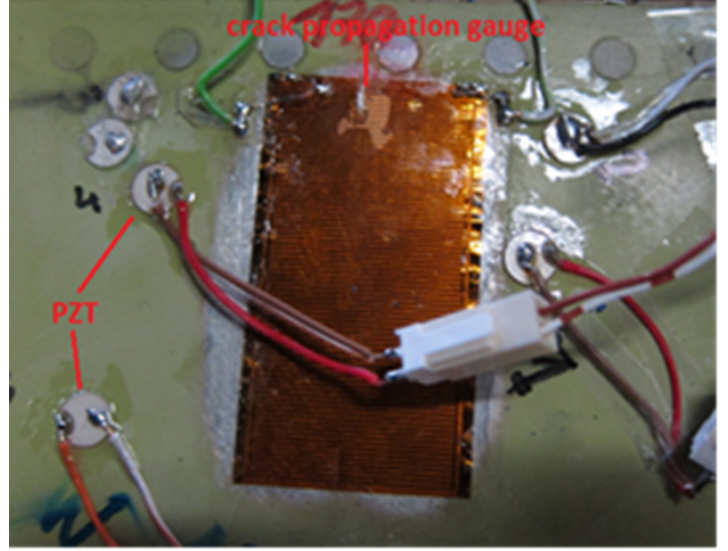

a) Damage non developing after PZTs placement

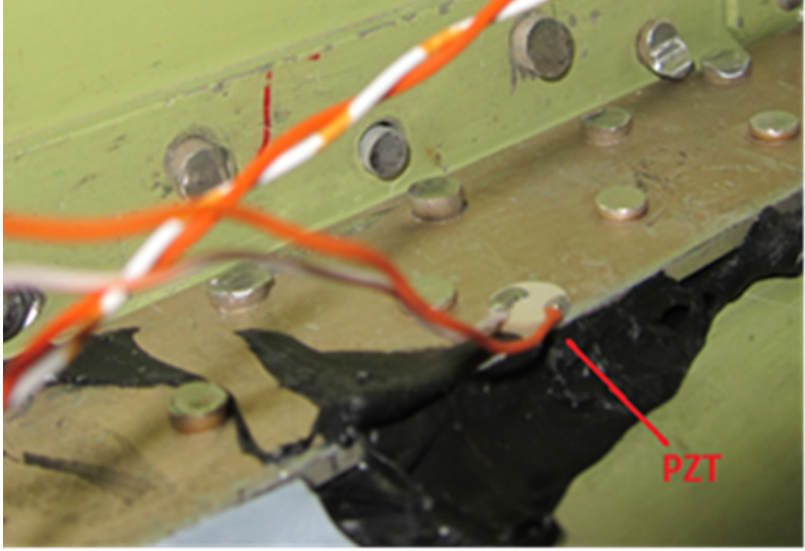

b) Damage developing after PZTs placement

Fig. 20. PZT transducers deployed on PZL-130 Orlik TC II during full scale fatigue test (FSFT)

\section{REFERENCES}

[1] Brzęczek J, Gruszecki H, Pieróg L, Pietruszka J. Selected Aspects Related to Preparation of a Fatigue Test Plan of a Metallic Airframe. Fatigue of Aircraft Structures. Issue 2014. Institute of Aviation Scientific Publications, Warsaw, Poland.

[2] Brzęczek J, Gruszecki H, Pieróg L, Pietruszka J. Selected Aspects Related to Preparation of Fatigue Tests of a Metallic Airframe. Fatigue of Aircraft Structures. Issue 2014. Institute of Aviation Scientific Publications, Warsaw, Poland.

[3] Brzęczek J, Chodur J, Pietruszka J. Selected Aspects Related to the Applied Loads Control during fatigue Tests of a Metallic Airframe. Fatigue of Aircraft Structures. Issue 2014. Institute of Aviation Scientific Publications, Warsaw, Poland.

[4] Brzęczek J, Gruszecki H, Pieróg L, Deszcz F, Pietruszka J. Stress Analysis of the PZL M28's Airframe Subjected to Repairs during Fatigue Tests. Fatigue of Aircraft Structures. Issue 2014. Institute of Aviation Scientific Publications, Warsaw, Poland.

[5] Rodzewicz M, Głowacki D. Investigation into Load Spectra of UAVS Aircraft. Fatigue of Aircraft Structures. Issue 2013. Institute of Aviation Scientific Publications, Warsaw, Poland.

[6] Gadalińska E, Baczmański A. Micromechanical Properties and Stress Measurements with Diffraction Methods. Fatigue of Aircraft Structures. Issue 2013. Institute of Aviation Scientific Publications, Warsaw, Poland.

[7] Kurdelski M, Leski A., Klimaszewski S., Stefaniuk M. Structural load monitoring systems for military aircraft in the Polish armed forces with examples of selected activities. ICAF 2011 Structural Integrity: Influence of Efficiency and Green Imperatives: Proceedings of the 26th Symposium of the International Committee on Aeronautical Fatigue (edited by J. Komorowski), Montreal, Canada, 1-3 June 2011.

[8] Leski A, Reymer P, Kurdelski M. Development of load spectrum for full scale fatigue test of a trainer aircraft. ICAF 2011 Structural Integrity: Influence of Efficiency and Green Imperatives: Proceedings of the 26th Symposium of the International Committee on Aeronautical Fatigue (edited by J. Komorowski), Montreal, Canada, 1-3 June 2011. 
[9] Sałaciński M., Leski A., Synaszko P., Stefaniuk M., Dragan K.: Determination of Composite Patch Thickness on the Accuracy of Nondestructive Testing of The Repaired Structure of PZL-130 ORLIK Aircraft. Proceedings of the AIAC16 Sixteenth Australian International Aerospace Congress. 23-26.02.2015 Melbourne, Australia.

[10] Reymer P., Leski A., Kurdelski M. Introduction of a Structure Integrity Program for a Military Trainer Aircraft. 28th International Congress of the Aeronautical Sciences. 23-28 Sept. 2012, Brisbane Australia. Proceedings of ICAS2012-12.6.2.

[11] Reymer P., Leski A. Flight Loads Acquisition for PZL-130 TC-II Full-Scale Fatigue Test. Fatigue of Aircraft Structures. Issue 2011. Institute of Aviation Scientific Publications, Warsaw Poland.

[12] Dragan, K., Klimaszewski, S. "Holistic Approach for Structural Integrity Evaluation of Composite Main Rotor Blades"WCNDT 2008, Shanghai, China

[13] Dragan K. NDE activities connected with Service Life Extension of Main Rotor Blades of Helicopters used in Polish Armed Forces. 7th Australian Pacific Vertiflite Conference on Helicopter Technology, 9 - 12 March, 2009, Melbourne.

[14] Dragan, K., Klimaszewski, S. "Holistic Approach for Structural Integrity Evaluation of Composite Main Rotor Blades", WCNDT 2008, Shanghai, China.

[15] Dragan K., Klimaszewski S. „In-service Flaw Detection and Quantification on the MiG-29 Composite Vertical Tail Skin”, 9th ECNDT Berlin, (Germany) 25.09.2006 - 29.09.2006.

[16] Dragan K.,Klimaszewski S., Salacinski M., Synaszko P., Latoszek A., „DAMAGE DETECTION AND FAILURE MODE DISTRIBUTION FOR THE MiG-29 VERTICAL STABILIZER", 2010 Aircraft Airworthiness and Sustainment Conference, 11-13 May, Austin Convention Center.

[17] Sałaciński M., Synaszko P., Stefaniuk M., Dragan K., Monitoring of Crack Growth in a Structure Under a Composite Patch, Journal of Fatigue of Aircraft Structures, Volume 1, Number 3 / August 2011, Pages, 103-111, ISSN 2081-7738.

[18] Dragan K., Leski A., Dziendzikowski M., „Health Monitoring of the aircraft structure based on the embedded piezosensor network on the example of PZL-130 Orlik", Proceedings of the $27^{\text {th }}$ ICAF Symposium, Jerusalem ISRAEL, 5-7 June 2013, pp.835-844 Volume 2.

[19] Leski A., Dragan K., Reymer P., „Full Scale Fatigue Test of PZL-130 Orlik structure”, Proceedings of the $27^{\text {th }}$ ICAF Symposium, Jerusalem ISRAEL, 5-7 June 2013, pp.199-208 Volume 1. 